CRITICAL INFORMATION CONSUMPTION

AND TEXTBOOKS USED IN TEACHER PREPARATION PROGRAMS

A Dissertation
presented to
the Faculty of the Graduate School
at the University of Missouri-Columbia
In Partial Fulfillment
of the Requirements for the Degree
Doctor of Educational Leadership and Policy Analysis
Dr. Cynthia MacGregor, Dissertation Supervisor
by

DECEMBER 2020 
(C) Copyright by Courtney K. Smith-Nelson 2020

All Rights Reserved 
The undersigned, appointed by the dean of the Graduate School, have examined the

dissertation entitled

\title{
CRITICAL INFORMATION CONSUMPTION
}

\section{AND TEXTBOOKS USED IN TEACHER PREPARATION PROGRAMS}

\author{
presented by Courtney K. Smith-Nelson,
}

a candidate for the degree of doctor of educational leadership and policy analysis, and hereby certify that, in their opinion, it is worthy of acceptance.

Dr. Cynthia MacGregor, Chair

Dr. Jeffrey H. D. Cornelius-White

Dr. T. C. Wall

Dr. James Sottile 


\section{Dedication Page}

This dissertation is dedicated to my mom. While the future may be uncertain, her love and support never are. 


\section{ACKNOWLEDGEMENTS}

2020 has been a year of challenges and unforeseen obstacles. This dissertation would never have been completed without the hard work and support of the following individuals and organizations. My everlasting gratitude goes to:

My advisor and dissertation committee chair, Dr. Mac;

The rest of the dissertation committee: Drs. Cornelius-White, Sottile, and Wall;

The exceedingly patient staff of the MSU Meyer Library, who had to put up with the bureaucratic and technical difficulties that plagued my data collection process;

And of course, Brian, Zepp, and Squirrel. 


\section{TABLE OF CONTENTS}

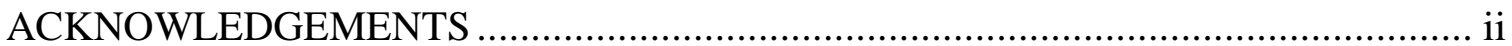

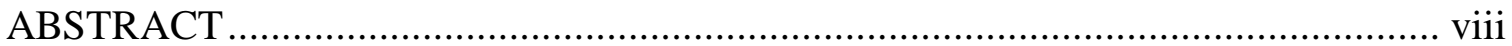

\section{Contents}

SECTION ONE: INTRODUCTION TO THE DISSERTATION .................................

Statement of the Problem..................................................................................................

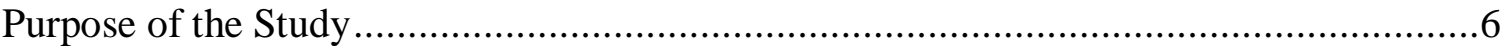

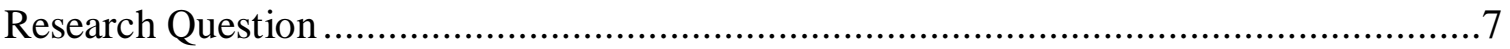

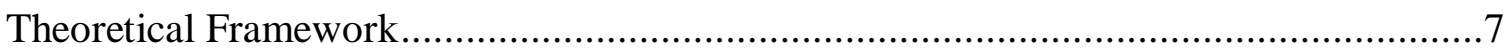

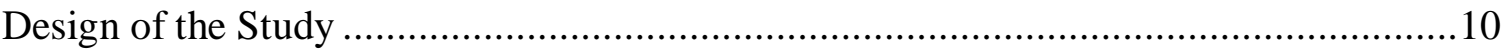

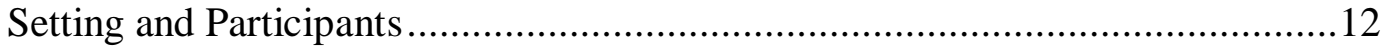

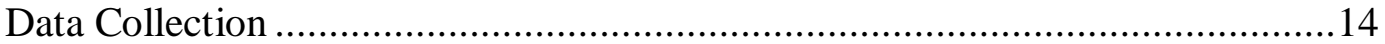

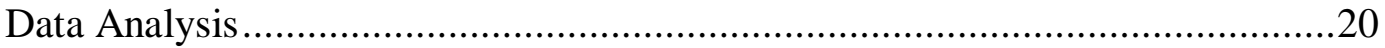

Limitations, Assumptions, and Design Controls....................................................22

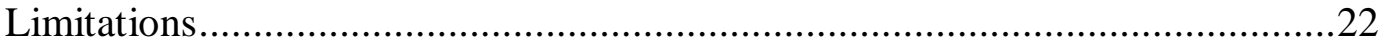

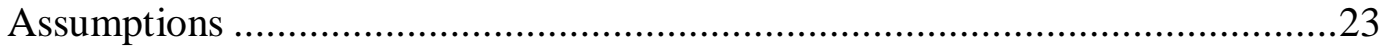

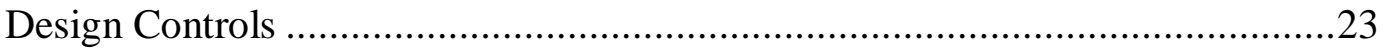

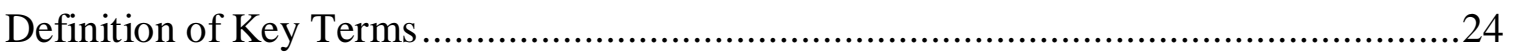

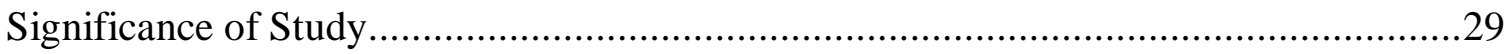


Summary 30

SECTION TWO: PRACTITIONER SETTING FOR THE STUDY.

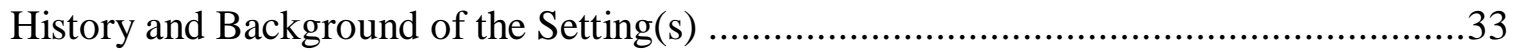

TPPs and the Purpose of Schooling in the United States .....................................34

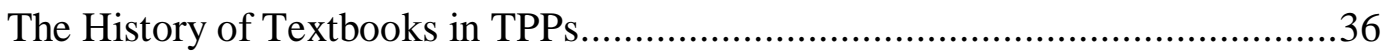

An Organizational Analysis of Teacher Preparation Programs ..........................................38

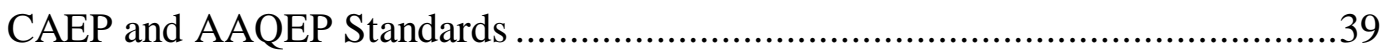

Implementation of TPPs and Pathways to Certification ...................................43

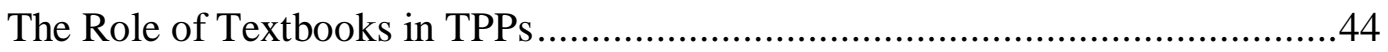

Leadership Theory and Practice in the Context of Teacher Preparation ..........................44

Implications for Research in the Practitioner Setting .................................................47

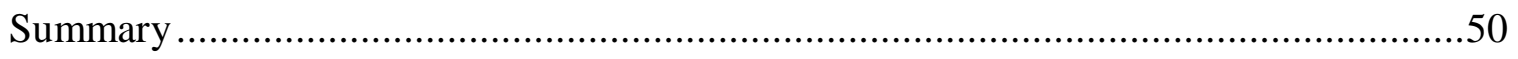

SECTION THREE: SCHOLARY REVIEW FOR THE STUDY ……….....................52

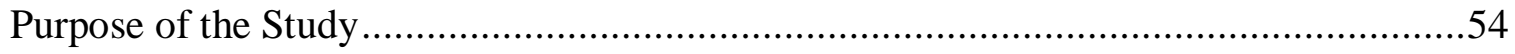

Theoretical and Conceptual Frameworks ……….......................................................55

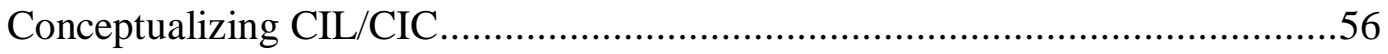

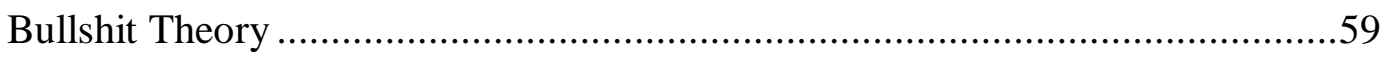

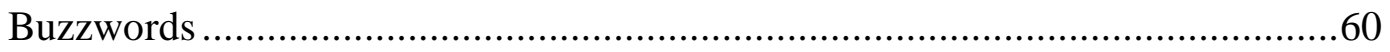

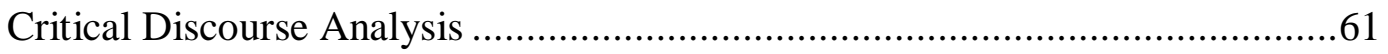

iv 
Teaching and Learning CIL/CIC Skills ......................................................64

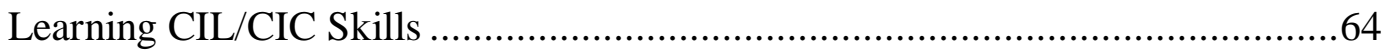

Teaching CIL/CIC Concepts ..........................................................6 66

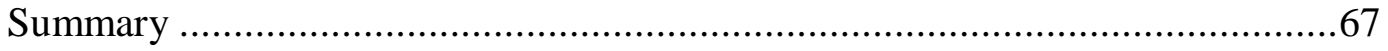

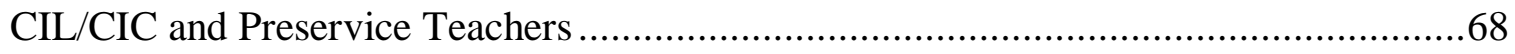

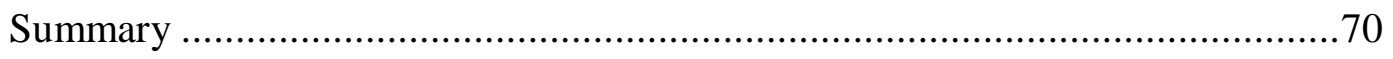

CIL/CIC in Professional Practice .................................................................... 71

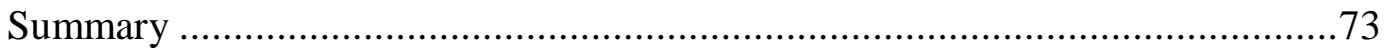

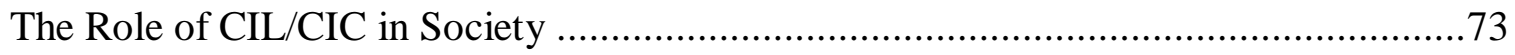

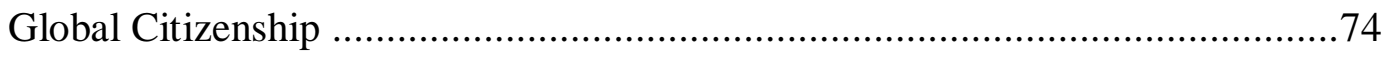

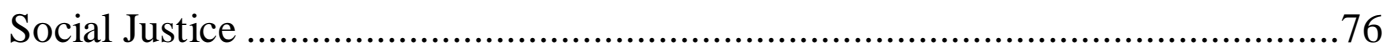

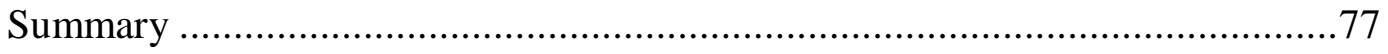

Summary of the Review of Literature ............................................................ 78

SECTION FOUR: CONTRIBUTION TO PRACTICE TO BE SUBMITTED TO

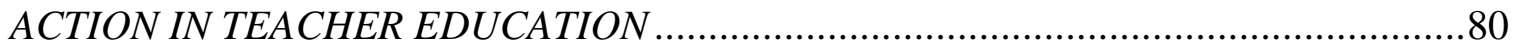

Critical Information Consumption: Textbook Evaluation Criteria for Teacher Preparation

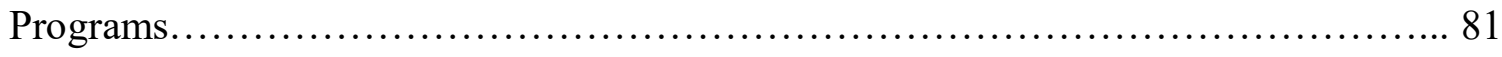


Abstract

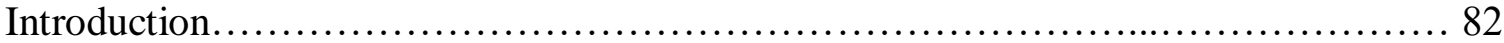

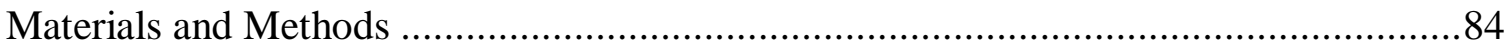

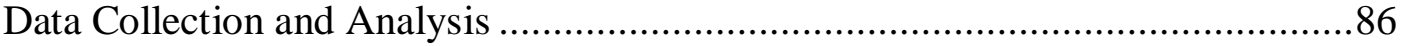

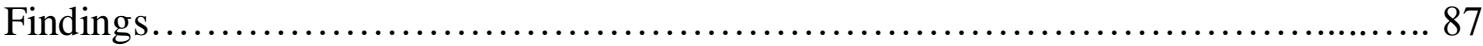

Conclusion: A Textbook Evaluation Checklist for CIL/CIC ..........................92

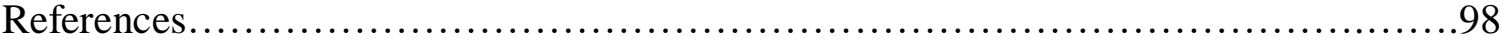

SECTION FIVE: CONTRIBUTION TO SCHOLARSHIP TO BE SUBMITTED TO

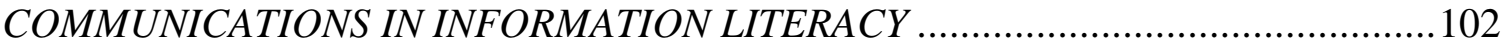

Critical Information Consumption and Textbooks in Teacher Preparation Programs....103

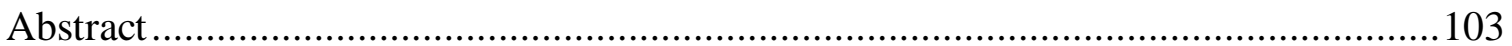

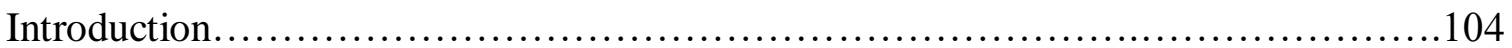

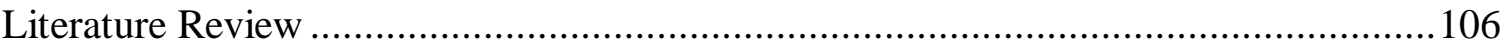

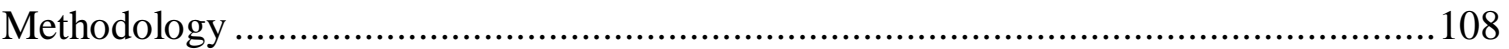

Findings................................................................ 110

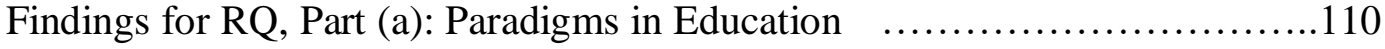

Findings for RQ, Part (b): Sources of Information............................112

Findings for RQ, Part (c): Epistemically Suspect Statements and

Buzzwords............................................................... 114

Findings from RQ, Part (d): Power, Bias, and Underlying

Assumptions........................................................ 115 
Conclusion.

References............................................................... 120

SECTION SIX: SCHOLARLY PRACTITIONER REFLECTION ....................129

How Has the Dissertation Influenced Your Practice as an Educational Leader?.........132

Complexity, Nuance, and Ambiguity................................. 133

Values.............................................................. 133

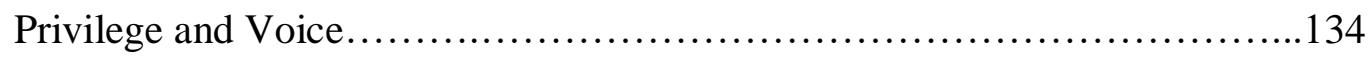

How Has the Dissertation Process Influenced You as a Scholar? .....................135

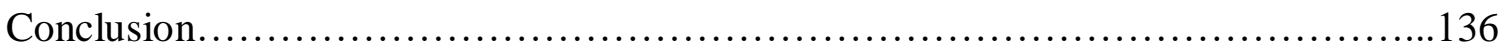

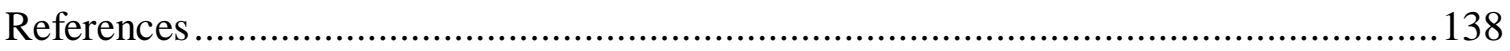

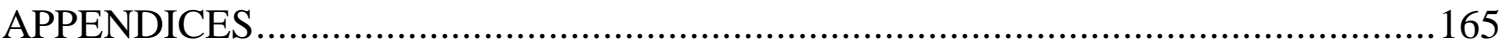

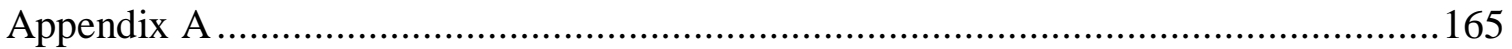

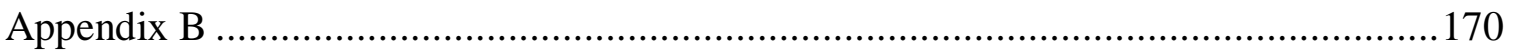

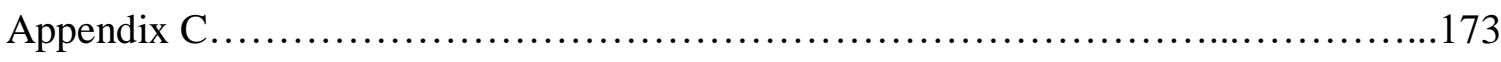

Appendix D.............................................................. 180

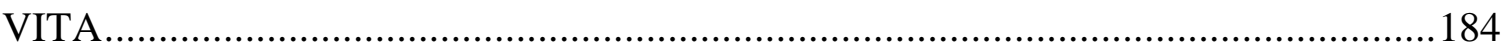




\begin{abstract}
Critical information literacy (CIL) and critical information consumption (CIC) are essential skills and habits of minds for pre-service teachers to develop as they prepare to educate future generations. The purpose of this critical discourse analysis was to investigate ways in which introductory teaching or pedagogy textbooks used in public universities' teacher preparation programs facilitate (or decline to facilitate) the direct and indirect application of CIL/CIC skills. Specifically, textbooks were evaluated on their (1) direct and indirect philosophical and epistemological discussion; (2) direct discussion of evaluating sources of information; (3) attention to power dynamics, biases, ideologies, and underlying assumptions in media and scholarly work; and (4) use of buzzwords and/or epistemically suspect statements. Findings were based on inductive analysis of emergent themes and suggest that there are key features of a text that indicate how CIL/CIC-favorable a work may be. These features include questioning, linguistic granularity, presenting strengths and criticisms of prominent paradigms, attending to power asymmetries in the classroom, and making explicit the hidden or implied messages in educational settings.
\end{abstract}

Key Terms: critical information literacy, critical information consumption, textbook evaluation, teacher preparation programs 
SECTION ONE: INTRODUCTION TO THE DISSERTATION 
At the onset of the third decade of the 21st century, the American public faces an information consumption crisis. Fake news, sponsored content, alternative facts, social media echo chambers, the replication crisis, fear-mongering propaganda, and the scienceversus-politics post-truth paradigm have converged into what researchers have described as a "complex contagion" of "viral misinformation" (Tornberg, 2018, p. 3), a problem of "information privilege" and "systemic bias and inequality" of information sources (Foster-Kaufman, 2019, pp. 272, 273), and an age of "information illiteracy" (Bilos, 2019, p. 1141). Time magazine even referred to the public's inability to distinguish fake news from factual reporting as a "public health crisis," asserting that "having a wellinformed citizenry may be, in the big picture, as important to survival as having clean air and water" (Steinmetz, 2018, pp. 28, 31). The contagious disease comparison is especially apt when, at the time of this writing, the COVID-19 pandemic continues to rage throughout the world. In the fall of 2020, the World Health Organization (WHO) classified the parallel spreads of coronavirus and the related mis- and dis-information campaigns as an "infodemic" that "costs lives" and "threaten[s] long-term prospects for advancing democracy, human rights and social cohesion” (WHO, 2020, n.p.).

From an academic perspective, the assumed solution to this dilemma of misinformation is improved critical information literacy education (Auberry, 2018; Dyer, 2017; Grigoryan \& King, 2008; Johnson, 2018). Critical information literacy (CIL) is a catch-all phrase that refers to the set of skills involved in evaluating information: where it comes from, its accuracy and validity, the context in which it was created and obtained, the underlying assumptions and purposes of information producers, and so on. Depending on the situation in which the phrase is used, CIL may refer to examining underlying 
assumptions or biases in mass media, attending to the power dynamics implicit in textbooks, recognizing psychological manipulation in the form of advertising, evaluating the use (and misuse) of statistical data, or identifying propaganda and so-called fake news on social media (Gretter, Yadav, \& Gleason, 2017; Johansson \& Limberg, 2017; Kellner \& Share, 2005; Lee, 2018; Ruswick, 2015). Considering the breadth of topics and skills described with the phrase 'critical information literacy,' it is almost ironically appropriate that there exists an emerging subset of CIL research dedicated to examining the skills, knowledge, and dispositions needed to detect "epistemically suspect" statements, lack of linguistic and semantic precision, and the "ontological confusion" of buzzwords with profound truth (Pennycook, Cheyne, Barr, Koehler, \& Fugelsang, 2015, p. 551).

The study of CIL thought processes associated with attending not only to the quality and validity of a source of information but also to its precision of language and profundity is a relatively recent development, and as such its conceptualization is an amorphous collection of cross-disciplinary research with little to no unifying structure (Hollis, 2019). For the purpose of clarity, this specific subset of CIL requires its own terminology to differentiate it from critical thinking and information literacy, which are too vague and broadly defined for precise operationalization. Yang (2009) used the term “critical consumption" (p. 101), and Cooke (2017) expanded it "critical information consumption" (p. 211), a phrase meant to imply more active participation on the part of the reader, or consumer, of information. Critical information consumption (CIC) and CIL are used interchangeably in this document to refer to the skills and mindsets that promote active attention to and evaluation of both sources of information (their accuracy, validity, assumptions, biases, power dynamics, etc.) and the ways in which these sources present 
their content (linguistic and semantic precision, epistemic soundness, use of buzzwords as opposed to meaningful ideas, etc.).

Authors of studies within these overlapping fields of CIL/CIC, ontological evaluation, and media literacy have suggested that academia in particular is susceptible to inadequacies regarding critical information literacy and consumption as they are defined here (Holbrook, 2005; Mott-Stenerson, 2005; Sterling, Jost, \& Pennycook, 2016). Thus, the purpose of this study was to investigate the potential successes and shortcomings of addressing CIL/CIC in education through the lens of textbooks used in teacher preparation programs. First, a problem of practice and associated gap in the extant literature are identified, which lead to defining the purpose of the study and the research question. A discussion of theoretical and conceptual frameworks, a detailed description of the study's design and methodologies, and the professional and scholarly significance of the study follow.

\section{Statement of the Problem}

In the past four decades, scholars have produced an abundance of literature detailing the need for improved CIL/CIC and related education for all ages of students, elementary though graduate school, as well as for their respective educators and leaders (Auberry, 2018; Flores-Koulish \& Deal, 2008; Pinto, Cordon, \& Diaz, 2010; Simons, Meeus, \& T'Sas, 2017; Song, 2017). The ongoing attention to CIL/CIC and related research implies that improved critical information literacy proficiencies are still needed and that the related problems of a CIL/CIC-ignorant populace continue.

Underpinning this body of work is an assumption of the cyclic nature of education as an American cultural institution: as students work their way through prescribed PK-12 
school systems and into higher education, some of them will choose to become educators themselves. After completing a teacher preparation program of some sort and achieving the required degrees and certificates, they eventually become the teachers and professors who educate the next generation of students. Later, these same educators may go on to become administrators or policymakers who are tasked with making decisions that will impact future generations of students and citizens, and so the cycle endures. If CIL/CIC education continues to be an ongoing public concern, then it follows that the current cycle of educating the populace and creating new educators is insufficient in regard to CIL/CIC-related skills. The questions that arise, then, are (1) how to find an entry point into this cycle in order to disrupt it and (2) how to examine the potential causes for the apparent inadequate exposure of students to CIL/CIC skills.

Much of CIL/CIC research that focuses on student (or general population) outputs tend to measure skills and abilities such as distinguishing fake news items from genuine, evaluating trustworthiness of websites, or differentiating meaningless jargon from profundity (Auberry, 2018; El Rayess, Chebl, Mhanna, \& Hage, 2018; Flores-Koulish \& Deal, 2008; Lee, 2018; Song, 2017; Sterling, Jost, \& Pennycook, 2016). Studies that concentrate on teaching or instructional inputs tend to examine how educational authorities (instructors, librarians, administrators, etc.) approach direct instruction of CIL/CIC-related topics within the context of their coursework, be it through assigned readings, project-based learning, Socratic discussions, or website evaluation (Higgins \& Begoray, 2012; Joanou, 2017; Rodesiler, 2010; Simmons, 2005; Sperry, 2012).

However, significantly less attention has been given to the resources provided to those authorities; in particular, the dearth of analyses or evaluation of textbooks used in 
teacher preparation programs (TPPs) indicates both a gap in literature and a problem of practice for both TPPs and the teachers they produce. Textbooks represent the bridge between the scholarly generation of knowledge and its practical application in classroom or professional settings (Serenko, Bontis, \& Moshonsky, 2012). Textbook evaluation research usually analyzes the content of the text in the regard to its curriculum alignment, subject matter, or suitability for its intended audience (Brass \& Harkness, 2016; Harkness \& Brass, 2017). Very few studies investigate the implicit messages of bias, assumptions, or attention to why the content is presented in a certain way or why other content is omitted (Pomerance, Greenberg, \& Walsh, 2016; Ruswick, 2015). It is possible, then, that one way to break the cycle of inadequate CIL and CIC education is through the examination and improvement of textbooks used in TPPs through a critical information literacy lens.

\section{Purpose of the Study}

The purpose of this critical discourse analysis was to investigate ways in which introductory teaching or pedagogy textbooks used in public universities' teacher preparation programs facilitate (or decline to facilitate) the direct and indirect application of CIL/CIC skills. Specifically, textbooks were evaluated on their (1) direct and indirect philosophical and epistemological discussion; (2) direct discussion of evaluating sources of information; (3) attention to power dynamics, biases, ideologies, and underlying assumptions in media and scholarly work; and (4) use of buzzwords and/or epistemically suspect statements.

Just as CIL/CIC is an interdisciplinary mélange of skills, attributes, and habits of mind, the framework and design of a study meant to achieve this objective are pulled 
from a variety of academic disciplines. In order to accomplish this purpose, the researcher created an evaluation rubric of the above CIL/CIC elements in order to apply it to the textbooks used in introductory education coursework at the largest public university in each of the United States. The data collected from these rubrics was analyzed with the qualitative approach of inductive content analysis.

\section{Research Question}

In alignment with the stated purpose above, the study was guided by the following research question:

To what extent do the textbooks used by teacher preparation programs in the largest public universities across the United States for introductory or foundations of education courses directly or indirectly address, utilize, or model the following components of critical information literacy/consumption skills:

a. Epistemological and philosophical paradigms in education;

b. Evaluating sources of information (whether for professional purposes or to teach CIC content to students);

c. Epistemically suspect statements and buzzwords in education; and

d. Power dynamics, biases, ideologies, and underlying assumptions in media and scholarly work?

\section{Theoretical Framework}

The theoretical lenses through which CIL/CIC research is constructed tends to vary widely with the backgrounds and purposes of individual researchers. There is no single framework that fully encompasses the purposes and needs of this study. Hence, the conceptual and theoretical bases for this study are constructed from three distinct but 
related frameworks in order to (1) define and operationalize specific components of CIL/CIC; (2) connect the messages found in textbooks to the appropriate epistemic assumptions; and (3) apply the conventions of critical discourse analysis and citation analysis to the topic of CIL/CIC.

Kellner and Share (2005) provided a framework upon which several CIL/CIC studies were based. Their model of media literacy was a set of five core concepts from which an understanding of media and critical literacy could be understood: (1) that all media messages are constructed by someone, (2) each form of media has its own conventions and rules for constructing messages, (3) audience members interpret media messages differently, (4) all media have implicit values and assumptions, and (5) all media messages exist for a reason, usually profit or power (Kellner \& Share, 2005). Further, Yang (2009) addressed CIL/CIC from the standpoint of a skill needed in the "analysis of social structures in the reproduction of inequality" (p. 102) and was one scholar in the field of CIL to begin referring to the umbrella of CIL and related topics as “critical consumption" (p. 101), the phrase from which 'critical information consumption' was adapted to connect the various components of the present study into a single, coherent construct.

Closely aligned to CIL/CIC is the theory of pseudo-profound, epistemically suspect statements, which in academia may be often referred to as 'buzzwords,' but which Frankfurt (2005) and later Pennycook, Cheyne, Barr, Koehler, and Fugelsang (2015) referred to as the "philosophy of bullshit" (p. 549). The authors operationalized the definition of pseudo-profound bullshit (particularly in the media) as a statement that “implies but does not contain adequate meaning or truth...[that] may have been 
constructed to impress upon the reader some sense of profundity at the expense of a clear exposition of meaning or truth" (Pennycook, et al., 2015, pp. 549-550). The focus of psychological research concerning bullshit has less to do with the authors of bullshit or their motivations, but on which variables can be attributed to an individual's receptivity or sensitivity to consuming it. Interestingly, correlates have been established between one's susceptibility to endorsing epistemically suspect statements as profound truth with cognitive measures, critical thinking and numeracy metrics, as well as certain political and psychological characteristics (Pennycook et al, 2015; Sterling, Jost, \& Pennycook, 2016). For example, Sterling, Jost, and Pennycook hypothesize that bullshit receptivity may result from "ideological asymmetries in epistemic motivation" (2016, p. 353). In other words, the information consumer is more motivated to accept and justify epistemically suspect statements from information constructed by sources ideologically aligned with their own, while being more likely to perceive and reject similarly suspect statements from ideologies outside their own.

The evaluation framework concerning teacher preparation textbooks was an amalgamation of these frameworks conducted through a critical discourse analysis design. Discourse analysis examines the relationships between text, context, and subtext, with the assumption that "the interrelationships between language and society as language cannot be divorced from its social context”' (Le \& Le, 2009a, p. 5). Critical discourse analysis examines these relationships through the lens of critical theory in order to examine the underlying assumptions of values or ideologies, power dynamics, and social constructs implicit in the text as it exists in its historical and social context (Locke, 2004). While critical discourse analysis may take several forms, this particular 
framework for research is referred to as "critique as revelation" and is loosely based on Foucault's archeology analysis of discourse (Locke, 2004, p. 27). Considering the nature of this study was to analyze textbooks used in universities around the United States, this branch of critical discourse analysis was well-suited to the study's goals.

\section{Design of the Study}

This study was designed as a critical discourse analysis of CIL/CIC principles and practices in textbooks used in TPPs in public universities. As CIL/CIC itself is a field of study is wide-ranging across multiple disciplines and applied in a variety of professional and educational settings, it is appropriate to utilize critical discourse analysis, a qualitative method which itself borrows from linguistics, philosophy, psychology, anthropology, and cultural studies (Le \& Le, 2009a). Further, a critical discourse analysis allows for situating a document or discourse within the sociocultural context in which it exists, its uses, meanings, ideologies, and - of particular significance for the purposes of this study - implicit use of metalanguage when conveying messages (Locke, 2004).

For example, research in recent years has debunked the myth surrounding learning styles theory, that students achieve better learning outcomes in some modalities than in others based on personality types, but many pedagogy textbooks still refer to it as a valid model for learning (Stix, 2011). Similarly, schools frequently cite the work of Ruby Payne as the basis for how to effectively teach students from impoverished backgrounds, despite the lack of empirical data to support her claims and criticism from educators and scholars about her use of deficit-thinking paradigms (Bomer, Dworin, May, \& Semingson, 2008). Conversely, when criticizing the use of textbooks as a tool for propaganda and 'patriotic' misinformation, educators and scholars frequently cite the 
misrepresentation of Christopher Columbus's conquest in the Americas as a rallying point for increased scrutiny of textbooks (Bello \& Shaver, 2011).

These are examples of topics the researcher searched for when analyzing the direct and indirect language of education textbooks throughout the study: direct language would refer to a text actually citing learning styles theory or Ruby Payne, or critiquing the portrayal of Columbus in schools, as part of its content; indirect (or unacknowledged) language would be the use of the language to frame other topics through the lens of learning styles or a deficit-thinking paradigm without actually citing the source of these ideologies. The purpose of this study's design, then, was to evaluate how the textbooks presented to pre-service teachers in their TPP coursework align (or do not align) with the principles of CIL/CIC and therefore model for these pre-service teachers the mindsets and perspectives that they will internalize as desirable in the profession.

Critical discourse analysis tends to be situated within the sphere of qualitative research as its primary purpose is to develop a holistic understanding of a communicated message within a social framework and how the recipients of the message construct meaning from and make sense of its sociohistorical context, linguistic features, and purpose (Locke, 2004). Such emphasis on the contextual and relative nature of truth and understanding, coupled with the inclination of critical discourse analysis research to be framed in terms of storytelling, imply a distinctively qualitative nature to a critical discourse analysis design (Locke, 2004; Merriam \& Tisdell, 2016). Discourse analysis, like many content analysis approaches, does borrow some elements from quantitative methods, such as the requisite systematic approach to selecting textbooks to analyze and calculating relative frequencies of explicitly defined concepts in order to make general, 
evaluative statements (Merriam \& Tisdell, 2016). The methods for this study aligned closely to the accepted practices for a qualitative research study using critical discourse analysis.

\section{Setting and Participants}

As this study was a critical discourse analysis of introductory education textbooks, there were no human participants; rather, data originated from textbooks used in introductory courses in teacher preparation programs at public universities across the United States. While random sampling is often considered the ideal method for selecting participants in empirical research (Field, 2018), it was not appropriate for the present study since not all public universities have teaching programs, or have programs that are small and may only serve a handful of students every year. In order to select textbooks to which a maximum number of pre-service teachers were more likely to be exposed, the sample of textbooks analyzed came from the largest public university (by number of enrolled students according to CollegeStats, which aggregates data collected from the National Center of Education Statistics (CollegeStats, 2019)) in each of the United States. In qualitative research, this is referred to as a purposive sample; however, in order to maintain the stated purpose of providing a cross-section of data throughout the entire United States, the sample used still encompassed the target population being studied (Merriam \& Tisdell, 2016; Creswell, 2014).

The next step in the participant selection process was to examine each university's publicly available undergraduate catalog to determine from which course in the teacher preparation program the textbooks to be analyzed would come. The ideal textbooks selected for analysis came from TPPs' foundational or introductory course in which pre- 
service teachers were first introduced to educational culture, general theories of pedagogy, and/or an initial field experience. This type of course is generally required for all undergraduate pre-service teachers regardless of content level or age group on which they will focus later in their program. For example, the largest public university in Missouri by student enrollment in the 2018-2019 school year was the University of Missouri at Columbia (CollegeStats, 2019). Its 2019-2020 undergraduate catalog for the College of Education indicated that all education majors are required to take the introductory course LTC 2040: Inquiring into Schools, Community, and Society I (University Registrar, 2019). This was the best candidate for the course from which to analyze the required texts: it was a textbook used at the largest university in the state in an introductory education course that all attending pre-service teachers were required to take. For the full list of universities and their respective foundations courses used in the study, see Appendix A. From there, the University of Missouri had an online component to their bookstore where textbook information about the courses offered in a given semester could be found. All of the participating texts were selected through this or a similar process, where textbooks for the most recent semester on which information is available for a given course was available. Not every university offered its foundational education course during the semester in which the researcher collected the textbook information (since some TPPs use cohort models or offer certain courses every other year based on demand). In these cases, syllabus information was sought for the most recent textbook data available from when the course was last offered, with priority given to course information from the last four semesters prior to data collection (Fall 2018 Spring 2020) wherever possible. Inevitably, some universities kept their textbook and 
syllabus information password-protected; this study was limited to publicly available information about textbooks used in the selected courses, and so these courses were excluded from the data collection pool.

Required course material information was collected for every institution listed in Appendix A. Only books belonging to the literary genre of textbook (as described in the key terms section below) were used. For example, some courses used novels or memoirs as a means of illustrating life as a teacher or student; while storytelling and reading fiction have been researched as valid avenues for strengthening CIL/CIC skills, this was beyond the scope of the study and were therefore excluded from the data collection process. In the case where a textbook was used by more than one university, it was only analyzed once.

\section{Data Collection}

Per institutional guidelines for conducting ethical research, IRB approval was obtained before any data collection began. In all applicable settings, anonymity and confidentiality of individuals and institutions was maintained as deemed necessary and appropriate. Prior to data collection, a rubric of criteria against which to evaluate the textbooks was established, based on (1) use of buzzwords and/or epistemically suspect statements; (2) direct discussion of evaluating sources of information; (3) indirect use of source analysis; (4) attention to power dynamics, biases, ideologies, and underlying assumptions in media and scholarly work; and (5) direct and indirect philosophical and epistemological discussion (see Appendix B for the full data collection rubric and Appendix $\mathrm{C}$ for the complete list of textbooks used for data collection). These criteria were selected from the theoretical and conceptual framework in which the study was 
situated, as well as to align with the stated purpose of the study and research question. Other research about textbook evaluation have constructed their models similarly based on the corresponding theoretical or conceptual components against which the texts were evaluated, which tends to vary according to the content of the textbooks and the purpose of the analysis (Brass \& Harkness, 2016; Harkness \& Brass, 2017; Pomerance, Greenberg, \& Walsh, 2016).

Each textbook selected for the study represented a population of data; rather than read fifty textbooks in their entirety, a sample chapter of each textbook was examined and evaluated using the pre-made rubric. Since the objective of the study was to analyze the use of specific CIL/CIC components, a randomly selected chapter or set of chapters would be inappropriate: what if a textbook does in fact address components of CIL/CIC, but the randomly selected chapter is not the section that addresses it? For each textbook from which data was collected, the table of contents was first analyzed for the necessary components addressed in the research question, and one chapter from the text was then purposefully chosen for analysis. A separate copy of the rubric was used for each chapter to analyze the direct and indirect language used in regard to CIL/CIC concepts as described in the research question.

The data collection rubric was constructed with attention to three dimensions of analysis. First, the rubric's structure refers to each of the components of CIC/CIL listed as foci of the research question. Second, each data piece collected from a given text was analyzed using the three-step Fairclough process for critical discourse analysis: description, interpretation, and explanation (Lee \& Otsuji, 2009). The explanation portion in particular was where the critical component of critical discourse analysis was most 
evident, originating in the assumption that "language intersects with social experience, especially in relation to the teaching experience" (Short, 2009, p. 153). Third, the interpretation step of analysis occurred through the lens of Locke's inductive process of thematic analysis. This process requires consideration of " 1 . Prosody; 2 . Cohesion; 3. Discourse organization; 4. Contextualization signals; and 5. Thematic organization" (Locke, 2004, p. 58).

To summarize: should a scholar decide to replicate the study in order to verify its findings or apply the methodologies used to their own subject of analysis, the step-bystep process for collecting and analyzing data was as follows.

1. The largest public university by enrollment in each state and the District of Columbia was found via CollegeStats.org, which collects data from individual universities and the National Center of Education Statistics about institutions of higher education in the United States.

2. At each university, undergraduate catalogs were accessed to assess which course from would provide the textbooks for data collection. Courses were selected from the most recently available undergraduate catalog (2019-2020 school year) on the following criteria:

a. The course had to be a part of an accredited teacher preparation program.

b. The course could not be limited to strictly elementary, secondary, or specific content areas, but a general education course for all pre-service teachers.

c. The catalog listed the course as a requirement for most, if not all, students enrolled in the teacher preparation program. 
d. The title or course description indicated that the course was intended to be an introduction to education, schooling, or foundations of education in the United States (other equivalent key words were also acceptable).

i. If no course met all of the criteria above, the course that met the most criteria, with priority given to criterion (d), was selected from the researcher's best judgement based on the information provided in the catalog.

3. The researcher then searched for textbook information for each selected course. Various sources were utilized to obtain the textbook information in the following order:

a. University bookstore websites

b. University library websites

c. University syllabus archives

d. Educational file-sharing websites

e. Strategic search engine use for finding the course syllabus by course code, course name, or other information provided in the undergraduate catalog or the previous resources (for example, finding the name of an instructor and obtaining a syllabus linked from their professional website).

For each of the resources, the priority was always to find the most up-to-date information. For courses with textbook information not listed with university bookstores or libraries, some of the syllabi were from previous school years. When multiple years' information was present, the most recent was used. When a course used more than one textbook or had more than one section/instructor, all textbook 
citations were taken; some courses had up to six unique textbooks to contribute to the data collection pool. See Appendix C for the full book list.

4. During the textbook information search process, schools and/or textbooks were eliminated from the data pool for the following reasons:

a. The search ended because the only avenue for obtaining textbook information was password protected or would otherwise require consent to obtain: one parameter set on the study was for all of the information to be publicly available. Seven universities in this study were eliminated for this reason.

b. A university did not a have an accredited teacher preparation program or a general foundations of education course. Four universities were eliminated for this reason.

c. The materials used in the course did not qualify as a member of the literary genre of textbook: some courses used memoirs or fictional narratives as course materials. While there is a subset of scholarly research dedicated to the examination of critical information consumption education through storytelling, that was not within the purpose or scope of this study, and so these non-textbook materials were removed. While several books were eliminated for this reason, only one course was completely eliminated from the study because for genre-specific reasons; all other courses that used these books also required more conventional textbooks. 
Exceptions to the above procedure: New York and Texas, two highly populated and educationally influential states, did not have the textbook information for the selected course from the large public university in the state publicly available. Since a nationwide data pool would arguably be incomplete without these two important states, another university was chosen from each - also based on size (by student enrollment) and availability of textbook information.

5. Critical discourse analysis data collection procedure:

For each textbook, the first step of data collection was an analysis of the table of contents and introductory section. The purpose of this was to determine the tone, objective, and central thesis of the book, and then from there select one chapter for analysis. The chapter was selected based on how likely they would be to address or be relevant to the five CIL components listed in the research question. The data collection for each chapter was comprised of pulling essential quotations from the work, explicating why this is relevant to one or more of the five CIL components, and encoding reflexive commentary in blue. For each piece of analysis, quote, or passage, the appropriate CIL component or dimension of analysis (prosody, cohesion, etc.) was typed in bold for thematic grouping in the data analysis phase. The rubric was not used to divide up the different components and dimensions but was included in each data collection document as a reminder and reference when the researcher was collecting data. Each unique textbook was analyzed once; that is, if a particular textbook was used in more than one university's selected course, it was not analyzed for each time it appeared in the data pool list. 
6. Data analysis procedure: Per standard inductive content analysis procedures, analyses from each textbook chapter were grouped into thematic findings for each of the five subcategories of the research question. Conclusions were based on frequency of each theme's occurrence (or lack thereof) across the population of textbooks.

\section{Data Analysis}

Critical discourse analysis is primarily a form of qualitative data analysis (Le \& Le, 2009a); the present study examined and communicated the data primarily in qualitative form but supplemented with descriptive statistics common in content analysis research. Qualitative critical discourse analysis can take many forms, including Locke's (2004) inductive process of thematic analysis and Fairclough's three-stage process for critical discourse analysis (Lee \& Otsuji, 2009).

Two distinct themes in the data were pre-selected for content analysis: direct versus indirect attention to CIL/CIC concepts. The distinction was made based on the assumption that for pre-service teachers, education textbooks serve as both resources for attaining new information and as models for appropriate information behavior. For example, in a relatively outdated text from the researcher's own undergraduate years, one chapter in particular contained a strong criticism of standardized testing as a means of measuring learning. However, at the end of every chapter in the book, there was a set of multiple-choice questions - the modus operandi of standardized tests and a relatively superficial metric of learning - to assess comprehension of the text (Jones, Pearman, \& Sheffield, 2007). This demonstrates a dissonance between the direct, explicitly stated philosophical paradigm for public education as described in the text and an implicit value 
being modeled by the structure of the textbook itself. In that regard, unacknowledged use of a given structure or principle was considered an example of implicit or indirect information in the data collection process.

Further, the rubric used in the data collection process was used to report organization of content patterns and word usage in order to calculate relative frequencies of CIL/CIC themes and related concepts. Descriptive statistical analyses of desirable and undesirable textbook characteristics were used as appropriate in order to answer the research question, as Merriam and Tisdell described content analysis types of research as potential avenues for "measuring the frequency and variety of messages" in texts or media when conducting qualitative content analyses (2016, p. 179).

As is the case with any qualitative research, researcher reflexivity was a necessary component of the data collection and analysis processes (Creswell, 2014). In critical discourse analysis, reflexivity is an extension of the assumption that all text is ideologically-charged or value-laden in some way, including that of the researcher; true neutrality is unrealistic in any sort of content analysis since the analysis and interpretations of the text originate from a human, and therefore flawed and biased, perspective (Le \& Le, 2009b; Warburton, 2016). In an effort to remain critically aware of their own assumptions, ideologies, and limitations, throughout the data collection and analysis processes the researcher also included any reflexive commentary in a separate color from the content analysis text, as indicated on the data analysis rubric. 


\section{Limitations, Assumptions, and Design Controls}

The limitations, assumptions, and design controls of the study align with those of any critical discourse analysis research and possess many of the same features commonly found in qualitative analyses.

\section{Limitations}

According to Mogashoa (2014), critical discourse analyses are limited by the interpretations and meaning-making of the researcher doing the analysis, writing, "meaning is never fixed and everything is always open to interpretation and negotiation...the general lack of explicit techniques for researchers to follow has been indicated a hindrance" (p. 111). Since critical discourse analysis is used in so many different disciplines and interpreted through so many different critical perspectives, there is no one unifying theory or technique with which to accomplish a critical discourse analysis study (Le \& Le, 2009a; Locke, 2004). In other words, the study’s depth, breadth, and rigor of analysis are limited by the knowledge, experience, and biases of the researcher. Inherent in this limitation is ideological asymmetry, a cognitive bias in which an individual is more likely to ascribe favorable outcomes to information that originates from an in-group source (a source the information consumer agrees with) than that of an out-group source (Levin, Sidanius, Rabinowitz, \& Federico, 1998).

Time and resource limitations were also such that full analyses of entire textbooks were not a feasible goal. Rather, chapters were purposively selected from each text for analysis. A longer, more impactful future study may strive to analyze full textbooks. 


\section{Assumptions}

In collecting information from undergraduate catalogs, university bookstores, and publicly available syllabi, it was assumed that the information about required textbooks for the pertinent courses from official university sources was accurate and up-to-date. It was assumed also that public universities' teacher preparation programs would be the broadest-reaching population from which to select high-exposure textbooks; while many states do utilize alternative pathways to teacher certification and private institutions are more prevalent in some locations than others, public universities were assumed to serve as a baseline for the model of standard teacher preparation programs.

Further, the underlying assumption of even conducting such a survey was that these chapters are in fact being consumed by pre-service teachers. Anecdotally, university students have observed that although a textbook is assigned in a syllabus, an instructor may choose to only use small portions of the text, preferring to supplement with scholarly articles and other sources that are not found in a textbook. Related to this assumption is the understanding that textbooks, while fundamental to the dissemination of knowledge and a tradition in the structure of educational institutions, they are not the only (or even the most influential) source of knowledge in the classroom. Even a textbook that 'scored' poorly in its analysis in the context of CIL/CIC education may be, when used in conjunction with lecture, class discussion, and assignments, an effective tool for modeling a critical approach to information consumption.

\section{Design Controls}

The study was designed with the intent to analyze textbooks that receive high levels of exposure to pre-service teachers. This was done through several layers of 
purposive sampling: first with the teacher preparation program from the largest public university by enrollment in each of the United States, then through selecting a foundation of education (or similar) course in each program that all pre-service teachers would be required to take regardless of content area or grade level. The required textbooks for these courses constituted the data collection sample. Since courses are not always offered every semester, the researcher also used syllabi, bookstore archives, and other publicly available course information for the last four semesters (Fall 2018 through Spring 2020) to find timely textbook information. Further, the study was designed with the intent to analyze textbooks, which constitute a nonfiction genre meant to disseminate information or report research. Thus, required readings in educational courses that were not within this genre were removed from the data collection pool.

\section{Definitions of Key Terms}

The following is a list of key terms and definition, in alphabetical order, that appear throughout this document.

Accreditation. According to the Council for Accreditation of Educator Preparation, "accreditation is quality assurance through external peer review" (CAEP, 2019a, n.p.). Accreditation is a status held by a program or institution that is nationally recognized as an indicator that the program upholds certain standards of quality and can be expected to produce capable education professionals (CAEP, 2019b).

Bullshit. This is a sociolinguistic phenomenon in which a statement is meant to appear impressive, profound, or important without any regard for actual truth or meaning; when paired with buzzwords or epistemically suspect statements (see below), these 
statements may also be referred to as pseudo-profound bullshit (Frankfurt, 2005; Pennycook, Cheyne, Barr, Koehler, \& Fugelsang, 2015).

Buzzword. Similar to bullshit, this is a word or phrase intended to sound important or technical, but that holds little true meaning. Buzzwords are often associated with trends or fads. Interestingly, the word 'buzzword' is commonly used in scholarly articles, often without much discussion of the meaning of the word itself - implying that 'buzzword' might itself be a buzzword.

Cohesion. This refers to the words, phrases, and linguistic devices that are used to bring the text together into a unified whole; when paired with discourse organization (see below), a text can be analyzed through a "structural plotting" of what message is communicated, how it is communicated rhetorically, and how it is communicated contextually or sub-textually (Locke, 2004, p. 64).

Contextualization signals. These are the linguistic elements within a text that alert the reader to how the authors situate themselves within the text, how and where the text is situated within a larger body of scholarly work, or where the text/authors are positioned within a larger conversation (be it culturally, historically, or otherwise) concerning the content of the text (Locke, 2004).

Critical discourse analysis (CDA). CDA is a method of qualitative research that encompasses the set of content analysis techniques and approaches from the perspective of investigating biases and power structures through indirect and direct uses of language (Le \& Le, 2009a; Locke, 2004; Rogers \& Schaenen, 2013).

\section{Critical information literacy/critical information consumption. Critical}

information literacy (CIL) is a catch-all phrase that refers to the set of skills involved in 
evaluating information: where it comes from, its accuracy and validity, the context in which it was obtained, and so on. Depending on the situation in which the phrase is used, CIL may refer to examining underlying assumptions or biases in mass media, attending to the power dynamics implicit in textbooks, recognizing psychological manipulation in the form of advertising, or identifying propaganda and so-called fake news on social media (Gretter, Yadav, \& Gleason, 2017; Johansson \& Limberg, 2017; Kellner \& Share, 2005; Lee, 2018; Ruswick, 2015). Critical information consumption (CIC) refers to the active attention to and evaluation of both sources of information (their accuracy, validity, assumptions, biases, power dynamics, etc.) and the ways in which these sources present their content (linguistic and semantic precision, epistemic soundness, use of buzzwords as opposed to meaningful ideas, etc.).

Direct (use, modelling, application, etc.). In the context of this study, all components of CIC that are examined for direct use within teacher preparation textbooks refer to when the authors of the textbooks explicitly discuss, define, or otherwise clearly include the topic as a part of the content or curriculum of the textbook. For example, a textbook that includes a checklist for identifying reliable versus unreliable sources of information on the internet would be directly addressing a component of CIC education.

Discourse organization. This refers to the logical, rhetorical structure of an argument or message that an author is communicating (Locke, 2004).

Disinformation. In contrast with misinformation (see below), disinformation is false or misleading information that is disseminated with the known intent of misleading or spreading falsehoods; disinformation is often used explicitly to refer to government organizations and mass media (Stahl, 2006). 
Epistemically suspect. An epistemically suspect statement is one of questionable validity, accuracy, reliability, or profundity. Pennycook et al. (2015) used it as a synonym for bullshit statements, but the phrase may also refer to pseudoscientific, antiscientific, or superstitious beliefs (Pennycook \& Rand, 2018a).

Fake news. Fake news is commonly defined as "fabricated content" created and distributed with intentions of passing "manipulation, disinformation, falseness, rumors, [and] conspiracy theories" as true (Kalsnes, 2018, p. 2).

Indirect (use, modelling, application, etc.). For the context of this study, indirect use (or misuse) of CIC components would be any instance of text, context, or subtext that relates to the CIC elements enumerated in the research question, but the use or appearance of which is unacknowledged or otherwise not addressed.

Information. This refers to any text, audio, visual, electronic or other media content that can be verified as factual or accurate, as opposed to opinion or fiction.

Misinformation. In contrast with disinformation, misinformation is the dissemination of misleading or false information, but with the belief that the information is true (or at least, without the intent of misleading) (Stahl, 2006). For example, if an information consumer reads a fake news item and then, believing it to be true, shares it over social media, that individual is an agent of misinformation, even if the original creator of the post is an agent of disinformation.

Prosody. While prosody refers to the general use of stress and rhythm in linguistics, Locke (2004) uses prosody in the content of CDA as a means to examine an author's the tone or "sound" of an author's text and how it is used to communicate a 
message; Locke recommends "reading [a text] with our ears" to identify patterns of prosody similar to how one would analyze the speech patterns of an orator (2004, p. 58).

Teacher preparation programs (TPPs). TPPs are defined for the purposes of this study as departments and/or programs that are designed in such a way that successful completion will result in a teaching license: the set of coursework, field experiences, and standardized testing requirements that comprises the training an individual must obtain in order to acquire the appropriate licensure to teach. These programs are often housed in colleges and universities as undergraduate, graduate, or certificate programs. For the purposes of this study, teacher preparation programs will only refer to programs in public universities that have accreditation from a reputable accrediting body, per the United States Department of Education.

Textbook. This refers to the literary genre designed for the sanctioned dissemination of knowledge (Lopez-Medina, 2016; Wakefield, 1998); textbooks are often considered the backbone of a course's curriculum and the "authorized version of human knowledge" to be taught and learned (Lopez-Medina, 2016, p. 163). For the purpose of this study, works that were written to disseminate the results of scientific research were deemed a subcategory of the textbook genre.

Thematic organization. Similar to other forms of qualitative content analysis, Locke's (2004) use of thematic organization refers to how a work structures its ideas, the subthemes that relate to those major ideas, and ultimately the patterns that emerge from analyzing multiple texts. 


\section{Significance of the Study}

Teachers in the United States are expected to prepare students to engage effectively and productively in a modern democracy (Cope, 2017; Storksdieck, 2016). Technological advances in the consumption of mass media have changed American social and political landscapes to the extent that CIL/CIC skills are increasingly necessary for functioning in society (Ma, Li, \& Liang, 2019). The question that arises, then, is how can teachers facilitate the development of CIL/CIC skills in their students if they are not themselves trained to do so in their own education and teaching preparation programs? Appropriate meta-education requires rigorous attention to not only the process, but the materials used in the implicit and explicit application of CIL/CIC skills. With limited scholarly consideration given to the implications of CIL/CIC development in the quality of textbooks used in teaching preparation programs, there is a potential disservice being done in modeling the CIL/CIC skills and critical consumption mindset necessary to actively engage pre-service teachers in the development and facilitation of the same in their future students.

The goal of the study was to contribute to the thoughtful and practical development of CIL/CIC skills and critical consumption in pre-service teachers who will eventually become the educators, leaders, scholars, and policymakers in schools. If the insights gleaned from this research foster improved attention to the quality of teacher preparation textbooks or engage educators (current or future) in deliberate reflection on their own CIL skills, critical information consumption proficiencies, and those of their students, then I will consider it a positive and meaningful contribution to the body of scholarship and educational praxis. 


\section{Summary}

The objective of this critical discourse analysis study was to examine the direct and indirect modeling of critical information consumption, a subset of critical information literacy, in introductory textbooks used in teacher preparation programs in the largest public universities in each of the United States. The framework of critical media consumption used in this study was based on Kellner and Share's (2005) conceptual framework for CIL and the operationalized definitions of bullshit theory initially proposed by Frankfurt (2005) and adapted into scholarly practice by Pennycook et al (2015). The design framework of critical discourse analysis provided a holistic, systematic approach to evaluating textbooks on CIL and critical consumption criteria. This study followed the accepted qualitative approaches associated with critical discourse analysis. Data collection occurred through the use of a textbook evaluation rubric designed to attend to language, content, context, and metalanguage of the texts. The findings presented in this study are intended to provide insights into the state of CIL/CIC education that may impact teacher preparation programs, classroom praxis, and ultimately the knowledge and skills of future generations of information consumers. 
SECTION TWO: PRACTITIONER SETTING FOR THE STUDY 
When Commissioner P. P. Claxton of the United States' Department of the Interior orchestrated a report on public universities' implementation of best practices concerning field experiences in their teacher preparation programs, he wrote, "no effective professional training can be given without...expert direction and intelligent sympathetic criticism" (p. 5). These words were written in 1917 in the Bureau of Education's Practice Teaching for Teachers in Secondary Schools bulletin. The question of how best to train teachers in the traditional university setting, then, is certainly not new. However, the answers to that question have evolved over time with changing technological and sociocultural landscapes.

The purpose of this section is to situate the present study in the context in which its target practitioner audience is set. The nature of this study would suggest that there are two closely related but distinct 'settings' to consider: (1) teacher preparation programs (TPPs) in American public universities, and (2) the textbooks being used in pedagogy and education coursework in these TPPs. TPPs are defined for the purposes of this study as departments and/or programs that are designed in such a way that successful completion will result in a teaching license. Further, this definition implies that all TPPs possess proper credentials through the Council for the Accreditation of Educator Preparation (CAEP) or other reputable accrediting body. TPPs represent the organizations made of people, information networks, social systems, and physical resources that constitute the traditional notion of a practitioner setting for a research study.

More precisely, the current study is a critical discourse analysis of textbooks used in TPPs, and as such these textbooks should receive separate consideration as a 'setting' not only for the context of the study, but as the backdrop against which TPP practitioners 
(teacher education faculty) do their work and pre-service teachers learn what it means to be an educator. Textbooks as a setting for scholarly analysis of their content, context, and subtext has existed in some form or another for nearly as long as humans have been writing with the intention to disseminate knowledge (O'Keeffe \& O'Donoghue, 2015; Sparke, 2018).

The following sections address each of the two settings in turn as appropriate, beginning with a brief historical summary of TPPs in American public universities and the use of textbooks in these programs. The next section details TPPs from an organizational analysis perspective and the roles that textbooks play within these structures, followed by a discussion of leadership theories and practices in TPPs and textbook selection processes. Finally, the present study's research question is revisited to address implications for the research in these settings.

\section{History and Background of the Setting(s)}

Prior to the early nineteenth century, standard teacher preparation in the United States did not exist in the capacity that is considered common today (i.e., receiving formal training from a college or university in order to earn a degree and/or professional license); rather, depending on the needs, resources, and values of a given community, an educator was anyone from a member of the clergy to a craftsman, childcare provider, or town official (Labaree, 2008; Nguyen, 2018). Pedagogues educated in the art and science of education were considered an Old World (or upper class) phenomenon that clashed with Americans' Puritanical roots, believing that the purpose of education was to further one's religious journey (Ducharme \& Ducharme, 2019; Harris \& Levin, 2001). By the 1820s, though, the United States saw the emergence of the first teacher preparation 
schools that trained educators-to-be in pedagogical methods, classroom management, and standards for morality (Nguyen, 2018). These early normal schools did not usually focus on higher levels of content matter, so more academically-inclined individuals were encouraged to find work elsewhere as doctors, lawyers, or in universities; the cultural norms at the time dictated that these more academically-inclined individuals were generally men, giving rise to teaching as one of the first respectable professions for American women (Ducharme \& Ducharme, 2019; Labaree, 2008).

With the establishment of the expectation that professional educators should hold some form of degree or certificate to demonstrate their fitness to teach, normal schools eventually evolved into state and regional colleges (Labaree, 2008). As prominent reform activists influenced public policy about schooling standards through the nineteenth and into the twentieth centuries, teacher preparation programs were gradually integrated into broader university communities with expectations that pre-service teachers experience academic rigor commensurate with their analogues in higher education. Emphasis on evidence-based practices, research into educational psychology, pedagogy, and psychometrics eventually molded university TPPs into the model with which most public university-educated teachers are familiar (Harris \& Levin, 2001; Nguyen, 2018).

\section{TPPs and the Purpose of Schooling in the United States}

As the American cultural perception of the purposes of public education have morphed over time, so too have the nature of schooling and by extension the training prospective educators receive in order to realize these purposes. While privately funded education had always existed for those with the means, public education in the United States was originally an extension of church communities and therefore existed to fulfill 
explicit religious objectives (Ducharme \& Ducharme, 2019; Harris \& Levin, 2001). With the arrival of public-school settings separate from churches and teachers trained in normal schools (and later teacher colleges), the perception of the purposes of public education gradually shifted to nurturing intellectual growth while upholding high standards for moral and ethical behavior in the context of civic duty ("Moral Instruction in Public Schools", 1882). Indeed, Dewey's 1916 Democracy and Education elucidated the notion of education - and therefore teaching - as essential for both individual and societal growth, and American educational ideals became increasingly associated with civic engagement.

During the first half of the twentieth century, Americans' educational priorities changed again; periods of robust economic growth and then sudden decay, followed by world wars and global competition for weapons and technology, led to schools being measured in terms of economic potential and the productivity of their outputs (read: students) (Labaree, 2008). These pressures contributed to the resulting factory model of education, a consequence of applying these priorities to schooling, according to Sir Ken Robinson (RSA Animate, 2010). While the merits and shortcomings of this perspective on education may be debated, it still influences the American public-school system in the twenty-first century. In the second half of the 1900s and the beginning of the 2000s, though, education as a validation of identity and inclusion of historically underserved populations also emerged as a major priority (Harris \& Levin, 2001).

At the onset of the third decade of the twenty-first century, what is the current state of the perceived purposes of education and of TPPs in the United States? The social movements of the latter half of the twentieth century, a paradigm shift to treating schools 
as businesses competing as in economic settings, and unprecedented advances in technology have contributed to the current state of public perspectives of education which are an amalgamation of the old and new (Brusic \& Shearer, 2014; Ducharme \& Ducharme, 2019). That is, public education today is intended to produce citizens who can be economically productive in current and future societal conditions; often classified under the umbrella term 'twenty-first century skills,' the purpose of education is now considered to be to provide students with the social, emotional, cognitive, technological, creative, problem-solving, and critical thinking skills necessary to compete in job markets that may not yet exist (Brusic \& Shearer, 2014; Casner-Lotto, 2006; Rahman, 2019).

The charge of TPPs, then, is to train pre-service teachers to carry out this purpose under the increasingly watchful eye of standards-heavy state and federal governments (Rothman, 2012). Just as school systems face the near-constant public scrutiny over concerns of whether the students they produce are ready for the workforce, so too do public universities' TPPs field similar criticisms about how well they prepare incoming teachers for the classroom (Casner-Lotto, 2006; Cochran-Smith, Burton, CummingsCarney, Sanchez, \& Miller, 2017; Klitmoller, 2016). Consequently, scholarly research into the successes and shortcomings of American TPPs is in demand, particularly that related to preparing pre-service teachers to teach, learn, and apply twenty-first century skills in their classrooms. The present study concentrates on the use of textbooks for this purpose.

\section{The History of Textbooks in TPPs}

Textbooks as a literary genre have existed for as long as formal schooling has (Wakefield, 1998). Their content, structure, and designs have varied widely between time 
periods and cultures, and therefore can provide insight into a particular people's values and educational philosophies; for example, analyses of textbooks used in Soviet-era Ukraine and post-apartheid South Africa have revealed profound insights into the use of public schooling for the dissemination of state-approved character education and oppressive cultural narratives (Bogachenko \& Perry, 2015; Subreenduth, 2013). Similarly, Rymarz and Engebretson (2005) argued that religion education coursework would only be as effective as the quality of and values espoused in the textbooks used. In other words, textbooks reflect an educational settings' purpose and values, and often provide the framework around which a learning experience is constructed (Wakefield, 1998).

The textbooks found in early TPPs of normal schools and teacher colleges emphasized the qualities of the 'ideal' (female) teacher in her attitude, comportment, intellect, and classroom management (Joseph \& Burnaford, 2009). One popular textbook of the early twentieth century warned prospective teachers that they must expect all aspects of their lives to be publicly scrutinized only to in the end be forgotten (Palmer \& Palmer, 1908). As standards for TPPs grew more rigorous, teacher education textbooks gradually became more specialized and evidence-based, with subject-specific texts for different content areas, pedagogy and methods, educational and developmental psychology, research methodologies, philosophy, and multicultural education (Labaree, 2008; Sileo \& Prater, 1998).

Like the changes in American schooling over time, TPPs and by extension the textbooks they use have co-evolved to accommodate the needs of the public-school system. A community's standards and values for education are demonstrated by what is 
addressed - and what is not - within a chosen textbook, as well how it is addressed and who has the power to make those decisions. Therein lies the necessity of critical discourse analyses of textbooks, a subfield in educational research that has been growing steadily for the last few decades; however, it has only been in recent years that significant attention to critical discourse analyses of teacher education textbooks has emerged (Rogers \& Schaenen, 2013; Sileo \& Prater, 1998; Zittleman \& Sadker, 2002). The intention of the present study was to contribute to the body of knowledge in this setting as a practical means of improving the quality of textbooks used in TPPs.

\section{An Organizational Analysis of Teacher Preparation Programs}

Implementation of American TPPs in public universities can vary widely from state to state or even from school to school, but there exist certain universal similarities based on standards for accreditation. The U.S. Department of Education recognizes institutional accrediting agencies for educational organizations, which in turn hold universities and other institutions accountable for providing high-quality TPPs that meet a minimum set of requirements (CAEP, 2019a; U.S. Department of Education, 2019). Further, the accrediting agencies themselves must earn and maintain accreditation through the Council for Higher Education Accreditation (CHEA). Among these agencies, the Council for the Accreditation of Educator Preparation is the largest and most respected TPP accrediting body in the United States; however, at the time of this writing, a new TPP accreditation agency, the Association for Advancing Quality in Educator Preparation (AAQEP), has an application for initial recognition pending with the CHEA (AAQEP, 2019a; CHEA, 2019). 


\section{CAEP and AAQEP Standards}

The features that accredited TPPs have in common are most likely those which comply with accreditation standards. It follows that from an organizational analysis perspective, the standards are a logical starting place to consider the underlying structures, assumptions, and values that drive accredited TPPs in American public universities. The CAEP distill their accreditation priorities into five standards, each containing a set of detailed descriptions of the evidence required and expected criteria for meeting the standard. They are:

1. "Content and pedagogical knowledge,

2. Clinical partnerships and practice,

3. Candidate quality, recruitment, and selectivity,

4. Program impact, and

5. Provider quality assurance and continuous improvement" (CAEP, 2019b, pp. $1-2)$.

The process of bestowing or renewing TPP accreditation is a form of program evaluation, and the CAEP standards align with McLaughlin and Jordan's (2015) explanation of logic models as used in program evaluation to assess structures, activities, and resources in place to transform the program's inputs into their desired outputs. In this case, the 'inputs' are the students accepted into a given TPP, and the 'outputs' are the trained, licensed professional educators who have completed the program. The quality of both a programs' inputs and outputs are quantified in the CAEP standards, with the selection process for prospective pre-service teachers required to use grade-point average and standardized test scores as a basis for admissions; similarly, the quality of the 
program's outputs is determined by metrics of the completers' hiring rates, job performance and retention, and impact on student achievement in schools (CAEP, 2019b).

The language used in the CAEP's standards document (2019b) even parallels that of logic models in McLaughlin and Jordan (2015). Rather than 'inputs,' the document refers to pre-service teachers as 'candidates;' the word 'output' can be directly replaced with 'completer' and 'impact.' TPP faculty and staff, the 'resources' of the basic logic model, are 'providers.' Since the CAEP standards focus attention on the organizational architecture of TPPs and the metrics used to monitor and uphold them, even using analogous language to that of an input/output logic model, this suggests that the CAEP understands TPPs through the structural frame of organization as described by Bolman and Deal (2013).

Bolman and Deal (2013) outline the structural frame as an approach that functions under a set of basic assumptions about organizations: there are explicitly-defined objectives around which the organization exists; specialization maximizes efficiency and performance; coordination, control, rationality, and clear definition of roles are necessary for functional processes (p. 45). If a TPP is considered an organization, then the CAEP standards outline certain roles, objectives, and functions common to all that earns accreditation through the CAEP regardless of differences in state and local standards for teacher certification. Of the five CAEP standards, two explicitly address the basic structural components of what CAEP-accredited TPPs provide to their pre-service teachers: content and pedagogical knowledge (e.g., program coursework) and access to field experiences (like student teaching) in partnership with local schools (CAEP, 2019b). 
The other three standards concern the metrics and procedures in place for monitoring the inputs and outputs (eligible candidates and newly graduated teachers) of the program.

While CAEP is the largest TPP accrediting body, a growing number of reputable public institutions are also accredited by AAQEP, such as the State University system New York (AAQEP, 2019a). Introduced in 2017 as a contrast to the CAEP standards, the AAQEP standards for TPP accreditation were written to specifically address "completer performance", "program practices", "foundational expectations", and "contextual challenges" (AAQEP, 2019b, p. 11). The AAQEP standards for TPP accreditation are presented in the form of four questions:

1. "At the end of the program, are completers ready to fill their target professional role effectively?

2. Were completers prepared to work in diverse contexts, have they done so successfully, and are they growing as professionals?

3. Does the program have the capacity (internally and with partners) to ensure that completers are prepared and succeed professionally?

4. Is the program engaged in strengthening the education system in conjunction with its stakeholders and in keeping with its institutional mission?" (AAQEP, 2019b, p. 11).

These standards are in many ways similar to those used by the CAEP. Both emphasize the importance of partnerships with stakeholders to ensure pre-service teachers receive quality field experiences; both indicate the need to monitor that a TPP's alumni are positively impacting their workplaces. Nevertheless, the AAQEP's approach 
to these criteria differ from the CAEP's in the implicit and explicit means of communicating their priorities for TPPs.

While the AAQEP also uses the word 'completer' in their standards, overall their linguistic choices indicate a marked difference from the CAEP in how the organization perceives the role of people in TPPs. The first two standards are written as questions to directly assess the needs and experiences of the programs' students; the last two address the program as a vehicle for meeting the needs of its students and community stakeholders. Further, in the explication of how each standard is to be interpreted, the standards document notes that criteria should be evaluated holistically. While the CAEP uses an explicit set of metrics as evidence for upholding their standards, the AAQEP does not adhere to any one predetermined type of evidence, but rather encourages TPPs to provide any and all evidence that supports their claims for maintaining each standard (AAQEP, 2019b; CAEP, 2019b).

These features, as well as the repeated, deliberate inclusion of culturally responsive practices and meeting the needs of pre-service teachers in their priorities, suggest that the AAQEP approach TPPs from the human resource frame of organizations as presented by Bolman and Deal (2013). The primary assumption of this frame is that "organizations exist to serve human needs rather than the converse" (Bolman \& Deal, 2013, p. 117), and that successful organizations put the motivations, talents, and unique identities of their people first. Such qualities are implied in the way that AAQEP frames their discussion of TPPs and the way they should be evaluated from the standpoint that TPPs serve people: the pre-service teachers enrolled in the programs, but also the students, parents, educators, and community members who are impacted by the 
program's work. From this perspective, accredited TPPs should have a human resource mindset, with activities and functions that demonstrate that they value their people.

\section{Implementation of TPPs and Pathways to Certification}

Beyond adherence to an accreditation organization's standards, TPPs may implement their program practices quite differently from one another depending on state and local expectations and access to resources (U.S. Department of Education, 2019). Along with completing an accredited TPP, pre-service teachers are required to pass one or more certification exams in order to obtain a teaching license in a given state. However, the number and type of exams and what constitutes a passing score are determined by each state and therefore also have considerable variance throughout the nation (Educational Testing Service, 2020). Further, TPPs at different institutions in the same state may differ in the way they provide their services, with credit hour requirements, number and type of field experiences, and general education prerequisites fluctuating from university to university.

Traditional TPPs are not the only method of obtaining teaching certificates. Particularly in states that struggle with teaching shortages, policymakers have enacted alternative pathways to the classroom that can truncate or eliminate entirely the education training portion of TPPs in order to speed candidates into high-need areas (Hootnick, 2014; Ingersoll \& Smith, 2003). While these alternative programs are not the focus of the present study, they represent additional evidence to the claim that TPPs cannot be assumed to have a single organizational system beyond the framework of their accrediting body's standards. 


\section{The Role of Textbooks in TPPs}

TPPs use textbooks in a similar manner to other academic programs as they "play canonical role in codifying and disseminating disciplinary knowledge and theory" (Sparke, 2018, p. 60). Since TPPs are expected to provide specialized coursework/training in content area knowledge, foundations of education, pedagogy, educational psychology, philosophy, multicultural education, education law in the U.S., and other subjects depending on the program, educational texts remain an essential component of TPP coursework (Arnold, 2013). Educational textbooks have an additional purpose than the dissemination of information: teaching methods textbooks provide an experience of meta-teaching and meta-learning not only in the content of their texts but also in how to present it; for pre-service teachers, these books are both academic references and practical models for how to effectively impart information (Chu, 2017; O’Keeffe \& O’Donoghue, 2015).

An organizational analysis of TPPs and the role textbooks play within them is incomplete without a discussion of the people who grow and maintain them: the administration, faculty, and stakeholders who write policy and make decisions that influence the course of a given program and its pre-service teachers. The following section examines the nature and impact of leadership in TPPs.

\section{Leadership Theory and Practice in the Context of Teacher Preparation}

The first challenge in engaging in an analysis of the leadership present in TPPs is to determine who is the 'real' leader in this context. According to Northouse (2016), leadership is the process of enacting change or influencing people to work toward achieving common goals. Regardless of the leadership style of a particular individual, 
this definition implies that leadership is defined by who has the power to make impactful decisions. Bolman and Deal (2013) would argue that this perspective is rooted firmly in a political framework for evaluating leadership based on power struggles and resource allocation. Since the ultimate authority for TPPs in public universities is a governmentapproved accrediting body and/or mandates from state governments themselves, a political perspective of leadership and power is valid.

To examine the leadership required to maintain an accredited TPP, it is helpful to construct a model of the power structures in place that directly impact the program. First, an accredited TPP is beholden to the standards and expectations of its accrediting body, as discussed above. Should the accreditor change its standards, the TPP must adjust accordingly. Similarly, TPPs at public universities must follow state laws and initiatives for higher education; for example, the Core 42 initiative in Missouri drastically changed the nature of some general education courses, impacting students and universities across the state (Prichett, 2019). Nevertheless, these structures do not represent leadership so much as the parameters within which a TPP must operate.

Any given TPP is now typically a department within a university (Labaree, 2008), and thus has leadership structures similar to others in higher education, from the provost to a department head. The activities and direction if a TPP are also influenced by stakeholder-leaders outside of the university: principals, superintendents, and school boards of partnering school districts, for example (Wells, 2010). The complex interactions between government, administrators, bureaucracy, and community mean that by necessity, leadership roles in TPPs are often perceived as a top-down managerial or transactional process in scholarly research; this is a stark contrast to the models of ideal 
leadership that classroom teachers themselves are expected to possess: transformational, charismatic, principled, with a passionate determination in the face of soulless bureaucrats (Khan, 2017; Suranna \& Moss, 2002; Trujillo \& Scott, 2014; Wells, 2010).

Just as textbooks in TPPs provide a model of meta-teaching and meta-learning for pre-service teachers (intentionally or not), so too do the leadership styles to which prospective educators are exposed in their TPPs. However, there is still relatively little consensus on how to approach - or even define - teacher leadership education to preservice teachers, as opposed to those individuals seeking principal or superintendent certificates (Bales, 2007; Labaree, 2008; Suranna \& Moss, 2002; Wells, 2010). In fact, many government- or think tank-sponsored-reports lamenting the state of TPPs and the teachers they produce do not even use the word 'leadership' outside of the context of principals, superintendents, or TPP administration (Greenberg, Putman, \& Walsh, 2014; Lubell, Drake, \& Putman, 2017; Meyer, 2016; Mitchel \& King, 2016; Montague, 2002; Suckow, 2018). The question remains, then, of how pre-service teachers are meant to learn effective leadership skills in their TPPs if teacher leadership is not a stated priority.

Any content matter not explicitly valued by policymakers for TPPs, such as teacher leadership, is left to the discretion of the teacher education faculty and their course content. In traditional university settings, the professor has the power to select the required textbook(s) for a given course and therefore significantly impact the way the course content is delivered (Clow, Stevens, \& McConkey, 2006). Even in settings where the course instructor does not have complete autonomy over textbook selection, they still tend to have significant influence over the choice of course materials (Woodward, Lloyd, \& Kimmons, 2017). Therefore, textbook analyses may be useful tools to gain insights 
into the values and priorities of TPP instructors and what knowledge and skills they believe are essential for their pre-service teachers to learn.

\section{Implications for Research in the Practitioner Setting}

The research question for the present study was as follows:

To what extent do the textbooks used by teacher preparation programs in the largest public universities across the United States for introductory or foundations of education courses directly or indirectly address, utilize, or model the following components of critical information literacy/consumption skills:

a. Epistemological and philosophical paradigms in education;

b. Evaluating sources of information (whether for professional purposes or to teach CIC content to students);

c. Epistemically suspect statements and buzzwords in education; and

d. Power dynamics, biases, ideologies, and underlying assumptions in media and scholarly work?

The impetus behind this research question was the content of education textbooks used in TPPs. The background of the setting provided in this section, though, illuminates the need for future research within a similar field of study, particularly in conjunction with the potential results of the present research. First, an expansion of the limited research on how and why higher education instructors make their textbook selections, specifically in the context of TPPs, is needed: what are the primary features that a professor seeks in a prospective text? How much time do they dedicate to textbook selection, and what (if any) evaluation tools do they use to assist in making their choice? Since one of the outcomes of the study is a CIL/CIC evaluation checklist for education 
textbooks (Appendix D), follow-up research would be needed on its perceived usefulness in the hands of TPP instructors.

Future research is also needed to assess and compare CIL/CIC attitudes and dispositions across content areas or fields of expertise in educational settings: Is there a significant difference in CIC attitudes in certain teaching fields than others? Is there a difference in CIL skills between teachers, administrators, and policymakers? The results of this research could have significant implications for TPP curriculum and implementation.

Lastly, while indirectly related to the research question of the present study, I was troubled by two recurring themes in my reading about TPPs in the United States. The first was noted above in the previous section: the distinct absence of discussion of teacher leadership in TPPs. Teachers in the twenty-first century are expected to be leaders in the classroom and beyond, and teacher leadership is by no means a new concept to scholars or education professionals (Vitucci \& Brown, 2019; Wells, 2010), but are they being trained to meet those expectations in their TPPs? Perhaps, as suggested above, individual instructors within their own spheres of influence are addressing this need, but it does appear to be a priority on any larger scale. One potential reason for this omission is the second disconcerting motif throughout the literature on TPP organization and leadership, that teaching is an inherently powerless profession.

When discussing teacher leadership as an essential component to educational reform, Suranna and Moss (2002) wrote that "a lack of substantial decision-making power in their profession... and an overwhelming feeling of being controlled and dominated" are significant challenges to engendering leadership roles in teachers (p. 4). 
Labaree (2008), in his historical account of teacher education and the status of the teacher profession in the United States, attributed this lack of autonomy to an unfortunate combination of the public perception of teaching versus the nature of the work itself:

"Teaching is an extraordinarily difficult job that looks easy, which is a devastating combination for its professional standing and for the standing of its professional educators...Teachers usually carry out their practice under conditions of isolation, in a self-contained classroom where they are the only professional and only adult in the room. Finally, teachers have to function in a situation in which they lack a proven technology that works, a clear definition of success, or even a definite fix on the identity of the client (who can be construed simultaneously as the student, the parent, and the community) ...teaching is a rare profession in which practitioners succeed by making themselves dispensable. Most professions rent their expertise, which requires clients to return every time they need help. But teachers give away their expertise, by showing children how to learn on their own. This makes the skills of the teacher seem transparent and ordinary, whereas the skills of other professionals seem obscure and remote" (pp. 298-299).

There is a wealth of potential scholarly research here for public perceptions of the teaching profession and the reasons behind those perceptions. These attitudes may influence the quality and content of TPPs due to the social status or stigma of pursuing a career in education. Further, CIL/CIC education is in part about empowerment of the information consumers. Should the present study achieve its stated purpose and aid in 
improving CIL/CIC awareness in TPPs, perhaps the perceptions of empowerment (or lack thereof) in the teaching profession may also change over time.

\section{Summary}

While the scholarly attention of the present study is directed toward critical information literacy/consumption, the settings in which the concept is situated should not be ignored. Teacher preparation programs represent an entryway into the generational cycle of education, where pre-service teachers are simultaneously students gaining knowledge and adults at the inception of their professional lives. TPPs have a rich and varied history in the United States, at different times under- and over-regulated. As they have evolved to a more-or-less universal standard of being housed within universities, TPPs can be considered a cohesive setting when examined through the lens of programs' accreditation. The two main accrediting bodies for TPPs in the United States, the AAQEP and the CAEP, each have their own set of standards with which to evaluate the quality and effectiveness of TPPs and the educators they produce. Beyond the framework of accreditation standards, TPP structures and implementation practices vary widely based on the culture, needs, and laws governing different states. Further, TPPs' complicated interactions with communities, schools, politicians, and the media have led to a mercurial relationship with public opinion.

Textbooks have historically played an essential role in education of any sort, but in TPPs they have the dual objectives of not only presenting information to students but modeling appropriate teaching and learning practices for pre-service teachers to use as examples when developing their own classroom practices. This study could contribute to 
improving the quality of textbooks used in TPPs, thus positively impacting the programs as a whole and the teachers they produce. 
SECTION THREE: SCHOLARY REVIEW FOR THE STUDY 
Engaged participants in twenty-first century United States society are by necessity citizens of two distinct social 'spaces.' The first is made of the physical locations where they live and work, and the second is the set of "cyber ecosystems" in which they interact with media, data, and information (Frau-Meigs, 2019, p. 11). The amount of content with which the average American interacts daily in these new ecosystems is historically unprecedented, with the onslaught of information being shaped by advertisers, algorithms, and political agendas; an increasing number of scholars agree that we are in the midst of an information crisis (Molina, Sundar, Le, \& Lee, 2019; Sweet, Shermak, \& Swanson, 2019; Tornberg, 2018). This problem of information overload, separating the 'good' from the 'bad,' and the extensive proliferation of misinformation has been described as a "wicked problem" (Oliphant, 2019, p. 261) and is often explained through the metaphor of a contagious disease (Frau-Meigs, 2019; Molina, Sundar, Le, \& Lee, 2019; Oliphant, 2019; Sweet, Shermak, \& Swanson, 2019; Tornberg, 2018). This comparison is alarmingly apt when, at the time of this document's writing, the world remains upended as nations grapple with the continued coronavirus pandemic and the ensuing spread of related misinformation.

The assumed cure for - or perhaps the vaccine against - this information disease is critical information literacy education. Critical information literacy (CIL) is a broad catch-all phrase that refers to the set of skills involved in evaluating information: where it comes from, its accuracy and validity, and the context in which it was obtained (Auberry, 2018; Dyer, 2017; Grigoryan \& King, 2008; Johnson, 2018). Closely related to CIL is the concept of critical information consumption (CIC), which implies more active participation by the consumer in acquiring information, evaluating the sources from 
which it was obtained and decoding the communicative structures used to present it (linguistically, semantically, graphically, epistemically, etc.) (Cooke, 2017; Yang, 2009).

Research on CIL and CIC education has typically focused on either educator inputs like lesson plans and classroom activities, or learning outcomes in the form of information behaviors such as who shares misinformation on social media and how often (Sommariva, Vamos, Mantzarlis, Doa, \& Tyson, 2018). Less attention is paid to the most traditional source of information modelling and retrieval in the classroom setting: the textbook. Since scholarly literature suggests that pre-service teachers need to improve their CIL/CIC skills (Aybek, 2016; Calik \& Karatas, 2019; Kovalik, Jensen, Schloman, \& Tipton, 2010), presumably to better pass along those skills to their future students, the focus of the present study was an examination of the textbooks used in teacher preparation programs through a CIL/CIC lens.

\section{Purpose of the Study}

As defined in the first section of this document, the purpose of this critical discourse analysis was to investigate ways in which introductory education textbooks used in public universities' teacher preparation programs facilitate or hinder both the direct and indirect application of CIL/CIC skills. CIL and CIC represent a large array of knowledge and skills; the subsets of these skills that correspond to the purpose of the study are (1) use of buzzwords and/or epistemically suspect statements; (2) direct discussion of evaluating sources; (3) attention to power dynamics and underlying assumptions in media and scholarly work; and (4) direct and indirect philosophical and epistemological discussion. These conceptualizations of CIL/CIC were selected based on 
the theoretical and conceptual frameworks on which the present study was based, as well as the extant literature of the associated topics.

The following scholarly review introduces these concepts and their relevance to the study. First, the theoretical and conceptual frameworks are presented: conceptualizing CIL/CIC for scholarly research; the theory of epistemically suspect language, more commonly known as bullshit theory; critical discourse analysis; and operationalized models of textbook evaluation. The subsequent sections review the literature of four distinct but intersecting themes prevalent in CIL/CIC research: teaching and learning CIL/CIC skills, research concerning pre-service teachers, research concerning professional practice and training other than teaching, and CIL/CIC as a necessary component of an engaged, civilized society, particularly in the contexts of global citizenship and social justice education.

\section{Theoretical and Conceptual Frameworks}

Authors of CIL/CIC-related research come from a broad range of academic and professional backgrounds, including but not limited to education, psychology, philosophy, healthcare, statistics, law, media studies, political science, and data analytics (Chang-Kredl, 2015; Correll, Bertini, \& Franconeri, 2019; Davis, Lohm, Flowers, Waller, \& Stephenson, 2014; Flores-Koulish \& Deal, 2008; Higgins \& Begoray, 2012; Shaffer, 2019; Tornberg, 2018; Weiland, 2017; Yoo, 2019). As such, CIL/CIC studies employ an equally wide variety of theoretical and conceptual lenses. The frameworks on which the present study was based derive from the four major components of its design: (1) conceptualizing CIC/CIC; (2) the philosophical basis of epistemically suspect language, or bullshit theory; (3) critical discourse analysis, and (4) models of textbook evaluation. 


\section{Conceptualizing CIL/CIC}

What does it mean to be critically literate of the information one consumes? Depending on the researcher, the context of a given study, and the models through which the concepts are conceptualized (often tailored to the academic or professional discipline in which the study is situated), the responses to such a question can vary substantially. As such, determining a suitable definition of CIL/CIC is a necessary but challenging component of establishing an appropriate theoretical framework, especially considering that some models of CIL/CIC diverge so dramatically that they provide contradictory descriptions of what is ostensibly the same concept. For example, Bauer (2014) and Badke (2017) associated CIL/CIC education with rebuilding trust in the community of scientific experts in order to combat popular pseudoscience and fake news; however, Hollis (2019), Cooke (2017), and others wrote of authority or expertise in the context of CIL/CIC as constructs to be verified rather than blindly trusted. In Weiland's (2016) model of critical statistical literacy, the author promoted incorporating statistical literacy into common notions of CIL/CIC in order to "evaluate the source, collection and reporting of statistical information and how they are influenced and shaped by the authors social position and sociopolitical and historical lens" (p. 989). While all of the authors reported the same objective of educating students to spot 'good' information from 'bad,' the approaches the two groups took endorsed almost mutually exclusive paradigms to achieve it.

For the purposes of the present study, then, an acceptable conceptualization of CIL/CIC skills utilizes definitions with which the majority of frameworks situated within the context of teaching agree: that CIL/CIC education has evolved from the exclusive 
domain of librarians to the responsibility of all teachers across content areas (Fulkerson, Ariew, \& Jacobson, 2017; Johansson \& Limberg, 2017; Pinto, Cordon, \& Diaz, 2010); that these skills are inherently evaluative in nature and thus require higher-order thinking skills, self-awareness, metacognition, and metaliteracy on the part of the information consumer (Dunaway, 2011; Fulkerson, Ariew, \& Jacobson, 2017; Jacobson \& Mackey, 2013); that they also require synthesis and sense-making across disciplines more than just a collection of 'facts' (Gretter \& Yadav, 2016; Dunaway, 2011; Weiland, 2016); and that the consumer is an active participant in the acquisition, organization, and dissemination of knowledge (Cooke, 2017; Fulkerson, Ariew, \& Jacobson, 2017; Hollis, 2019; Jacobson \& Mackey, 2013; Johansson \& Limberg, 2017; Weiland, 2016).

Kellner and Share's (2005) model of critical media literacy provided a framework that agreed with each of the assumptions above and allowed for expansion as needed using the definitions of CIL/CIC. The model was based on five core concepts, the first of which is that "all media messages are "constructed"' (Kellner \& Share, 2005, p. 374). This mirrors the CIL/CIC principle that every source of information will exhibit some form of bias, assumptions of power dynamics, or underlying ideologies that should be addressed (Foster-Kaufman, 2019; Yang, 2009). Second, “media messages are constructed using a creative language with its own code" (Kellner \& Share, 2005, 374). This concept corresponds to the emerging subset of CIL research dedicated to examining the skills, knowledge, and dispositions needed to detect "epistemically suspect" statements, lack of linguistic and semantic precision, and the "ontological confusion" of buzzwords with profound truth (Pennycook, Cheyne, Barr, Koehler, \& Fugelsang, 2015, p. 551). The third, fourth, and fifth concepts, "different people experience the same media 
message differently," "media have embedded values and points of view," and "media are organized to gain profit and/or power" (Kellner \& Share, 2005, pp. 375-376), are all related to the critical component of CIL/CIC: that there is no such thing as 'neutrality' in information, there will always be an agenda or purpose to the way information is represented (or misrepresented), that every agenda has the potential to be a tool of systemic oppression, and every information consumer has an ethical responsibility to be aware of this (Cooke, 2017; Yanzi, Hidayat, Mentari, \& Budimansyah, 2019).

Within this (and most other) frameworks of CIL, there exists the underlying assumption that when it comes to consuming information, our social and academic epistemologies must submit to the notion that 'truth' can in some capacity be known, even though this is a long-standing philosophical point of contention among academics (Merriam \& Tisdell, 2016). Superficially, it would seem that CIL must necessarily be grounded in a post-positivist understanding of objective truth; however, in his defense of the value of post-modernist philosophy in science, Hardos rejected this assumption by arguing "one cannot get to truth without realizing the extent of subjectivity when we ask research questions, build concepts, choose the tools, and model the world and how thisoften unconscious - dealing with the world around us can color our perceptions" (2019, p. 314). CIL's philosophical and conceptual flexibility comprise an essential component of its interdisciplinary allure in so many diverse fields of research.

In sum, CIL/CIC was defined for the purpose of this study as active attention to and evaluation of both sources of information (their accuracy, validity, assumptions, biases, power dynamics, etc.) and the ways in which these sources present their content (linguistic and semantic precision, epistemic soundness, use of buzzwords as opposed to 
meaningful ideas, etc.). Since many of the theoretical and conceptual frames presented above emphasize content of information without also examining the linguistic considerations of its presentation, some of this definition derives from the work of an emerging subgroup of CIL/CIC researchers focusing on ontological and epistemic evaluation of buzzwords and "pseudo-profound bullshit" (Pennycook, Cheyne, Barr, Koehler, \& Fugelsang, 2015, p. 549).

\section{Bullshit Theory}

In 2005, Princeton University professor Harry Frankfurt published the philosophical essay On Bullshit, in which he discussed messages that are designed to persuade or convey an impression of the message creator without regard for truth, clarity, or profundity (Frankfurt, 2005). Shortly thereafter, researchers in psychology and social sciences began using this framework as the basis for studying the prevalence of bullshit in modern society, how adept the American public is at identifying it, and what traits or skills are common among those who do (and those who do not) display proficiencies in this skill (Eriandsson, Nilsson, Tinghog, \& Vastfjall, 2018; Kedar, 2019; Misak, 2008; Pennycook et al, 2015; Pennycook \& Rand, 2018a; Pennycook \& Rand, 2018b; Pfattheicher \& Schindler, 2016; Shang \& Petrocelli, 2019; Sinclair, 2019; Sterling, Jost, \& Pennycook, 2016). In particular, Pennycook et al expanded the definition of bullshit to include the use of buzzwords, pretentious obfuscation, and "ontological confusion" to conflate "epistemically suspect" statements and "pseudo-profound bullshit" with truth and meaning (Pennycook et al, 2015, p. 551).

Research in this area of bullshit receptivity or susceptibility to epistemically suspect statements has grown rapidly in recent years, focusing mainly on the social 
contexts or traits exhibited by individuals who tend to uncritically accept bullshit, fake news, or pseudoscience. For example, in an experiment comparing participants' selfreported values when asked to rank emotion and reason, Martel, Pennycook, and Rand (2019) found that individuals who value emotion over reason were more likely to believe fake news than those who prioritize reason. Similarly, cognitive dispositions favorable toward analytic thinking and basic scientific literacy were found to be highly correlated with resistance to partisan-fueled fake news, epistemically suspect statements, and pseudo-profound bullshit across several studies and contexts (Erceg, Galic, \& Bubic, 2019; McPhetres \& Pennycook, 2019; Pennycook, Cheyne, Barr, Koehler, \& Fugelsang, 2015; Pennycook \& Rand, 2018a; Ross, Rand, \& Pennycook, 2019). These results suggest that the most effective way to combat the wicked problem of misinformation is to inoculate the public with the CIL/CIC skills and habits of mind necessary to cultivate a skeptical and rational approach to information consumption. Further, bullshit theory as a framework for the study adds a dimension of linguistic analysis, as well as philosophic considerations of truth and profundity in communication, that enriches the model of CIL/CIC described above. Thus, a component of bullshit (mis)use and awareness was also added to the study's conceptualization of CIL/CIC.

Buzzwords. The buzzword as an epistemological construct seems to be universally understood in modern culture but rarely explicitly defined. Consider the plethora of articles and books that feature 'buzzword' in the title without a clear explanation of how the word is being used (Bury, 2020; Cairns \& Krzywoszynska, 2016; Childers, 2003; Grzanka, 2020; Stoll, 2020; Winter, 2001). In education, buzzword is used as a synonym of jargon or subject-specific lingo (Ravitch, 2007) or to mean a word 
that "gets thrown around a lot" (Kraft, Schmiesing, \& Phillips, 2016, p. 16); in business, buzzwords can be a signal of expertise (Gross-Klussmann, Koenig, \& Ebner, 2019). Scholarly inquiry into the sociolinguistic implications of buzzwords is limited, but what research does exist tends to describe them as a form fashionable, trendy, or popular language which may or may not have a lasting presence in the vernacular (Caled, Beyssac, Xexeo, \& Zimbrao, 2016; Neuman, Nave, \& Dolev, 2011). Ironically, the lack of a coherent definition and its common use as an attention-grabber in media headlines suggest that the word 'buzzword' is, in fact, a buzzword. Despite ambiguous meanings and faddish use in popular media, buzzwords are inextricably tied to epistemically suspect statements and pseudo-profound bullshit, predicated on the assumption that use of a buzzword gives the façade of truth and/or expertise of the buzzword user (Pennycook et al, 2015).

\section{Critical Discourse Analysis}

Beyond the frameworks necessary to model the concepts of the present study, critical discourse analysis "is a theoretical and methodological approach, rooted in political ecology, which regards language as social practice and investigates the social contexts within which symbolic forms are deployed and index power" (Colston \& Thomas, 2019, p. 4). Critical discourse analysis in particular is recommended as an approach to examining how a text, its context, and subtext are used to promote underlying assumptions about power, ideology, social and social norms (Le \& Le, 2009a; Locke, 2004). Textbook evaluations with emphases on what is being communicated beyond the surface content often use critical discourse analysis as the lens through which 
the evaluation is conducted (Colston \& Thomas, 2019; Serenko, Bontis, \& Moshonsky, 2012), which is why it is appropriate for the purpose of the present study.

\section{Textbook Evaluation}

Textbooks are a ubiquitous part of traditional education settings and are often taken for granted as the "authorized version of human knowledge and culture" (LopezMedina, 2016, p. 163). Textbook evaluation research, then, typically assesses the quality of deliberately chosen features of a textbook: use of graphics, size and layout of text, or quantity of exercises for learners (Rezaee \& Hashemi, 2017). Critical textbook evaluation, where a text's content and language are examined in terms of social and political power, has expanded beyond its conventional application in history courses where such considerations are more directly content-related, into all content and grade level texts (Brass, 2016; Nicholls, 2003; Ruswick, 2015). This use of textbook evaluation is based on the notion that "school textbooks are based upon the cultural, ideological, and political power of dominant groups and they tend to enforce and reinforce cultural homogeneity" (Crawford, 2003, p. 5).

Across both types of textbook evaluation, there exist common techniques considered standard in the practice. In a meta-analysis of textbook evaluation research, Nicholls (2003) outlined a textbook evaluation model endorsed by the Georg Eckert Institute and the United Nations Educational, Scientific, and Cultural Organization (UNESCO): a precise, deliberate, and explicitly defined sample; a combination of quantitative and qualitative data analyses; and an evaluation instrument (often a checklist or rubric) based on "a framework or criteria of categories and questions fine-tuned to the specific aims and objectives of a particular textbook project” (Nicholls, 2003, p. 14). In 
fact, the author noted that UNESCO declined to formulate a more detailed model than this due to the individualized nature of textbook evaluation.

When the instrument of evaluation is itself the end goal of the research, the framework and criteria may be based on survey or questionnaire data of the intended audience for the text, as in Lopez-Medina's (2016) work on creating a checklist for evaluating the suitability of content textbooks for non-native language readers. Others, though, base their criteria on conceptual or theoretical lenses established in the literature, then focus the data collection on the application of the instrument to the textbooks themselves. This is the case in the respective studies of Bocu and Razi (2016), Brass (2016), and Muniz-Velasquez and Delmar (2019), each of which used a previously established rubric or set of criteria against which to assess texts.

The present study utilized the latter form of the textbook evaluation model, using a rubric to assess textbooks used in teacher preparation programs on their attention to and use of CIL/CIC concepts. The criteria used on the rubric were questions established to operationalize the concepts of CIL/CIC and bullshit theory described above, approached through the lens of critical discourse analysis (see Appendix B).

\section{Summary}

The present study was constructed within a combination of interdisciplinary frameworks, mirroring the inherent interdisciplinarity of CIL/CIC as a construct. Conceptually, the study approached critical information literacy and consumption with Kellner and Share's (2005) model of critical media literacy, with the added linguistic component of bullshit theory as defined by Frankfurt (2005) and operationalized by Pennycook et al. (2015) and others. This theory also encompasses the use of buzzwords 
to construct an aura of profundity or expertise of the speaker/author. Methodologically, the study's design derived from the principles of critical discourse analysis and precedents set in previous textbook analysis research.

\section{Teaching and Learning CIL/CIC Skills}

Literature pertaining to CIL/CIC education is multifaceted and, much like structures of secondary and higher education, divided into content area siloes based on who the authors consider responsible for spearheading the CIL/CIC charge. The most traditional perspective is that of librarians and research specialists, given that in the preInternet age they were the gatekeepers of information literacy, and to some extent still fulfill this role despite the push of individual access to information and technology in the classroom and at home (Auberry, 2018; Johnson, 2018; Pinto, Cordon, \& Diaz, 2010). While many scholars agree that CIL/CIC proficiencies are inherently interdisciplinary and tied to technological and digital literacies (Oleskeviciene, Puksas, Gulbinskiene, \& Mockiene, 2019; Saglam, Cankaya, Ucer, \& Cetin, 2017), an extensive body of research exists on the teaching and learning (or lack thereof) that occurs in the core coursework of language arts, social sciences, mathematics, and science.

\section{Learning CIL/CIC Skills}

Research that targets student CIL/CIC outcomes tends to address two main themes: quantifying the problem of CIL/CIC inadequacy and/or presenting interventions to remedy it. Of the former, concerns about students' struggles with information literacy keeping pace with technological advances have been in circulation for decades (Brimble, 1948). In more recent years, the problem of information illiteracy has focused more on source evaluation in both academic and social contexts, i.e. identifying fake news. In a 
university-wide Qualtrics assessment task sent to undergraduate students at Notre Dame University in Louaize, Lebanon, El Rayess, Chebl, Mhanna, and Hage (2018) found that the mean score for correctly identifying if a news item was real or fake was 50\%; further, $60 \%$ of students scored below the mean, and $90 \%$ of students could correctly identify the veracity of a news item less than $75 \%$ of the time.

Researchers in the United States share similar concerns. O'Sullivan and Scott's (2000) action research project in a high school classroom introducing source evaluation on the Internet concluded that young people are beholden to a challenging dichotomy with modern technology: captivated by the wealth of content available to them, but frustrated with the difficulty in sifting the 'good' from the 'bad.' Iwuanyanwu (2019) framed a similar concern in the more academically-specific context of science education; examining high school science curricula, he found that what is currently being taught in science classes has not changed for at least two decades, demonstrating that students' needs for explicit instruction in twenty-first century skills are not being met.

The latter half of student-focused CIL/CIC research is solution-oriented, reporting on interventions that educators and institutions have tried to improve their students' CIL/CIC skills. Intervention research occurs both within specific curricular contexts and isolated as CIL/CIC lessons unto themselves. For example, within a health and nutrition undergraduate course, students were assigned a health literacy course that involved source evaluation and identifying propaganda; instructor observations and student feedback indicated increased CIL/CIC outcomes compared to another section of the same course that was not given the assignment (Crist, Duncan, \& Bianchi, 2017). Similarly, political pamphlets were presented as primary sources in a communications course as a 
means of engaging in the critical component of CIL/CIC through the introduction of critical primary source analysis (Porterfield, 2018). The findings of this case study noted that students were more willing to engage in the analysis of the historical documents before turning the critical eye on contemporary, and thus more personally relatable topics, thus perhaps lessening the initial discomfort of cognitive dissonance when one critically self-reflects.

Student interventions need not be embedded in other curricular contexts, though. The University of Newcastle in New South Wales, Australia introduced a new course to undergraduate students pursuing degrees in the sciences. In their year, undergraduate students are required to take a 'Professional Scientific Thinking' course, the syllabus for which aligns with CIL/CIC skills and concepts; the analysis of the initial offering of the course indicated that the majority of students who completed the course had the appropriate habits of mind and skills for scientific reasoning both in the classroom and when exposed to mass media (McBain et al., 2019). Nevertheless, when research focuses on how CIL/CIC is taught, engaging with core curricular coursework is often an assumed component.

\section{Teaching CIL/CIC Concepts}

Language arts educators - reading, literature, journalism, and so on - often engage with CIL/CIC through the lens of individual identity, stressing the transformative process of engaging in critical self-reflection in order to improve as both consumers and producers of media content (Critten, 2015; Dyer, 2017; Flores-Koulish \& Deal, 2008; Gretter, Yadav, \& Gleason, 2017; Joanou, 2017; Morrell, 2012). Research into social studies coursework such as history, political science, and psychology indicates that 
CIL/CIC integration occurs through discussions of social justice, the sociocultural context in which information is presented, the voices of power and the voiceless in informational texts, and the relationship of information to the dominant ideology in which it is produced (Grigoryan \& King, 2008; Harshman, 2017; Orlowski, 2006; O’Sullivan \& Scott, 2000). Science, technology, engineering, and mathematics (STEM) content areas have recently experienced an increase in the number of scholars and educators who recommend that numeracy education be integrated into CIL/CIC frameworks, and vice versa. Along with the attention that STEM has received for its role in 21 st century skills, educators increasingly acknowledge the role that the development of critical thinking through basic understandings of the scientific method and statistical analysis of data plays in inoculating the public against fake news, misleading advertisements, and cognitive biases (Crist, Duncan, \& Bianchi, 2017; Iwuanyanwu, 2019; Levitt \& Dubner, 2014; Soltys \& McClintlock, 2014; Storksdieck, 2016; Walker, Stange, Dixon, Koehler, \& Fugelsang, 2019).

Regardless of content area, grade level, or technological aptitude, pre-service teachers are expected to cultivate a working understanding of CIL/CIC skills to pass onto their future students. Hence, regardless of the type of teaching that pre-service teachers intend to do after their training is complete, literature involving the CIL/CIC proficiencies of students in teacher preparation programs inhabits its own scholarly silo distinct from certificated teachers.

\section{Summary}

The literature demonstrates a gap concerning what is taught versus what is learned about CIL/CIC in high schools and universities. Research about students and 
learning outcomes either focus on articulating the severity of the information illiteracy problem or on presenting potentially beneficial interventions to improve CIL/CIC education. Conversely, explorations into teachers' engagements with CIL/CIC education tend to frame their discussions in the context of a specific content area, examining how CIL/CIC instruction can fit into a mathematics, literature, or history classroom.

\section{CIL/CIC and Preservice Teachers}

Scholarly research pertaining to CIL/CIC skills in preservice teachers tends to approach the topic from the perspective of assessing for or cultivating the "habits of mind and attitudes" necessary for achieving CIL/CIC competence (Calik \& Karatas, 2019, p. 35). For example, Kurup, Li, Powell, and Brown (2019) found that while preservice elementary teachers possessed positive intentions about teaching 21 st century skills and cross-curricular thinking skills, their assessed understanding of those topics was underdeveloped. This study confirmed for a narrower population of preservice teachers what Aybek (2016) generalized for prospective teachers across content and grade levels, that these individuals overall tend to perform poorly on critical thinking assessments. The study also yielded statistically significant findings indicating that preservice teachers with higher levels of media literacy were more likely to also have a higher "critical thinking disposition" level ( $r=.317, p<.001$ for $n=166)$ (Aybek, 2016, p. 269). The author also compared these results to other similar studies, showing these results to be aligned with what other researchers had previously established. Interestingly, Aybek (2016) never explicitly uses the terms 'critical information literacy' or 'critical information consumption,' but the instruments used in the study were designed to measure traits that correspond closely with these concepts, such as analyticity, curiosity, and the inclination 
to search for the truth. Thus, it can be inferred that CIL/CIC skills are also generally low in the preservice teaching population, but that a relationship may exist between these competencies and media literacy.

Calik and Karatas (2019) also investigated CIL/CIC in prospective teachers through the lens of growing individuals' habits of mind. The authors referred to these thinking skills as "scientific habits of mind" (Calik \& Karatas, 2019, p. 36) rather than CIL/CIC, although their definition overlapped considerably (similarly to the study discussed above). These traits included objectivity, curiosity, rationality, skepticism, open-mindedness, and "mistrust of arguments from authorities" (Calik \& Karatas, 2019, p. 41). Interestingly, when the authors attempted an intervention to cultivate these habits of mind in preservice teachers through a "science, technology and social change" course (p. 35), most of the post-intervention scores for these dispositions were lower than those of the pre-intervention; the authors attributed this apparent failure of the intervention to "[the participants did] not have enough opportunities to reflect on their own previously uncritically assimilated assumptions, beliefs, values, and perspectives...the course should have been designed to facilitate challenges for the [participants] to critically reflect on their own value systems" (Calik \& Karatas, 2019, p. 44). This is an essential element of CIL/CIC, and thus should be included as a necessary criterion in the textbook evaluation rubric.

Deviating from the pattern of approaching CIL/CIC through the development on an individual basis is a subset of research that consider CIL/CIC education in preservice teachers as the responsibility of the university programs in which they are trained. Kovalic, Jenson, Schloman, \& Tipton (2010) surveyed teacher education faculty in 
universities across the United States about the extent to which information literacies are embedded in their teacher preparation programs. The results were mixed: while nearly $100 \%$ of participants responded that their institution explicitly teaches information literacies and reported adding assignments and activities related to information literacy in their courses, the responses were almost perfectly split on the question "Is information literacy a required component in student-created lesson plans?" (Kovalic et al, 2010, p. 157). Further, the results indicated that the most commonly taught skills were more inclined to academic literacies such as "formulating search strategies" for databases (p. 159), and source evaluation was one of the less popular responses. The authors concluded that while American universities are aware of the need for information literacies and are working toward embedding them in their teacher preparation programs, there remains substantial room for improvement (Kovalic, Jenson, Schlomann, \& Tipton, 2010).

\section{Summary}

The available research appears to indicate that there is a gap between the extent to which universities address CIL/CIC education with their preservice teachers in their teacher preparation programs and what CIL/CIC skills preservice teachers can actually demonstrate. Empirical studies relating preservice teachers and CIL/CIC skills often measure the presence or absence of desirable habits of mind or traits that make an individual more likely to engage in the critical thought processes necessary for CIL/CIC. Results from these studies are mixed at best concerning the prevalence of these traits in students in teacher preparation programs and their actual demonstration of CIL/CIC skills. 


\section{CIL/CIC in Professional Practice}

Research in CIC/CIL topics often expand beyond schooling into a variety of professional settings. Just as numeracy and communication skills are intended to transfer from the classroom to the 'real world' of work and society, so too are CIL/CIC skills integral to optimal functioning in business, healthcare, law, media, and organizational leadership (Berg, Phillip, \& Taff, 2019; Chang-Kredl, 2015; Davis, Lohm, Flowers, Waller, \& Stephenson, 2014; Ferraro \& Chipman, 2019; Higgins \& Begoray, 2012; Schildkamp, Poortman, Ebbeler, \& Pieters, 2019). According to the Pew Research Center, technological advances in artificial intelligence will change the American workplace so significantly within the next 20 years that "uniquely human skills" such as skepticism, evaluation and synthesis of multiple sources, problem-solving, and understanding of social dynamics will become exponentially more valuable to employers across all sectors (Rainie \& Anderson, 2017, p. 13).

The healthcare field in particular has a growing body of research dedicated to the applications of CIL/CIC skills. In a qualitative content analysis of case studies embedded into occupational therapy training, Berg, Phillip, and Taff (2019) found that explicitly addressing CIL/CIC components in the context of analyzing social determinants of health promotes a deeper understanding of patient care and improved healthcare decisionmaking; from the results of this study, they recommended a framework for addressing social determinants of health in occupational therapy curricula that includes attention to personal biases and assumptions, awareness of power dynamics and oppression of minorities, and that "challenge[s] epistemologies, or "how we know what we believe to know"” (Berg, Phillip, \& Taff, 2019, p. 10). Similarly, Higgins and Begoray developed a 
construct of "critical media health literacy" with which healthcare providers should engage to foster healthy choices in their patients (2012, p. 136). This framework is comprised of three "defining attributes of [critical media health literacy": "reflective and analytical skills," "critical consciousness and empowerment," and "informed and involved citizenry of critical media consumers" (Higgins \& Begoray, 2010, p. 140). Indeed, this framework overlaps significantly with the conceptual frameworks established for this study but in the context of healthcare literacy, with the authors valuing similar skills and attributes in their patients as teachers and learners in the previous sections. Professional stakeholders outside of healthcare have also endorsed CIL/CIC processes and skills as necessary to their respective fields; for example, Yoo (2019) argued the need for legal scholars, attorneys, and lawmakers to be aware of cognitive biases in the creation of and search for legal documents housed in law libraries. The Washington Post reported that the viral spread of misinformation - and the public's uncritical consumption of it - has culminated in a new age of corporate espionage in which businesses can fail overnight (Ferraro \& Chipman, 2019). In sum, CIL/CIC skills are necessary not only in academic settings, but for professional and economic functions in society as well.

At its essence, the purpose of CIL/CIC is to improve how the information consumer approaches any topic about which they need to acquire knowledge or skills; to indicate the application of CIL/CIC mindsets in any given subject matter is to simply replacing the word 'information' in critical information literacy with a descriptor of the type of information being consumed. For example, morticians and death-positive activists refer to critical death literacy in the context of knowing one's rights and responsibilities 
when handling the disposal of one's postmortem body (or that of a loved one) (Doughty, 2018); critical food literacy combines agricultural sciences and a vote-with-yourpocketbook mentality to promote conscientious food choices in the name of equitable sustainability and reducing food waste (Yamashita \& Robinson, 2015). While CIL/CIC skills are typically studied in the context of media and the news, they are also meant to transfer into any personal, political, or professional context.

\section{Summary}

Critical information consumption extends beyond the classroom into a wide variety of professional practices. As technology advances, the uniquely human capabilities of metacognition and contextual information evaluation are in greater demand, particularly in healthcare, business, and law. Research indicates a considerable need for healthcare professionals to engage in critical health literacy education not only to improve their own professional practices, but to be able to educate their patients as well. Further, CIL/CIC mindsets are valued in nearly any professional or personal context where meaningful thought occurs, or decisions need to be made.

\section{The Role of CIL/CIC in Society}

Critical information consumption is one facet of the myriad ways that humans create, seek, hoard, distort, or avoid information, collectively known as information behavior (Cooke, 2017). While exposure to information across various media has skyrocketed due to relatively recent technological advancements, the social problems underlying all information behavior needs - and the impetus for critical information consumption education - are not new. In 1917, America magazine implored its readers to maintain a healthy level of skepticism for the printed word: "Strange to say, the very man 
who is quite capable of giving another's spoken word its real value, and who subjects to a careful scrutiny to assertions made in written letters whose authors he knows, will accept without hesitation the wildest statements made in the daily papers by unknown and irresponsible people" (Is "What's printed true?," 1917, p. 450). Moreover, the complexity of information behavior in democratic society has not diminished over time; while an educated, thoughtful populace is necessary for societal progress to occur, misinformation, disinformation, and information inequality are at their worst tools of oppression (Dehdar, Sayenagi, Arbab, Arzhandeh, Rashanray, Raeisi, \& Kuhi, 2019; Grambo, 2019; Magnus, Faber, \& Belanger, 2019; McMillan, 2018). In a society where information is power, critical information consumption education is a form of emancipation and empowerment (Folk, 2019; Gutstein, 2013; Harshman, 2017; Lawal, 2019).

\section{Global Citizenship}

Much of the current attention to CIL/CIC skills is a direct result of technological advances in global communication; when information can be instantaneously presented to massive quantities of consumers worldwide, then paradigms about what it means to be an engaged global citizen are inevitably altered (McGrew, Ortega, Breakstone, \& Wineburg, 2017; Rheingold, 2012; Yanzi et al, 2019). In a meta-analysis of research concerning global citizenship and information/digital literacies, Yanzi et al (2019) concluded that CIL/CIC skills are necessary not only to meet the practical and economic needs of life in the age of the Internet, but also for individuals and communities to thoughtfully engage with the complex ethical and moral dilemmas inherent in our technologically-connected global society. Further, according to McGrew et al (2017), digital natives are not any more skilled in using CIL/CIC skills for civic engagement than the general population. 
The study, conducted by Stanford History Education Group, tested digital natives (individuals who have fluently navigated digital spaces since childhood) on their abilities to successfully identify misleading news stories and sponsored content about topics specifically related to political and civic awareness: climate change, fossil fuels, international employment, food prices, and comparing healthcare systems in different countries. Across all age groups, the majority of students struggled to distinguish reliable sources from advertisements and fake news, implying a dearth in awareness of how to obtain credible information necessary to make informed choices (McGrew et al, 2017).

Global citizenship in the age of technology is largely based on "meaningful access to information. This reflects an understanding that the physical and legal availability of information...cannot make a difference when people do not have the skills...and social and cultural conditions to apply it" (Leitner, 2019, p. ii). According to the annual report produced by the International Federation of Library Associations, inequitable access both to information and to the CIL/CIC skills necessary to make meaning of it can exacerbate extant systemic oppression of minorities (Garrido, Fellows, \& Norlander, 2019). Thus, CIL/CIC has emerged as an avenue of research for promoting social justice and empowering historically marginalized populations.

The events of 2020 shed light on a new dimension of CIL/CIC and its necessity for participating in global issues. At the time of this writing, the COVID-19 pandemic rages on in the United States and around the world. The World Health Organization has labeled the ensuing onslaught of politically motivated mis/disinformation, conspiracy theories, and inequitable access to accurate medical information as an infodemic that can have catastrophic consequences (WHO, 2020). In response, health officials and scholars 
alike have ignited a more fervent campaign to inoculate the public via fact-checking, assessing the legitimacy of information shared online, and other CIL/CIC skills (Affelt, 2020; Garcia-Marin, 2020).

\section{Social Justice}

Literacy as a tool of empowerment of the disenfranchised is not unique to the Internet age; indeed, much modern research of the connections between CIL/CIC and social justice cite Freire's (1970/1993) Pedagogy of the Oppressed as an essential conceptual framework. For example, in recent years scholars have increasingly connected the subset of CIL/CIC concerned with critical numeracy skills to equitable access to social and economic resources (Grotluschen, Buddeberg, Redmer, Ansen, \& Dannath, 2019; Yang, 2009). Yang (2009) involved socioeconomically disadvantaged high school students in a participatory action research project that culminated in the use of statistics to create a "school accountability report card" of their district's allocation of resources, noting "the state has defaulted on its promise of adequate education, and the youth have repossessed the master's tools and schools to hold themselves, their teachers, and the state accountable" (Yang, 2009, p. 100).

Beyond numeracy, the more conventional aspects of CIL/CIC skills have been directly connected to social justice and equity as cultural capital to which dominant groups typically have disproportionate access (Folk, 2019). A case study of teaching CIL/CIC skills through evaluation of Wikipedia articles elaborated on this point, with the author writing, "In terms of systemic bias...Wikipedia [is an] excellent case study for discussing critical information literacy and the role that power, oppression, and bias play within systems that organize, produce, and provide access to information" (Foster- 
Kaufman, 2019, p. 271). The author argued that Wikipedia has the same types of systemic bias, "Western, white, cisgender, straight, and male voices," that more 'legitimate' sources of information also have, but that students are typically unaware of them (Foster-Kaufman, 2019, p. 271). Thus, CIL/CIC education is necessary in order to engage students in meaningful dialogues about power and oppression through the dual perspectives of who has access to information and through whose voice the information is filtered. Emancipatory education is by no means a new concept; access to both information and the tools necessary to consume it has long been intertwined with civil rights movements (Wiggan, Scott, Watson, \& Reynolds, 2014). CIL/CIC skills offer not only the intellectual emancipation of cultivating independent thought, but the socioeconomic and political emancipation to achieve advanced degrees, find more fulfilling and stable careers, and participate fully in democratic society (Carrino, 2016).

\section{Summary}

Information behavior and its consequences for democratic society are not new topics of academic exploration, but technological and cultural progress demand comparative increase in "developing a critically thinking citizenry capable of understanding what is in the best interests of everybody" (Orlowski, 2006, p. 179). As our society becomes steadily more globalized, CIL/CIC education promotes civic engagement with diverse populations. Further, with the understanding of information inequality and the underlying power structures of dominant information authorities comes tools for empowering historically underserved populations, making CIL/CIC research a valuable instrument for social justice. 


\section{Summary of the Review of Literature}

CIL and CIC are increasingly necessary skillsets for consumers and citizens. The review of literature provided here indicates that nearly all aspects of democratic society benefit from a populous that is critically engaged with the information that they consume: educationally, professionally, economically, politically, and socially. Since CIL and CIC have a wide range of uses based on the context in which they are studied, their meanings have been operationalized for the purpose of the present study as an expansion of Kellner and Share's (2005) framework for critical media literacy that integrates commonly agreed-upon definitions of CIL/CIC skills. Additionally, this review outlined the scholarly basis for the critical discourse analysis and textbook evaluation frameworks that were used in the study. Pre-service teachers need additional CIL/CIC support in their teacher preparation programs, and evaluation of the textbooks used to introduce this population to the craft of teaching through the lens of developing CIL/CIC awareness is one potential avenue for improving this educational dilemma.

To conclude, critical information consumption is a necessary skillset in an era of intense information exposure. Since research for the past several years has consistently disparaged the general public's ability to appropriately interact with information of varying quality and purposes, academia has demanded an improvement in CIL/CIC education. Thus, the present study was an examination of CIL/CIC concepts in textbooks used in United States teacher preparation programs. The study was constructed from a combination of Kellner and Share's (2005) framework for critical media literacy as well as Frankfurt (2005) and Pennycook et al.'s (2015) bullshit theory. The study's methodology was grounded in literature pertaining to critical discourse analysis and 
textbook evaluation. A review of the relevant literature suggests that there is a gap between what CIL/CIC skills are taught versus what is actually learned; while studies have been conducted on how educators are working to incorporate CIL/CIC education into their curricula, there remains a need for research into their relative effectiveness. Further, while universities report addressing CIL/CIC concepts in their teacher preparation programs, the literature indicates that pre-service teachers are still entering the education profession with mixed levels of CIL/CIC knowledge, skills, and mindsets. The cycle of CIL/CIC education extends beyond the classroom: many professions have begun addressing their own need for improved CIL/CIC skills among their practitioners, particularly in healthcare where the professionals need such skills not only to effectively perform their duties, but to educate patients on health literacy. Lastly, but perhaps most importantly, CIL/CIC education contributes to the promotion of global citizenship and social justice objectives. Critically engaged, thoughtful citizens who promote equitable access to information and have the means to mitigate the spread of disinformation are the key to breaking the cycle of injustice and oppression. 


\section{SECTION FOUR: CONTRIBUTION TO PRACTICE}

TO BE SUBMITTED TO ACTION IN TEACHER EDUCATION 


\title{
Critical Information Consumption: Textbook Evaluation Criteria for Teacher Preparation Programs
}

The following document was prepared with the intention of submission to Action in Teacher Education, the official publication of the Association of Teacher Educators. The stated goal of the publication is to serve as a "forum for the exchange of information and ideas related to the improvement of teacher education at all levels" (Taylor \& Francis Online, 2019, n.p.). The components and structure of this document meet the guidelines found in the author instructions guidelines on the journal's website (Taylor \& Francis Online, 2019). The abstract and keywords required for submission are provided here, and the references for this article are provided at the end of the section.

\begin{abstract}
Critical information literacy (CIL) and critical information consumption (CIC) are essential skills and habits of minds for pre-service teachers to develop as they prepare to educate future generations. The purpose of this critical discourse analysis was to investigate ways in which introductory teaching or pedagogy textbooks used in public universities' teacher preparation programs facilitate (or decline to facilitate) the direct and indirect application of CIL/CIC skills. Specifically, textbooks were evaluated on their (1) direct and indirect philosophical and epistemological discussion; (2) direct discussion of evaluating sources of information; (3) attention to power dynamics, biases, ideologies, and underlying assumptions in media and scholarly work; and (4) use of buzzwords and/or epistemically suspect statements. Findings were based on inductive analysis of emergent themes and suggest that there are key features of a text that indicate how CIL/CIC-favorable a work may be, and were used to construct a checklist for teacher
\end{abstract}


educators and administrators to use when selecting textbooks for their education courses. This checklist includes considerations for questioning, linguistic granularity, presenting strengths and criticisms of prominent paradigms, attending to power asymmetries in the classroom, and making explicit the hidden or implied messages in educational settings.

Key Terms: critical information literacy, critical information consumption, textbook evaluation, teacher preparation programs

\section{Introduction}

At the onset of the third decade of the 21st century, the American public faces an information consumption crisis. Fake news, sponsored content, alternative facts, social media echo chambers, the replication crisis, fear-mongering propaganda, and the scienceversus-politics post-truth paradigm have converged into what researchers have described as a "complex contagion" of "viral misinformation" (Tornberg, 2018, p. 3), a problem of “information privilege" and "systemic bias and inequality" of information sources (Foster-Kaufman, 2019, pp. 272, 273), and an age of "information illiteracy" (Bilos, 2019, p. 1141). The assumed solution to this dilemma of misinformation is improved critical information literacy education (Auberry, 2018; Dyer, 2017; Grigoryan \& King, 2008; Johnson, 2018). Critical information literacy (CIL) is a catch-all phrase that refers to the set of skills involved in evaluating information: where it comes from, its accuracy and validity, the context in which it was created and obtained, the underlying assumptions and purposes of information producers, and so on. Depending on the situation in which the phrase is used, CIL may refer to examining underlying assumptions or biases in mass media, attending to the power dynamics implicit in textbooks, recognizing psychological manipulation in the form of advertising, evaluating the use 
(and misuse) of statistical data, or identifying propaganda and so-called fake news on social media (Gretter, Yadav, \& Gleason, 2017; Johansson \& Limberg, 2017; Kellner \& Share, 2005; Lee, 2018; Ruswick, 2015).

Considering the breadth of topics and skills described with the phrase 'critical information literacy,' it is almost ironically appropriate that there exists an emerging subset of CIL research dedicated to examining the skills, knowledge, and dispositions needed to detect "epistemically suspect" statements, lack of linguistic and semantic precision, and the "ontological confusion" of buzzwords with profound truth (Pennycook, Cheyne, Barr, Koehler, \& Fugelsang, 2015, p. 551). Further, Yang (2009) used the term “critical consumption" (p. 101), and Cooke (2017) expanded it "critical information consumption" (p. 211), a phrase meant to imply more active participation on the part of the reader, or consumer, of information. Critical information consumption (CIC) and CIL are used interchangeably here to refer to the skills and mindsets that promote active attention to and evaluation of both sources of information (their accuracy, validity, assumptions, biases, power dynamics, etc.) and the ways these sources present their content.

Research suggests that students and teachers alike do not possess adequate CIL/CIC skills to navigate the complex information ecosystem of the Internet and social media (Aybek, 2016; Iwuanyanwu, 2019; Kovalic, Jenson, Schlomann, \& Tipton, 2010; Kurup, Li, Powell, \& Brown, 2019; El Rayess, Chebl, Mhanna, \& Hage, 2018; O'Sullivan \& Scott, 2000). Therefore, there exists a need in educational research to investigate how teachers can be better prepared to implement CIL/CIC skills and mindsets in their classrooms. Given this need, the purpose of this critical discourse 
analysis was to investigate ways in which introductory teaching or pedagogy textbooks used in public universities' teacher preparation programs facilitate (or decline to facilitate) the direct and indirect application of CIL/CIC skills. The research question guiding this study was:

To what extent do the textbooks used by teacher preparation programs in the largest public universities across the United States for introductory or foundations of education courses directly or indirectly address, utilize, or model the following components of critical information literacy/consumption skills:

a. Epistemological and philosophical paradigms in education;

b. Evaluating sources of information (whether for professional purposes or to teach CIC content to students);

c. Epistemically suspect statements and buzzwords in education; and

d. Power dynamics, biases, ideologies, and underlying assumptions in media and scholarly work?

\section{Materials and Methods}

Required textbooks in teacher preparation programs in the United States were selected for analysis based on the courses in which they were used in the largest public university in each state and the District of Columbia. At each university, undergraduate catalogs were accessed to assess which course would provide the textbooks for data collection. Courses were selected from the most recently available undergraduate catalog (2019-2020 school year) on the following criteria:

1. The course had to be a part of an accredited teacher preparation program. 
2. The course could not be limited to strictly elementary, secondary, or specific content areas, but a general education course for all pre-service teachers.

3. The catalog listed the course as a requirement for most - if not all - students enrolled in the teacher preparation program.

4. The title or course description indicated that the course was intended to be an introduction to education, schooling, or foundations of education in the United States (other equivalent key words were also acceptable).

If no course met all the criteria above, then course that met the most criteria, with priority given to component (4), was selected from the researcher's best judgement based on the information provided in the catalog.

Various sources were utilized as necessary to obtain the textbook information: university bookstore and library websites, syllabus archives, educational file-sharing websites, and publicly accessible course websites and syllabi. For courses with textbook information not listed with university bookstores or libraries, some of the syllabi were from previous school years. When multiple years' information was present, the most recent was always selected. When a course used more than one textbook or had more than one section/instructor, all textbook citations were taken; some courses had up to six unique textbooks to contribute to the data collection pool.

During the textbook information search process, schools and/or textbooks were eliminated from the data pool for the following reasons:

1. The search ended because the only avenue for obtaining textbook information was password protected or was otherwise not available to the public. Seven universities in this study were eliminated for this reason. 
2. A university did not a have an accredited teacher preparation program or a general foundations of education course. Four universities were eliminated for this reason.

3. The materials used in the course did not qualify as a member of the literary genre of textbook: some courses used memoirs or fictional narratives as course materials. While there is a subset of scholarly research dedicated to the examination of critical information consumption education through storytelling, that was not within the purpose or scope of this study, and so these non-textbook materials were removed. While several books were eliminated for this reason, only one course was eliminated from the study because for genre-specific reasons; all other courses that used these books also required more conventional textbooks.

Exceptions to the above procedure: New York and Texas, two highly populated and educationally influential states, did not have the textbook information for the selected course from the large public university in the state publicly available. Since a nationwide data pool would arguably be incomplete without these two important states, another university was chosen from each - also based on size (by student enrollment) and availability of textbook information.

\section{Data Collection and Analysis}

One chapter was purposively sampled from each textbook based on its relevance to the study's purpose: through an analysis of the table of contents and the foreword or introduction to the work, the researcher determined the central purpose or thesis of the text and selected the chapter that would be most likely to include CIL/CIC-relevant content. For example, in Black Ants and Buddhists: Thinking Critically and Teaching Differently in the Primary Grades, chapter 8, titled 'Nurturing History Detectives," was 
selected because it focused on teaching students that history texts are written by authors with distinct values and perspectives that may conflict with other values and perspectives (Cowhey, 2006, p. 141). Data collection occurred with the aid of a rubric to guide the researcher on what features of the text to analyze, based on an amalgamated framework of (a) Kellner and Share's model of media literacy (2005); (b) the theory of pseudoprofound, epistemically suspect statements (also referred to as buzzwords or bullshit theory) (Frankfurt, 2005; Pennycook, Cheyne, Barr, Koehler, \& Fugelsang, 2015); and (c) critical discourse analysis design as operationalized by Locke (2004) and Le and Le (2009a) . In the tradition of critical discourse analysis, findings from each textbook chapter were grouped into thematic and textual features for each subcategory of the research question.

The findings were used to generate a checklist for teacher educators and administrators to examine their own textbooks' use of CIL/CIC concepts, or to use as a reference when selecting new textbooks for teacher preparation programs. The checklist is in the conclusion section.

\section{Findings}

Thirty-nine education courses from teacher preparation programs across the United States produced a set of sixty required books, most of which were used during the 2019-2020 school year. Of these, data collection and analysis occurred for forty-nine textbooks, while 11 were deemed inappropriate for the purposes of the study (i.e., fictional works or memoirs) and thus eliminated from the study. Emergent themes were based on the four components of CIL/CIC mindsets as enumerated in the research question: epistemological and philosophical paradigms in education; evaluating sources 
of information; epistemically suspect statements and buzzwords in education; and power dynamics, biases, ideologies, and underlying assumptions.

Themes that corresponded to CIL/CIC-aligned mindsets were far more frequent than opposing attitudes. The most common themes that emerged from the analyzed textbook chapters were descriptions of what it means to be well-educated or what 'good' education looks like (as valued by the authors) that align with the operationalization of CIL/CIC skills and mindsets. The most prevalent of these tenets that emerged from the analyzed chapters was that knowledge creation and learning are inherently interdisciplinary acts, so an effective education is one that regularly exposes learners to multiple perspectives (63\%). Whether directly or indirectly, these texts took the stance that learning does not exist in a vacuum, and therefore is enriched by diverse approaches.

The second most commonly expressed CIL/CIC-aligned theme was the acknowledgement and discussion of the need for educators and students to 'read between the lines' in order to decipher the hidden messages and hidden curriculum that occur in schooling; the unspoken cultural capital and the ability to code-switch that puts some students at an advantage over others without regard for the students' academic performance $(52 \%)$. These coded, socially-constructed messages are a form of information consumption that necessitate critical attention from the information consumer in order to process and contextualized this information, a common component of CIL/CIC research (Auberry, 2018; Kellner \& Share, 2005; McGrew, Ortega, Breakstone, \& Wineburg, 2016).

The next most commonly emergent themes were direct discussions of what an effective education entails and the textbooks' most frequently modeled CIL/CIC 
components. According to a plurality of chapters analyzed in this study, a well-educated citizen (and by extension, an appropriately trained teacher) is one who has the ability and attitude to challenge the status quo and critically question authority figures (47\%), as well as one who avoids paradigms which are antithetical to critical education: antiintellectualism, deficit-thinking, oversimplification of complex ideas, and a blind acceptance of messages constructed by individuals and institutions who profit from the construction and consumption of those messages (45\%). The individual empowerment to question and deconstruct information messages was modeled by $47 \%$ of chapters through the explicit discussion of beliefs about the purpose(s) of education and how they have changed over time as societal values have changed, as well as by $45 \%$ of chapters that engaged the reader in critical reflection through the use of probing, provocative, and thoughtful questioning. It should be noted that the latter theme was not used to enumerate every time a textbook posed any questions to its readers; rather, the depth of thinking required to answer the questions was what differentiated 'good' questioning from 'bad.' Most textbooks, for example, have end-of-chapter questions meant to summarize and process the information provided, but many of these entailed no more work on the part of the reader than searching for the appropriate paragraph and regurgitating verbatim its contents. These types of questions were not considered an appropriate model for this finding, and the most probing and thought-provoking questions were generally found peppered throughout the chapter and not in the summary section.

Less frequent but still present were mainly themes relating to what educators should value in order to correct systemic failures on the part of the U.S. schooling 
system. All of the following findings were present in $37 \%$ of chapters (although not the same $37 \%$ for each):

- Nuance, complexity, and controversy are valuable and essential to meaningful education. This was a direct extension of the findings above warning about counterproductive mindsets. Comfort with complexity is anathema to oversimplification and anti-intellectualism; deficit thinking and other harmful paradigms are counteracted with an appreciation of nuance and controversy.

- Representation matters in education; just as in mass media, education is more accessible to all when all perspectives and backgrounds are valued, not just the Western, white male perspective that has historically dominated U.S. culture (Foster-Kaufman, 2019).

- Social justice and emancipation of underrepresented populations is not only desirable, but an essential outcome of critical education, a notion echoed by other CIL/CIC researchers (Folk, 2019; Harshman, 2017).

- Power asymmetries are inherent in the U.S. schooling system, and thus educators have an ethical obligation to be aware of and attentive to the potential unintended consequences of this asymmetry: the implicit privileging of one population's education over another (Lawal, 2019).

Lastly, several themes occurred infrequently (in 33\% of chapters or fewer) but were nevertheless salient to the purposes of this study and the construction of the textbook evaluation checklist found in the subsequent section of this document. In particular, from the discussion and motifs found in the analyzed chapters relating to epistemically suspect statements emerged a working model for how to distinguish 
genuinely profound discourse from buzzword-laden bullshit: the presence or absence of linguistic granularity. Consider, for example, one textbook's treatment of the word equality in education. The author noted that when someone refers to educational equality, they may in fact mean one of two distinct ideas: equality of educational opportunity versus equality of educational outcomes (Goyette, 2017). When a text is transparent in the semantic and linguistic distinctions of easily-conflated educational jargon, it avoids the obfuscation of its message by buzzwords left to the reader to decipher. In total, $31 \%$ of chapters provided such clarity in their texts, while $8 \%$ noticeably neglected the need for linguistic granularity.

Other more infrequent CIL/CIC themes included:

- Direct discussion of the "isms" (paradigms and basic assumptions) that occur in education and how they impact one's decisions as an educator (33\%). From this discussion often developed the notion that no single "ism" is infallible and therefore merits critical consideration of both its strengths and flaws, particularly because every educational paradigm inherently takes a stance on some fundamental aspect of schooling, and is therefore unavoidably political (16\%).

- Education is at its core an expression of values (27\%), and in the United States, those values typically include being an active, patriotic participant in democracy (29\%). Transparency of one's values, then, is essential for all educators in order to provide critical education in a democracy (24\%).

- Not all textbooks successfully practiced the values which were textually expressed, causing some values dissonance between what was 'said' and what was 'done' in the work; for example, when celebrating pioneers of education 
throughout history, Ornstein (2002) showcased nine men (of whom only one was non-white) and two women, while simultaneously endorsing multiculturalism and equity in education in the text. This 'do as I say and not as I do' approach to diversity and inclusion was found in $16 \%$ of the selected chapters.

These findings were used to craft the textbook evaluation checklist in the following section, should an educator or administrator wish to select a textbook for a teacher preparation program that aligns with CIL/CIC skills and habits of mind. The summary of the findings and their relative frequencies can be seen in Table 1 on page 93 .

\section{Conclusion: A Textbook Evaluation Checklist for CIL/CIC}

This study used teacher preparation program textbooks as an entry point to consider in the educative cycle where teachers who were once students themselves, find themselves teaching future generations of educators. Appropriate meta-education requires rigorous attention to the process and the materials used in the implicit and explicit application of CIL/CIC skills; teacher preparation textbooks serve not only as an instrument of information dissemination but also a model for pre-service teachers for teaching and learning. It should be noted that there were far more examples of positive or desirable CIL/CIC behaviors exhibited in the textbooks than undesirable, and many textbooks contained both CIL-positive and CIL-adverse components (sometimes on the same page). 
Table 1

CIL/CIC Themes Evident in Education Textbooks

(In Descending Order of Relative Frequency Expressed as a Percent)

Interdisciplinarity/multiple perspectives are necessary components of education $\quad 63 \%$

Attention to hidden messages and the hidden curriculum of schooling $52 \%$

Discussion of the purpose(s) of schooling and education $47 \%$

An educated citizen will question authority and challenge the status quo

$47 \%$

Warnings about mindsets antithetical to critical education (deficit thinking, etc.) $45 \%$

\begin{tabular}{ll}
\hline Use of challenging and provocative questions to engage the reader & $45 \%$ \\
\hline
\end{tabular}

Attention to nuance, complexity, and controversy as valuable to education $37 \%$

Representation matters in education $37 \%$

Social justice/emancipation are valued as essential outcomes of education

$37 \%$

Analysis of power asymmetries in schooling $37 \%$

Direct discussion of "isms" in education $33 \%$

Avoidance of buzzwords/presence of linguistic granularity

$31 \%$

Education is a necessary component of democracy and patriotism $29 \%$

Discussion of teachers as gatekeepers $29 \%$

Power asymmetries in the classroom are inherent in U.S. schooling $27 \%$

Education is an expression of values $27 \%$

Transparency of values and information are necessary for critical education $24 \%$

Assumption of numeracy on the part of readers $20 \%$

Schools are assumed to be the cure for all societal problems in the U.S.

Presence of values dissonance in text versus subtext $18 \%$ Political stances are a natural consequence of "isms"

Political stances are a natural consequence of "isms" 
Should a teacher educator or administrator wish to select a textbook for their own introductory education course that models CIL/CIC mindsets, consider the following checklist. This tool was built from analysis of 49 textbook chapters from books being used across the United States (the checklist is also presented as a standalone document in Appendix D).

The following questions are intended to be used as a guide for evaluating education textbooks through the lens of critical information literacy/consumption.

- What kinds of questions are asked in the work?

Whether in the body of the text or located at the end of chapters for processing one's learning, questions should be thought-provoking, open-ended, and require critical reflection or metacognition on the part of the reader. Questions that can be answered by regurgitating passages from the work are typically insufficient for providing opportunities to practice CIL/CIC skills.

- How does the work approach the purpose(s) of schooling?

The purposes outlined in the work should align with those of the instructor and/or institution and include a multidimensional examination (that is, schooling tends to have social, economic, civic, and ethical objectives).

- How does the work engage readers in exploration of complexity, nuance, and ambiguity in the knowledge creation process?

Works that encourage the use of false dichotomies or oversimplify matters in the name of brevity do a disservice to its readers. In other words, "simplicity at the expense of accuracy is no virtue; complexity in the service of accuracy is no vice" (Patton, 2008, p. 482). 
- How does the author directly or indirectly demonstrate their values?

A direct demonstration of values may look like the key terms that are bolded or an explicit statement of what the author is attempting to accomplish in the textbook; indirect demonstrations of values occur when an author uses examples to illustrate a concept in a positive or negative light or in how much space and references are devoted to a given topic.

- What assumptions has the author made about their readers?

Pay close attention to the use of the word 'we.' If the author uses this word to address the readers, how are the readers being grouped with the author? What traits or perspectives is the author imposing on the reader (or alienating the reader from) by assuming group membership with 'we'?

- How does the work use and comment on primary sources?

Some textbooks present passages from primary sources with little to no commentary on what the intended purpose of the passage's use is; a CIL/CICminded textbook will provide context, commentary, and critiques of a primary source to help the reader situate their understanding of the passage.

- Does the work 'practice what it preaches;' that is, does it model the values, behaviors, and habits of mind that are discussed in the text?

For example, if a work states the need for deeper thinking and complexity in education but does not adequately meet the questioning criterion listed above, then the reader is receiving conflicting messages from the text.

- How does the work treat educational jargon? 
Linguistic granularity marks the difference between meaningful discourse and empty buzzwords. Consider how the author approaches the definitions of key terms, either in paragraph form or in special vocabulary sections. Is there space dedicated to common misconceptions of an educational term, or delineation of similar but distinct subsets of a key term or phrase (for example, explaining the difference between the educational opportunity gap versus the educational achievement gap).

- How does the work demonstrate the necessity of interdisciplinarity and considering multiple perspectives in learning?

Related to the direct versus indirect demonstration of values, lip service to multiple perspectives in learning is insufficient to assess a textbook author's commitment to it; for example, who does the author hail as expert? Who is considered an 'alternative' source? If a text praises truth as derived from multiple perspectives, but only showcases the perspectives of Western, white men, then perhaps it is not appropriately modeling this concept. Similarly, if a textbook hails interdisciplinarity as a necessity for critical education but does not, for example, encourage pre-service teachers to master more than one subject area, then there may be a dissonance between the author's espoused beliefs and actions.

- How does the work address whose voices are heard and whose are not in the messages it constructs? Further, how transparent is the work in acknowledging that all information messages are constructed, giving voice to the information producer? 
In a similar capacity to some of the questions listed above, a CIL/CIC-minded textbook author will situate its information and its "isms" in the context of who constructed it, for what purposes, and to whom is the concept meant to be taught. Textbooks that minimize or disregard the need for discussion of the context and construction of information messages will likely overlook essential components of what it means to learn and teach in diverse educational settings.

- How does the work examine power asymmetry in the classroom and/or the teacher's role as gatekeeper?

Teachers have a complex relationship with empowerment, and therefore must be aware of their power over their students and over the information they are to teach. This is a nuanced, subtle topic that is not always intuitive, so a direct and frank discussion of it is a hallmark of a CIL/CIC-minded textbook.

- What connections are made in the work between education and social justice? Education in the context of CIL/CIC is emancipatory and at its core opposed to accepting the status quo. Therefore, textbooks with this in mind will approach education as a necessity for marginalized groups to be empowered.

The objective of this research was to contribute to the thoughtful and practical development of CIL/CIC skills in pre-service teachers who will eventually become the educators, leaders, scholars, and policymakers in schools. If the insights gleaned here foster improved attention to the quality of teacher preparation textbooks or engage educators (current or future) in deliberate reflection on their own CIL/CIC skills those of their students, then I will consider it a positive and meaningful contribution to the body of scholarship and educational praxis. 


\section{References}

Auberry, K. (2018). Increasing students' ability to identify fake news through information literacy education and content management systems. The Reference Librarian, 59(4), 179-187.

Aybek, B. (2016). The relationship between prospective teachers' media and television literacy and their critical thinking dispositions. Eurasian Journal of Educational Research, 63, 261-278.

Bilos, A. (2019). Emerging focus on fake news issues in scientific research: A preliminary meta- analysis approach. Interdisciplinary Management Research, 15, 1139-1150.

Cooke, N. A. (2017). Posttruth, truthiness, and alternative facts: Information behavior and critical information consumption for a new age. Library Quarterly: Information, Community, Policy, 87(3), 211-221.

Cowhey, M. (2006). Black ants and Buddhists: Thinking critically and teaching differently in the primary grades. Portland, ME: Stenhouse.

Dyer, J. (2017). Can news literacy be taught? Nieman Reports, Spring 2017, 8-12.

El Rayess, M., Chebl, C., Mhanna, J., \& Hage, R. M. (2018). Fake news judgement: The case of undergraduate students at Notre Dame University-Louaize, Lebanon. Reference Services Review, 46(1), 146-159.

Folk, A. L. (2019). Reframing information literacy as academic cultural capital: A critical and equity-based foundation for practice, assessment, and scholarship. College and Research Libraries, 80(5), 658-673. 
Foster-Kaufman, A. (2019). Wikipedia-based assignments and critical information literacy: A case study. In A. Pashia \& J. Critten (Eds.), Critical Approaches to Credit-Bearing Information Literacy Courses (pp. 271-294). Chicago, IL: Association of College and Research Libraries.

Frankfurt, H. G. (2005). On bullshit. Princeton, NJ: Princeton University Press.

Goyette, K. A. (2017). Education in America. Oakland, CA: University of California Press.

Gretter, S., Yadav, A., \& Gleason, B. (2017). Walking the line between reality and fiction in online spaces: Understanding the effects of narrative transportation. Journal of Media Literacy Education, 9(1), 1-21.

Grigoryan, A., \& King, J. M. (2008). Adbusting: Critical media literacy in a multi-skills academic writing lesson. English Teaching Forum, 4, 2-9.

Harshman, J. (2017). Developing globally minded, critical media literacy skills. Journal of Social Studies Education Research, 8(1), 69-92.

Iwuanyanwu, P. N. (2019). What we teach in science, and what learners learn: A gap that needs bridging. Pedagogical Research, 4(2), 1-12.

Johansson, V., \& Limberg, L. (2017). Seeking critical literacies in information practices: Reconceptualising critical literacy as situated and tool-mediated enactments of meaning. Information Research, 22(1), 1-16.

Johnson, M. (2018). Fighting "fake news": How we overhauled our website evaluation lessons. Knowledge Quest, 47(1), 32-36.

Kellner, D., \& Share, J. (2005). Toward critical media literacy: Core concepts, debates, 
organizations, and policy. Discourse: Studies in the Cultural Politics of Education, 26(3), 369-386.

Kovalik, C. L., Jensen, M. E., Schloman, B., \& Tipton, M. (2010). Information literacy, collaboration, and teacher education. Communications in Information Literacy, 4(2), 145-168.

Kurup, P. M., Li, X., Powell, G., \& Brown, M. (2019). Building future primary teachers' capacity in STEM based on a platform of beliefs, understandings and intentions. International Journal of STEM Education, 6(10), 1-14.

Lawal, V. (2019). Critical information literacy and participatory democracy: An analysis of the role of libraries in Jos Metropolis, Plateau State. Library Philosophy and Practice (e-journal), 2637, https://digitalcommons.unl.edu/libphilprac/2637

Le, T., \& Le, Q. (2009a). Critical discourse analysis: An overview. In T. Le, Q. Le, \& M. Short (Eds.), Critical discourse analysis: An interdisciplinary perspective (pp. 315). New York, NY: Nova Science Publishers.

Lee, N. M. (2018). Fake news, phishing, and fraud: A call for research on digital media literacy education beyond the classroom. Communication Education, 67(4), 460466.

Locke, T. (2004). Critical discourse analysis. New York, NY: Continuum.

McGrew, S., Ortega, T., Breakstone, J., \& Wineburg, S. (2017). That challenge that's bigger than fake news: Civic reasoning in a social media environment. American Educator, Fall 2017, 4-10.

Ornstein, A. C., \& Levine, D. U. (2002). Foundations of education (8th Ed.). Boston, MA: Houghton Mifflin. 
O’Sullivan, M., \& Scott, T. (2000). Teaching internet information literacy: A critical evaluation. Multimedia Schools, 7(2), 40-43.

Patton, M. Q. (2008). Utilization-focused evaluation (4th ed.). Thousand Oaks, CA: Sage. Pennycook, G., Cheyne, J. A., Barr, N., Koehler, D. J., \& Fugelsang, J. A. (2015). On the reception and detection of pseudo-profound bullshit. Judgment and Decision Making, 10(6), 549-563.

Porterfield, J. M. (2018). Overcoming challenges to critical information literacy: Primary source analysis as consciousness-raising. Pennsylvania Libraries: Research \& Practice, 6(2), 106-112.

Ruswick, B. (2015). What does it mean to be an American? Training history students and prospective teachers to see the assumptions in their textbooks. The History Teacher, 48(4), 667-692.

Tornberg, P. (2018). Echo chambers and viral misinformation: Modeling fake news as complex contagion. PLoS ONE, 13(9), 1-21.

Yang, K. W. (2009). Mathematics, critical literacy, and youth participatory action research. New Directions for Youth Development, 123, 99-118. 
SECTION FIVE: CONTRIBUTION TO SCHOLARSHIP

TO BE SUBMITTED TO COMMUNICATIONS IN INFORMATION LITERACY 


\title{
Critical Information Consumption and Textbooks in Teacher Preparation Programs
}

The following document was created with the intent to submit for publication to the scholarly journal Communications in Information Literacy. The submissions page for the journal details the specifications for research-based articles: inclusion of an abstract and references, with a standard social science research structure, but without the use of headers or footers (Digital Commons, 2019). The abstract and keywords required for submission are provided here, and the references for this article are provided at the end of the section. The word count for this article references is 5,996, which falls within the required word limit for the publication.

\begin{abstract}
The purpose of this critical discourse analysis was to investigate ways in which introductory teaching or pedagogy textbooks used in public universities' teacher preparation programs facilitate (or decline to facilitate) the direct and indirect application of CIL/CIC skills. Specifically, textbooks were evaluated on their (1) direct and indirect philosophical and epistemological discussion; (2) direct discussion of evaluating sources of information; (3) attention to power dynamics, biases, ideologies, and underlying assumptions in media and scholarly work; and (4) use of buzzwords and/or epistemically suspect statements. Findings were based on inductive analysis of emergent themes and suggest that there are key features of a text that indicate how CIL/CIC-favorable a work may be. These features include questioning, linguistic granularity, presenting strengths and criticisms of prominent paradigms, attending to power asymmetries in the classroom, and making explicit the hidden or implied messages in educational settings.
\end{abstract}


Key Terms: critical information literacy, critical information consumption, textbook evaluation, teacher preparation programs

\section{Introduction}

Engaged participants in twenty-first century United States society are by necessity citizens of two distinct social 'spaces.' The first is made of the physical locations where they live and work, and the second is the set of "cyber ecosystems" in which they interact with media, data, and information (Frau-Meigs, 2019, p. 11). The amount of content with which the average American interacts daily in these new ecosystems is historically unprecedented, with the onslaught of information being shaped by advertisers, algorithms, and political agendas; an increasing number of scholars agree that we are in the midst of an information crisis (Molina, Sundar, Le, \& Lee, 2019; Sweet, Shermak, \& Swanson, 2019; Tornberg, 2018). This problem of information overload, separating the 'good' from the 'bad,' and the extensive proliferation of misinformation has been described as a "wicked problem" (Oliphant, 2019, p. 261) and is often explained through the metaphor of a contagious disease (Frau-Meigs, 2019; Molina, Sundar, Le, \& Lee, 2019; Oliphant, 2019; Sweet, Shermak, \& Swanson, 2019; Tornberg, 2018).

The assumed cure for - or perhaps the vaccine against - this information disease is critical information literacy (CIL) education. Depending on the situation in which the phrase is used, CIL may refer to examining underlying assumptions or biases in mass media, attending to the power dynamics implicit in textbooks, recognizing psychological manipulation in the form of advertising, evaluating the use (and misuse) of statistical data, or identifying propaganda and so-called fake news on social media (Gretter, Yadav, \& Gleason, 2017; Johansson \& Limberg, 2017; Kellner \& Share, 2005; Lee, 2018; 
Ruswick, 2015). Yang (2009) used the term “critical consumption” (p. 101), and Cooke (2017) expanded it "critical information consumption" (p. 211) to encompass the behaviors that occur when an information consumer engages with an information source. Critical information consumption (CIC) and CIL are used interchangeably here to refer to the skills and mindsets that promote active attention to and evaluation of both sources of information and the ways in which these sources present their content. The purpose of this critical discourse analysis was to investigate ways in which introductory teaching or pedagogy textbooks used in public universities' teacher preparation programs facilitate the application of CIL/CIC skills, with the following research question:

To what extent do the textbooks used by teacher preparation programs in the largest public universities across the United States for introductory or foundations of education courses directly or indirectly address, utilize, or model the following components of critical information literacy/consumption skills:

a. Epistemological and philosophical paradigms in education;

b. Evaluating sources of information (whether for professional purposes or to teach CIC content to students);

c. Epistemically suspect statements and buzzwords in education; and

d. Power dynamics, biases, ideologies, and underlying assumptions in media and scholarly work?

Underpinning this study was an assumption of the cyclic nature of education as an American cultural institution: as students work their way through prescribed PK-12 school systems and into higher education, some of them will choose to become educators themselves. After completing a teacher preparation program of some sort and achieving 
the required degrees and certificates, they eventually become the teachers and professors who educate the next generation of students. Later, these same educators may go on to become administrators or policymakers who are tasked with making decisions that will impact future generations of students and citizens, and so the cycle endures. If CIL/CIC education continues to be an ongoing public concern, then it follows that the current cycle of educating the populace and creating new educators is insufficient in regard to CIL/CIC-related skills. The question that arises is how to find an entry point into this cycle in order to disrupt it. This study, then, evaluated textbooks used in teacher preparation programs as a potential entry point in the educative cycle.

\section{Literature Review}

In CIL/CIC research, little attention is paid to the most traditional source of information modelling and retrieval in the classroom setting: the textbook. Since scholarly literature suggests that pre-service teachers need to improve their CIL/CIC skills (Aybek, 2016; Calik \& Karatas, 2019; Kovalik, Jensen, Schloman, \& Tipton, 2010), presumably to better pass along those skills to their future students, the focus of the present study was an examination of the textbooks used in teacher preparation programs through a CIL/CIC lens, framed within Kellner and Share's (2005) model of media literacy and critical discourse analysis. The primary features of the model are that all messages are constructed, usually with some sort of insider's code; and all messages are inherently value-laden and have some underlying motive. This study expanded the model from the sphere of profit-driven media messages into informational messages that may be constructed from a variety of underlying motivations. These concepts correspond to the emerging subset of CIL research dedicated to examining the skills, knowledge, and 
dispositions needed to detect "epistemically suspect" statements, lack of linguistic and semantic precision, and the "ontological confusion" of buzzwords and bullshit with profound truth (Pennycook, Cheyne, Barr, Koehler, \& Fugelsang, 2015, p. 551).

The buzzword as an epistemological construct seems to be universally understood in modern culture but rarely explicitly defined. Consider the plethora of articles and books that feature 'buzzword' in the title without a clear explanation of how the word is being used (Bury, 2020; Cairns \& Krzywoszynska, 2016; Childers, 2003; Grzanka, 2020; Stoll, 2020; Winter, 2001). In education, buzzword is used as a synonym of jargon or subject-specific lingo (Ravitch, 2007) or to mean a word that "gets thrown around a lot" (Kraft, Schmiesing, \& Phillips, 2016, p. 16). Scholarly inquiry into the sociolinguistic implications of buzzwords is limited, but what research does exist tends to describe them as a form fashionable, trendy, or popular language which may or may not have a lasting presence in the vernacular (Caled, Beyssac, Xexeo, \& Zimbrao, 2016; Neuman, Nave, \& Dolev, 2011). Despite ambiguous meanings and faddish use in popular media, buzzwords are inextricably tied to epistemically suspect statements and pseudo-profound bullshit, predicated on the assumption that use of a buzzword gives the façade of truth and/or expertise of the buzzword user (Pennycook et al, 2015).

In more recent years, the problem of information illiteracy has focused more on source evaluation in both academic and social contexts, i.e. identifying fake news. O'Sullivan and Scott's (2000) action research project in a high school classroom introducing source evaluation on the Internet concluded that young people are beholden to a challenging dichotomy with modern technology: captivated by the wealth of content available to them, but frustrated with the difficulty in sifting the 'good' from the 'bad.' 
CIL/CIC education research often has a social justice component as well, based in considerations the sociocultural context in which information is presented, the voices of power and the voiceless in informational texts, and the relationship of information to the dominant ideology in which it is produced (Grigoryan \& King, 2008; Harshman, 2017;

Orlowski, 2006; O’Sullivan \& Scott, 2000). Further, research pertaining to CIL/CIC skills in preservice teachers tends to approach the topic from the perspective of assessing for or cultivating the "habits of mind and attitudes" necessary for achieving CIL/CIC competence (Calik \& Karatas, 2019, p. 35). For example, Kurup, Li, Powell, and Brown (2019) found that while preservice elementary teachers possessed positive intentions about teaching 21 st century skills and cross-curricular thinking skills, their assessed understanding of those topics was underdeveloped. This study confirmed for a narrower population of preservice teachers what Aybek (2016) generalized for prospective teachers across content and grade levels, that these individuals overall tend to perform poorly on critical thinking assessments.

\section{Methodology}

This study was designed as a critical discourse analysis of CIL/CIC principles and practices in textbooks used in teacher preparation programs in public universities. Critical discourse analysis "is a theoretical and methodological approach, rooted in political ecology, which regards language as social practice and investigates the social contexts within which symbolic forms are deployed and index power" (Colston \& Thomas, 2019, p. 4). Textbook evaluations with emphases on what is being communicated beyond the surface content often use critical discourse analysis as the lens through which the evaluation is conducted (Colston \& Thomas, 2019; Serenko, Bontis, \& Moshonsky, 
2012). The researcher analyzed the direct and indirect language of education textbooks throughout the study: direct language refers to the explicit content of a textbook; indirect (or unacknowledged) language refers to the use of linguistic features that imply a hidden or underlying message without acknowledging it.

Data collection originated from textbooks used in introductory courses in teacher preparation programs at public universities across the United States. The sample of textbooks analyzed came from the largest public university in each of the United States. The researcher then examined each university's publicly-available undergraduate catalog to determine from which course in the teacher preparation program the textbooks to be analyzed would come, usually foundational or introductory courses. Syllabus information and university bookstores provided the required textbook(s) from each course from which the data was collected.

Prior to data collection, a rubric of criteria against which to evaluate the textbooks was established, based on the four components listed in the research question. A sample chapter of each textbook was purposively selected for its relevance to CIL/CIC concepts, then examined and evaluated using the pre-made rubric. For example, in Black Ants and Buddhists: Thinking Critically and Teaching Differently in the Primary Grades, chapter 8, titled "Nurturing History Detectives," was selected because it focused on teaching students that history texts are written by authors with distinct values and perspectives that may conflict with other values and perspectives (Cowhey, 2006, p. 141).

The data collection rubric was constructed with attention to three dimensions of analysis. First, the rubric's structure refers to each of the components of CIC/CIL listed in the research question. Second, each data piece collected from a given text was analyzed 
using the three-step Fairclough process for critical discourse analysis: description, interpretation, and explanation (Lee \& Otsuji, 2009). Third, the interpretation step of analysis occurred through the lens of Locke's inductive process of thematic analysis. This process requires consideration of "1. Prosody; 2. Cohesion; 3. Discourse organization; 4. Contextualization signals; and 5. Thematic organization” (Locke, 2004, p. 58).

\section{Findings}

Thirty-nine education courses from teacher preparation programs across the United States produced a set of sixty required books, most of which were used during the 2019-2020 school year. Of these, data collection and analysis occurred for forty-nine textbooks, while 11 were deemed inappropriate for the purposes of the study (i.e., fictional works or memoirs) and thus eliminated from the study.

\section{Findings for Research Question, Part (a): Paradigms in Education}

Three distinct themes emerged from the textbook analyses regarding the use and discussion of epistemological and philosophical paradigms in education, particularly those that directly address or impact CIL/CIC as operationalized in this study. The first was how the textbooks addressed - or neglected to address - the "isms" that comprise the foundations of the structure of the schooling in the U.S., and by extension the structure of the texts themselves. A subset of texts expanded on this theme with the understanding that education is inherently political; each "ism" takes a stance about what education is and what it should be, has its own set of values and assumptions, and impacts classroom policies and practices. Direct discussion of the philosophies, ideologies, and paradigms associated with schooling (the "isms") occurred in 33\% of textbooks, while examining the inherently political nature of these ideas occurred in $16 \%$ of textbooks. This type of 
action aligns with Kellner and Share's (2005) framework for media literacy as well as the Association of College \& Research Libraries (ACRL) Framework for Information Literacy for Higher Education (Fulkerson, Ariew, \& Jacobson, 2017), both of which acknowledge that all information is grounded in the context in which it is created and constructed by an information actor. Information - and therefore education - cannot maintain political neutrality because the very act of education takes a stance (Cope, 2017; Gutstein, 2013; Joanou, 2017; Orlowski, 2006).

Second, the paradigms discussed and/or adopted in the textbooks naturally lead to an examination of the perceived purposes of schooling (47\%): economic, political, societal, and ethical. For $29 \%$ of texts, this included an acknowledgement that schooling is inherently tied to democracy and patriotism (although the definition and expression of patriotism varied); the essential purposes of education - and the need for CIL/CIC education in order to achieve these goals - are essential themes in CIL/CIC research (Carrino, 2016; Storksdieck, 2016). Eighteen percent of chapters acknowledged in some form or another that the United States has a history of assuming that schools are the cure for (and sometimes the cause of) all of society's ills.

Lastly, as "isms" progress into perspectives on the purpose and goals of education, so to do these goals imply that certain societal elements are necessary for, or anathema to, a sufficiently educated populace. In particular, 37\% textbooks directly stated or indirectly implied an assumption that education is messy: nuance, complexity, controversy, and ambiguity in the creation of knowledge creation was valued, which is a fundamental component of CIL/CIC mindsets (Cope, 2017; Gutstein, 2013; Hollis, 2019). Conversely, anti-intellectualism, the use of deficit thinking paradigms, 
oversimplification of ideas into false dichotomies, and wariness toward profit-driven education were featured more often (45\%) as elements of inequitable schooling (even as some texts fell back on those outlooks themselves).

\section{Findings for Research Question, Part (b): Sources of Information}

Many textbooks in the data collection pool provided rich descriptions and discussions of the nature of information and how it relates to education. Several prominent CIL/CIC-oriented themes emerged (although rarely did a text mention 'critical literacy' by name). The most prominent theme (present in $45 \%$ of the analyzed chapters) was the role of questions when processing and assessing information. Questions that are challenging, probing, provocative, and controversial were valued as essential to the education process; notably, a minority of textbooks only provided superficial questions that encouraged regurgitation of the chapter's contents. Also, questioning occurred throughout the body of text in many cases, even when more traditional end-of-chapter assessment questions were also provided. This affirms one of the central tenets of CIL/CIC mindsets, that information should be questioned and challenged rather than blindly accepted (Cooke, 2017; Rheingold, 2012).

Second, over half of the analyzed texts made direct or indirect mention of the multi-layered nature of information curation and dissemination: beneath the explicit, superficial content of a message lies the hidden, contextual messages that requires decoding on the part of the information consumer. Colloquially, this could be referred to as reading between the lines. In the context of schooling, this phenomenon was most often explicated in the context of code-switching, cultural capital, and the hidden curriculum in schools. Awareness of these underlying but omnipresent components of 
any constructed message is intrinsic to CIL/CIC education (the notion of constructed messages and what that means in the case of profit-earning businesses and mass media in the classroom also made an appearance here) (Auberry, 2018; Kellner \& Share, 2005; McGrew, Ortega, Breakstone, \& Wineburg, 2016).

Third, nearly two-thirds of the analyzed works made direct or indirect acknowledgement that information (and thus learning) does not exist in a vacuum: interdisciplinarity is crucial to meaningful depth of thought and the creation of knowledge; approaching a topic from multiple perspectives is more likely to result in deeper understanding than a singular standpoint. Related to this was the relatively common assumption (20\%) on the textbook authors' part that their readership possessed a certain level of critical numeracy - that is, the ability to use data and statistical measures to solve problems or reduce inequity - when approaching sociopolitical issues in education. Critical numeracy and statistical literacy comprise their own subset of CIL/CIC research, with researchers calling for increased attention to the mathematics of critical literacies (Grotluschen, Buddeberg, Redmer, Ansen, \& Dannath, 2019; Weiland, 2016; Weiland, 2017).

Lastly, but perhaps most critical to developing CIL/CIC skills, was the consideration that critical approaches to information are necessary to educate citizens of a democratic nation. This theme appeared when regarding primary sources, examining theories, evidence-based decision-making. One of the central tenets of CIL/CIC mindsets is that no point of view is infallible, and therefore deserves to have both its strengths and criticisms analyzed (Morrell, 2012; Porterfield, 2018). Many textbooks (47\%) referred to this necessity as questioning the official version of the truth, and that in a participatory 
democracy such challenges of authority and the status quo are not only essential, but a form of patriotism. In the spirit of valuing critique and dissent in education, some textbooks (18\%) even included a discussion of the inadequacy of textbooks to foster such mindsets.

\section{Findings for Research Question, Part (c): Epistemically Suspect Statements and}

\section{Buzzwords}

Buzzwords and epistemically suspect statements can be challenging to identify in the context of academic language since they are often used to foster an air of expertise (even, or especially, when false) (Frankfurt, 2005; Pennycook, Cheyne, Barr, Koehler, \& Fugelsang, 2015). Perhaps the most salient finding of this study is that buzzwords and bullshit can be differentiated from legitimately profound discourse based on the presence or absence of linguistic granularity in a textbook's content. Works that made clear, direct reference to the definition of relevant jargon and then used those definitions in context avoided their messages being obfuscated by meaningless and extraneous verbiage. For example, Goyette (2017) critiqued the overuse of the word 'equality' in education by clarifying that when a stakeholder uses this term, they may in fact be referring to one of two distinct concepts: equality of opportunity versus equality of outcomes. Similarly, Hall, Quinn, and Gollnick (2020) provided careful semantic distinctions between the 'opportunity gap' and 'achievement gap.' Conversely, several textbooks would mention trendy catchphrases in education such as 'multiculturalism' or 'value-added measurement' without any dissection of what these terms meant in the context of the topic being discussed, and sometimes without ever returning to the word after it was mentioned once. Fifteen textbooks in this study (31\%) called out the use of buzzwords in 
education or possessed sufficient linguistic granularity to avoid them; four texts blatantly disregarded such clarifications.

Findings for Research Question, Part (d): Power, Bias, and Underlying Assumptions

Four themes emerged from the analyses concerning power, bias, and underlying assumptions in the textbooks and the classroom. Three of these themes are rooted in the essential truth of the fourth: that education, whether from a text, a teacher, a policy, or a procedure, is an expression of values (a point stated in $27 \%$ of analyzed chapters). Whether those values are directly stated or assumed, their existence must be acknowledged in order to identify power asymmetries and biases, which affirms the findings of Critten (2015), Foster-Kaufman (2019), and Harshman (2017). For example, in this study I have explicitly communicated that as a scholar and educator, I value an emphasis on CIL/CIC skills to foster meaningful participation in an informationoverloaded democracy. Less obvious - but present nonetheless - is the reflection of my values as a researcher in the findings that I am presenting here versus those that I am not. Just as in media and textbooks, the information and messages presented here are constructed by a human with her own set of biases, assumptions, and paradigms. Thus, it should be noted that $24 \%$ of the textbooks analyzed in this study actively engaged in discussions concerning transparency of values as an additional necessity to transparency of information in an educational setting.

The remaining three themes that developed from this essential assumption of values are that (1) as in media, representation of all stakeholders matters in academia (37\%), (2) schooling in the U.S. is constructed around power asymmetry in the classroom (27\%), and (3) such power asymmetry is reduced when education is approached from a lens of 
social justice and emancipation (37\%). When considered holistically, these findings echo those of other social-justice-minded researchers in the field of CIL/CIC education (Folk, 2019; Harshman, 2017).

In textbooks, representation is the measure of whose voice is heard and whose is not in the work (Ruswick, 2015). For example, a text about the history of schooling in the U.S. may acknowledge that the early days of the 'education for all' objective of public schools was in fact limited to education for all white, property-owning males, or that even after access to education became a priority in the nation, middle-class white men represented the vast majority of educational policymakers. These acknowledgements address the fact that having voice in educational matters is a form of privilege often denied to those on the disadvantaged end of power asymmetry (Lawal, 2019). While 37\% of analyzed chapters addressed these asymmetries, there were others that demonstrated an underlying dissonance between the content of the text in regard to equity and the voices/perspectives being modelled; for example, when celebrating pioneers of education throughout history, Ornstein (2002) showcased nine men (of whom only one was nonwhite) and two women, while simultaneously endorsing multiculturalism and equity in education in the text. This 'do as I say and not as I do' approach to diversity and inclusion was found in $16 \%$ of the selected chapters.

Another extension of the underlying values of the U.S. education system is that our current mode of schooling promotes power asymmetry in the classroom, where teachers act as gatekeepers of knowledge with the authority to decide who deserve to receive more education (Folk, 2019). Twenty-nine percent of the analyzed chapters made overt reference to such asymmetries and gatekeeping. This power imbalance of educational 
privilege was implicitly reinforced in the sociolinguistic choices of the textbooks themselves, with text indicating that the textbook reader is an 'insider' in this sphere. Using the first-person plural 'we' when discussing dominant cultural traits, or referring to underrepresented groups as 'contributing' to American culture (implying that they are fully American) are examples of linguistic othering that can occur within a text and erode the work's stated valuing of equity and diversity; the use of we as an attempt to grant insider status to the readers (as opposed to the we of multiple authors referring to themselves, as in 'in this chapter we explore...') was used in 35\% of analyzed chapters. This is not to assume that all uses of we in this context are inherently problematic; when introducing the topic of this study and its use to the American education system I also use we to refer to American educators. It is when the word alienates (intentionally or not) the readership by making assumptions about who would be reading such a book that its use reinforces power asymmetries in education. However, $24 \%$ of selected chapters explicitly stated that education by its very nature is a force for social justice in a democratic society, and these asymmetries can be rectified through approaching education as emancipatory.

\section{Conclusion}

The textbooks examined in this study tended to display more CIL/CIC-positive traits than negative, although some of the most significant mindsets for developing CIL/CIC skills were not as frequent as others. Four textbooks stood out as exemplars of fostering and modelling CIL/CIC mindsets and deserve recognition in this context.

- Cowhey, M. (2006). Black ants and Buddhists: Thinking critically and teaching differently in the primary grades. Portland, ME: Stenhouse. 
This work modeled strategies for engaging students in CIL/CIC mindsets and examined the rewards and challenges associated with such a commitment in the classroom.

- Giroux, H. A., \& Pollock, G. (2010). The mouse that roared: Disney and the end of innocence. Lanham, MD: Rowman \& Littlefield.

While not directly related to pedagogy or classroom experiences, this work examines how mass media (in particular, Disney) influences nearly every aspect of modern society, and how it is in the best interest of profit-driven corporations for citizens to lack CIL/CIC awareness.

- Johnston, P. H. (2012). Opening minds: Using language to change lives. Portland, ME: Stenhouse.

A subset of CIL/CIC skills rely on approaching language use with scrutiny. This work is predicated on the notion that the way students and teachers engage linguistically with learning can impact the depth and richness of learning.

- Westheimer, J. (2015). What kind of citizen? Educating our children for the common good. New York, NY: Teachers College Press.

This work argues that U.S. education needs to be reoriented on producing civicand ethically-minded citizens who are prepared to engage in a diverse democratic society.

The objective of this study was to examine the direct and indirect modeling of CIL/CIC mindsets in introductory textbooks used in teacher preparation programs in the largest public universities in each of the United States. The findings presented in this study are intended to provide insights into the state of CIL/CIC education that may 
impact teacher preparation programs, classroom praxis, and ultimately the knowledge and skills of future generations of information consumers. This study considered textbooks as an entry point into the educative cycle in the United States in order to disrupt a problematic attention to CIL/CIC education; other potential area of future research in this entry point may focus on how and why teacher educators choose the textbooks they use with their preservice teachers, or how those textbooks are used in conjunction with other materials and learning experiences in these teacher education courses. Further, researchers may consider other entry points in the cycle for evaluation of CIL/CIC education: administrators' and policymakers' attitudes toward CIC/CIL education (or even an assessment of their own CIL/CIC skills); the extent to which CIL/CIC skills are present in the different core content areas in public schools; or the attention to and implementation of CIL/CIC skills and mindsets in professional development for classroom teachers. 


\section{References}

Auberry, K. (2018). Increasing students' ability to identify fake news through information literacy education and content management systems. The Reference Librarian, 59(4), 179-187.

Aybek, B. (2016). The relationship between prospective teachers' media and television literacy and their critical thinking dispositions. Eurasian Journal of Educational Research, 63, 261-278.

Brimble, L. J. F. (1948, May). The exposition of the truth. Bulletin of the Atomic Scientists, 4(5), 141-144.

Bury, C. (2020, May 1). Artificial intelligence: Adding value or just another buzzword? TVB Europe, 26-27.

Cairns, R., \& Krzywoszynska, A. (2016). Anatomy of a buzzword: The emergence of 'the water-energy-food nexus' in UK natural resource debates. Environmental Science \& Policy, 64, 164-170.

Caled, D., Beyssac, P., Xexeo, G., \& Zimbrao, G. (2016). Buzzword detection in the scientific scenario. Pattern Recognition Letters, 69, 42-48.

Calik, M., \& Karatas, F. O. (2019). Does a "science, technology and social change" course improve scientific habits of mind and attitudes toward socio-scientific issues? Australian Journal of Teacher Education, 44(6), 35-52.

Carrino, C. B. (2016). Gatekeepers to success: Missouri's exclusionary approach to school discipline. Washington University Journal of Law and Policy, 52, 171-194.

Childers, S. (2003). Computer literacy: Necessity or buzzword? Information Technology \& Libraries, 22(3), 100-104. 
Colston, N. M., \& Thomas, J. (2019). Climate change skeptics teach climate literacy? A critical discourse analysis of children's books. Journal of Science and Communication, 18(4), A02, 1-22.

Cooke, N. A. (2017). Posttruth, truthiness, and alternative facts: Information behavior and critical information consumption for a new age. Library Quarterly: Information, Community, Policy, 87(3), 211-221.

Cope, J. T. (2017). The reconquista student: Critical information literacy, civics, and confronting student intolerance. Communications in Information Literacy, 11(2), 264-282.

Cowhey, M. (2006). Black ants and Buddhists: Thinking critically and teaching differently in the primary grades. Portland, ME: Stenhouse.

Crist, C. A., Duncan, S. E., \& Bianchi, L. M. (2017). Incorporation of cross-disciplinary teaching and a wiki research project to engage undergraduate students to develop information literacy, critical thinking, and communication skills. Journal of Food Science Education, 16, 81-91.

Critten, J. (2015). Ideology and critical self-reflection in information literacy instruction. Communications in Information Literacy, 9(1), 145-156.

Dehdar, M., Sayenagi, L., Arbab, E., Arzhandeh, M., Rashanray, M., Raeisi, A., \& Kuhi, L. (2019). Role of schools in educating the active citizen. UTC Journal of Social Sciences and Humanities Research, 7(2), 31-36.

Folk, A. L. (2019). Reframing information literacy as academic cultural capital: A critical and equity-based foundation for practice, assessment, and scholarship. College and Research Libraries, 80(5), 658-673. 
Foster-Kaufman, A. (2019). Wikipedia-based assignments and critical information literacy: A case study. In A. Pashia \& J. Critten (Eds.), Critical Approaches to Credit-Bearing Information Literacy Courses (pp. 271-294). Chicago, IL: Association of College and Research Libraries.

Frankfurt, H. G. (2005). On bullshit. Princeton, NJ: Princeton University Press.

Frau-Meigs, D. (2019). Information disorders: Risks and opportunities for digital media and information literacy? Media Studies, 10(19), 10-28.

Fulkerson, D. M., Ariew, S. A., \& Jacobson, T. E. (2017). Revisiting metacognition and metaliteracy in the ACRL framework. Communications in Information Literacy, 11(1), 21-41.

Giroux, H. A., \& Pollock, G. (2010). The mouse that roared: Disney and the end of innocence. Lanham, MD: Rowman \& Littlefield.

Goyette, K. A. (2017). Education in America. Oakland, CA: University of California Press.

Grambo, K. (2019). Fake news and racial, ethnic, and religious minorities: A precarious quest for truth. Journal of Constitutional Law, 21(5), 1299-1348.

Gretter, S., Yadav, A., \& Gleason, B. (2017). Walking the line between reality and fiction in online spaces: Understanding the effects of narrative transportation. Journal of Media Literacy Education, 9(1), 1-21.

Grigoryan, A., \& King, J. M. (2008). Adbusting: Critical media literacy in a multi-skills academic writing lesson. English Teaching Forum, 4, 2-9. 
Grotluschen, A., Buddeberg, K., Redmer, A., Ansen, H., \& Dannath, J. (2019).

Vulnerable subgroups and numeracy practices: How poverty, debt, and unemployment relate to everyday numeracy practices. Adult Education Quarterly, 69(4), 251-270.

Grzanka, P. R. (2020). From buzzword to critical psychology: An invitation to take intersectionality seriously. Women \& Therapy, 43(3/4), 244-261.

Gutstein, E. R. (2013). Rethink mathematics and its intersection with race. In E. R. Gutstein \& B. Peterson (Eds.), Rethinking Mathematics: Teaching Social Justice by the Numbers (2nd Ed.) (pp. 26-29). Milwaukee, WI: Rethinking Schools.

Hall, G. E., Quinn, L. F., \& Gollnick, D. M. (2020). Introduction to teaching: Making a difference in student learning. Thousand Oaks, CA: Sage.

Harshman, J. (2017). Developing globally minded, critical media literacy skills. Journal of Social Studies Education Research, 8(1), 69-92.

Hollis, H. (2019, June). Information literacy and critical thinking: Different concepts, shared conceptions. Paper presented at Conceptions of Library and Information Science 10th International Conference, Ljubljana, Slovenia. Retrieved from http://discovery.ucl.ac.uk/10074076/

Iwuanyanwu, P. N. (2019). What we teach in science, and what learners learn: A gap that needs bridging. Pedagogical Research, 4(2), 1-12.

Joanou, J. P. (2017). Examining the world around us: Critical media literacy in teacher education. Multicultural Perspectives, 19(1), 40-46. 
Johansson, V., \& Limberg, L. (2017). Seeking critical literacies in information practices: Reconceptualising critical literacy as situated and tool-mediated enactments of meaning. Information Research, 22(1), 1-16.

Johnson, M. (2018). Fighting "fake news": How we overhauled our website evaluation lessons. Knowledge Quest, 47(1), 32-36.

Kellner, D., \& Share, J. (2005). Toward critical media literacy: Core concepts, debates, organizations, and policy. Discourse: Studies in the Cultural Politics of Education, 26(3), 369-386.

Kovalik, C. L., Jensen, M. E., Schloman, B., \& Tipton, M. (2010). Information literacy, collaboration, and teacher education. Communications in Information Literacy, $4(2), 145-168$.

Kraft, J., Schmiesing, D., \& Phillips, S. (2016). Critical thinking: From buzzword to action. Children's Technology and Engineering, 20(4), 16-19.

Kurup, P. M., Li, X., Powell, G., \& Brown, M. (2019). Building future primary teachers' capacity in STEM based on a platform of beliefs, understandings and intentions. International Journal of STEM Education, 6(10), 1-14.

Lawal, V. (2019). Critical information literacy and participatory democracy: An analysis of the role of libraries in Jos Metropolis, Plateau State. Library Philosophy and Practice (e-journal), 2637, https://digitalcommons.unl.edu/libphilprac/2637

Lee, N. M. (2018). Fake news, phishing, and fraud: A call for research on digital media literacy education beyond the classroom. Communication Education, 67(4), 460466. 
Lee, A., \& Otsuji, E. (2009). Critical discourse analysis and the problem of methodology. In T. Le, Q. Le, \& M. Short (Eds.), Critical discourse analysis: An interdisciplinary perspective (pp. 65-77). New York, NY: Nova.

Levitt, S. D., \& Dubner, S. J. (2014). Think like a freak: Secrets of the rogue economist. London, UK: Penguin.

Locke, T. (2004). Critical discourse analysis. New York, NY: Continuum.

Lopez-Medina, B. (2016). Developing a CLIL textbook evaluation checklist. LACLIL, 9(1), 159-173.

Magnus, E., Faber, M., \& Belanger, J. (2019). A consideration of power structures (and the tensions they create) in library assessment activities. Library Assessment Conference: Building Effective, Sustainable, Practical Assessment. Retrieved from https://www.researchgate.net/publication/336574179_A_Consideration_of_Power _Structures_and_the_Tensions_They_Create_in_Library_Assessment_Activities

McGrew, S., Ortega, T., Breakstone, J., \& Wineburg, S. (2017). That challenge that's bigger than fake news: Civic reasoning in a social media environment. American Educator, Fall 2017, 4-10.

McMillan, C. (2018). 'I've learned to question everything': Critical thinking, or, the pedagogical logic of late capitalism. Journal for Critical Education Policy Studies, 16(1), 1-29.

Molina, M. D., Sundar, S. S., Le, T., \& Lee, D. (2019). "Fake news" is not simply false information: A concept explication and taxonomy of online content. American Behavioral Scientist, 63(11), 1-33. 
Morrell, E. (2012). 21st-century literacies, critical media pedagogies, and language arts. The Reading Teacher, 66(4), 300-302.

Neuman, Y., Nave, O., \& Dolev, E. (2011). Buzzwords on their way to a tipping-point: A view from the blogosphere. Complexity, 16(4), 58-68.

Oliphant, T. (2019). The self and others: Revisiting information needs and libraries as public, social institutions in a post-truth world. Open Information Science, 3, 261273.

Orlowski, P. (2006). Educating in an era of Orwellian spin: Critical media literacy in the classroom. Canadian Journal of Education, 29(1), 176-198.

O’Sullivan, M., \& Scott, T. (2000). Teaching internet information literacy: A critical evaluation. Multimedia Schools, 7(2), 40-43.

Pennycook, G., Cheyne, J. A., Barr, N., Koehler, D. J., \& Fugelsang, J. A. (2015). On the reception and detection of pseudo-profound bullshit. Judgment and Decision Making, 10(6), 549-563.

Porterfield, J. M. (2018). Overcoming challenges to critical information literacy: Primary source analysis as consciousness-raising. Pennsylvania Libraries: Research \& Practice, 6(2), 106-112.

Ravitch, D. (2007). EdSpeak: A glossary of education term, phrases, buzzwords, and jargon. Alexandria, VA: Association for Supervision and Curriculum Development.

Rheingold, H. (2012). Stewards of digital literacies. Knowledge Quest, 41(1), 52-55. 
Ruswick, B. (2015). What does it mean to be an American? Training history students and prospective teachers to see the assumptions in their textbooks. The History Teacher, 48(4), 667-692.

Serenko, A., Bontis, N., \& Moshonsky, M. (2012). Books as a knowledge translation mechanism: citation analysis and author survey. Journal of Knowledge Management, 16(3), 495-511.

Soltys, S., \& McClintlock, S. (2014). Freakatistics: Discussion assignments for the statistics classroom. PRIMUS, 24(1), 81-94.

Stoll, J. D. (2020, May 1). Sustainability was corporate America's buzzword. This crisis changes that. The Wall Street Journal [online edition]. Retrieved from https://www.wsj.com/articles/sustainability-was-corporate-americas-buzzwordthis-crisis-changes-that-11588352181

Storksdieck, M. (2016). Critical information literacy as core skill for lifelong STEM learning in the 21 st century: reflections on the desirability and feasibility for widespread science media education. Cultural Studies of Science Education, 11(1), 167-182.

Sweet, C. A., Shermak, T., \& Swanson, J. (2019). "You shall listen to all sides and filter them from yourself': Information literacy and post-truth skepticism. In A. P. Baer, R. Schroeder, \& E. S. Cahoy (Eds.), Libraries Promoting Reflective Dialogue in a Time of Political Polarization (pp. 91-111). Chicago, IL: Association of College and Research Libraries.

Tornberg, P. (2018). Echo chambers and viral misinformation: Modeling fake news as complex contagion. PLOS ONE, 13(9), 1-21. 
Walker, A. C., Stange, M., Dixon, M. J., Koehler, D. J., \& Fugelsang, J. A. (2019). Graphical depiction of statistical information improves gambling-related judgements. Journal of Gambling Studies, https://doi.org/10.1007/s10899-01909860-1

Weiland, T. (2016). Towards a framework for a critical statistical literacy in high school mathematics. In M. B. Wood, E. E. Turner, M. Civil, \& J. A. Eli (Eds.), Proceedings of the 38th Annual Meeting of the North American Chapter of the International Group for the Psychology of Mathematics Education (pp.984-991), Tucson, AZ: University of Arizona.

Weiland, T. (2017). Problematizing statistical literacy: An intersection of critical and statistical literacies. Educational Studies in Mathematics, 96, 33-47.

Westheimer, J. (2015). What kind of citizen? Educating our children for the common good. New York, NY: Teachers College Press.

Winter, S. (2001). Ontology: buzzword or paradigm shift in GL science? International Journal of Geographical Information Science, 15(7), 587-590.

Yang, K. W. (2009). Mathematics, critical literacy, and youth participatory action research. New Directions for Youth Development, 123, 99-118. 
SECTION SIX: SCHOLARLY PRACTITIONER REFLECTION 
Completing this dissertation has been one of the most challenging experiences of my life. Shortly after I presented the proposal for this study to my committee, the world shut down and my life changed. While I do not often journal, I wrote a note to my future self to include somewhere in my dissertation's final product. Here is an abbreviated version of that message:

"2020 has been a rough year, and it is only June.

My dissertation proposal was accepted with minor revisions, and from there I finished compiling the book list from which data would be collected. Since I was also a full-time teacher at the time, the plan was to begin data collection in earnest over Spring Break in March.

You may already see where this story is headed.

Spring Break 2020 was when the nation - the whole world, it seemed - shut down and everything changed. Schools everywhere, including my own, made the abrupt switch to online learning. I only left the house to buy groceries and take my geriatric pug to the vet. And more importantly for this study, university and public libraries all closed. You know, the place where the books live.

So, my work came to a halt. No access to textbooks meant no data collection, and while my advisor stayed optimistic on my behalf, it would ultimately mean pushing back my defense (and thus, graduation) by at least a semester. When the libraries started to reopen some two months later, I was not able to just immediately pick back up where I had left off, partially due to a bureaucratic comedy of errors regarding my access to the university library, partly because of the nation-wide Black Lives Matter protests that led 
me to read anti-racist literature and reflect on my own biases and privilege, but mostly because my life was put on hold when my mom was diagnosed with pancreatic cancer.

The suddenness of her illness was a shock - and still is. In the space of about a month, she went from being a high-ranking executive at a large hospital to homebound, barely able to walk without assistance. During and after the surgery to remove the tumor, I stayed with my parents to help my dad take care of her. I am not ashamed to say that my dissertation was not exactly a high priority for me then.

At the time of this writing, I am back home. My mom finally turned a corner in recovering from her surgery, and she is not scheduled to start chemotherapy for a couple of weeks. When that begins, I will go back to help. I have a small stack of textbooks from the library waiting for me to begin my data collection. They have been staring at me accusingly for the last week while I have been doing everything but read them: cleaning the house, bathing the dogs, starting a new exercise routine, binge-watching an Unsolved Mysteries-esque web series on YouTube.

Psychologists will tell you that procrastination is rooted in anxiety. Since I have been anxious about so many other things for months now, it is no surprise that some bled over into my dissertation. I am not sure what finally changed within me that I woke up this morning in mid-June, sat down at my computer, and started writing all this down in anticipation of jumping back into the research. Regardless, I am here now. So here goes nothing”(C. K. Smith-Nelson, personal diary, June 12, 2020).

Surprisingly little has changed since I wrote that, but I somehow managed to find the time and motivation to finally make it to the last steps of perhaps the biggest achievement of my life. Reflecting on the processes and circumstances that got me here has been a 
deeply personal experience, and one that could not be adequately communicated through academic language alone. That said, I do not intend to neglect my duties as an educator and scholar-practitioner to reflect on how the dissertation process has made me better at both of those pursuits. In the following sections, I examine how this dissertation has influenced my practice as an educational leader and as a scholar.

\section{How Has the Dissertation Influenced Your Practice as an Educational Leader?}

I teach at an International Baccalaureate high school where one of my duties is to serve as students' advisors for completing the extended essay, an independent research project where the student explores a topic of interest. This project is intended to be a culminating experience where students apply the skills they have developed over the course of the program to engage in scholarly inquiry. When advising my students on how to choose a topic, I emphasize that this will be a subject that they are stuck with for the next year or more, so it needs to be about something that they truly value and want to learn. The advice I received for choosing a dissertation topic was nearly identical.

The most profound theme of this doctoral program and the dissertation process for me was that one's decisions in life, work, and academia are a reflection of one's values; from choosing an initial topic to enumerating the findings of the research, every step has clarified for me what I value as a teacher, learner, citizen, and leader. When rereading the scholarly practitioner reflection paper that I submitted as part of the written comprehensive exams for the program (about a year before compiling the findings and conclusions of this dissertation), I was surprised at how closely what I had written then aligns with what I was currently writing: that any problem worth solving will have a certain amount of nuance, complexity, and ambiguity with which to grapple; that what 
we see and focus on is a reflection of what our values tend to affirm or challenge; that those with the privilege of having a voice with which to make educational decisions bear the professional and ethical obligations of considering the consequences - deliberate and unintended - of their actions; and that critical examination and/or dissent from the status quo demonstrates caring for an institution enough to want to improve it.

\section{Complexity, Nuance, and Ambiguity}

One of the first major projects of this program was to unravel a wicked problem, a task that required everyone involved to embrace nuance and ambiguity. This notion of embracing wicked problems in all of their messy glory stayed with me through the completion of this dissertation; the question of how to improve CIL/CIC education, the larger question of what it means to adequately prepare educators for the inevitable and innumerable challenges of the classroom, and even the establishment of a foundational purpose of education in modern society all represent significant problems of practice of which this dissertation can only scratch the surface. These problems are quintessentially ingrained in scholarly and professional settings and require solutions that possess a corresponding depth and acceptance of uncertainty (O’Leary, 2005; Perry, 2016). Perhaps my favorite adage from all the readings throughout the course and my work here is: "Simplicity at the expense of accuracy is no virtue; complexity in the service of accuracy is no vice" (Patton, 2008, p. 482).

\section{Values}

The underlying theme of CIL/CIC habits of mind is to consider the motivation behind the construction of a message. Further, assessing these motivations as an expression of the values of the message creator and how it affirms or challenges the 
message consumer's values is at the core of taking a critical approach to information, media, and education. In this regard my 'favorite' text that I analyzed in this study was The Mouse that Roared (Giroux, 2010), a critique of how "mass-produced images fill our daily lives and condition our most intimate perceptions and desires. At issue for parents, educators, and others is how culture, especially media culture, has become a substantial, if not the primary, educational force in regulating the meanings, values, and tastes that set the norms...[of] what it means to claim an identity as a male, female, white, black, citizen, noncitizen" (pp. 2-3). The author later refers to this conditioning as "public pedagogy," and warns of the "political and economic threat that Disney and other corporations present to a democracy because of their control over information" (Giroux, 2010 , p. 4). This text particularly challenged me and forced me to confront some ethical and cognitive dissonance (my celebratory goal after finishing the dissertation is a trip to Disney World) between my internalized acceptance of the Disney brand while recognizing the potential harm its power and influence have in our consumer-driven culture. But if one is not challenged or driven to discomfort in the creation of knowledge, did any meaningful learning truly occur?

\section{Privilege and Voice}

As a white, middle-class, cisgender woman, I have a considerable amount of unearned privilege. That privilege means I am less likely to face a host of injustices that others regularly encounter. While the events of the last year brought that privilege more prominently into mainstream discourse, the findings from the study's textbook analyses also highlighted for me the subtle ways in which I enjoy privilege in educational settings. When authors use the word 'we' when describing dominant cultural norms, I know that I 
am a part of the 'we' to which they refer (mostly); I am an insider in the sphere of education scholars and professionals. When reading a text on educational history, I know that my ancestors were considered worthy of education and when texts gloss over what was meant by 'access for all,' I am included (again, mostly) in that narrow definition of all. It is therefore my professional and ethical responsibility to confront the reality that not all voices are heard equitably in educational settings, that others do not enjoy the same luxuries, and to demand that these injustices be corrected.

\section{How Has the Dissertation Process Influenced You as a Scholar?}

I have distinct memories from my undergraduate teacher preparation program of being told many times over that teachers must remain politically/ideologically neutral in the classroom. Anything else, they said, is unprofessional and smacks of taking advantage of the influence you hold over your students. Superficially, this is true; laws concerning electioneering in the classroom are necessary. But beyond campaign buttons or sharing opinions on politicians, it cannot be ignored that teaching and learning are inherently political acts: by promoting equitable opportunities for all students, I am taking a political stance. By involving myself in the sexuality and gender acceptance movement in order to make schools safer and more welcoming for my LGBTQ+ students, I am stating a political opinion. Indeed, one of the most prominent findings from this study is that any "ism" you may adhere to in the classroom is by its very nature announcing a position. The façade of neutrality is another aspect of privilege; when one's rights and existence are not challenged, then one has the luxury of affecting neutrality.

So too is neutrality impossible in academia; every researcher approaches the creation of new knowledge from the perspective of their own assumptions and biases. 
Thus, if one can accept that neutrality is not an option, the question that arises is how to appropriately acknowledge and manage one's ideological stances in a way that does not jeopardize the quality of the research? In academia, as in professional life, transparency may be the most effective solution. To state for one's audience "I made this decision because..." is to empower the audience to evaluate the legitimacy of one's claims themselves. Blind trust is not a desirable trait in an educated, thoughtful populace. Thus, critical examination and questioning are vital components of CIL/CIC education.

Indeed, one of the more profound links between scholarship, professional practice, and civic life is the need to ask the right questions. In academia, this is often framed in terms of research questions: what precisely is the point of the research? What gap in knowledge would answering this question fill? How is a given construct or variable measured, and how will you know when you have successfully answered your questions (Creswell, 2014; O’Leary, 2005)? In professional educational settings, asking the right questions is an essential skill in using data ethically and effectively to make decisions, as well as in promoting social justice change: from whom were these data collected, who was excluded from the data collection, and why? How were the data collection instruments designed and by whom? Why were these variables chosen to measure a given construct as opposed to others? Who made the decision for a certain curriculum content to be included versus others that were excluded, and why? Who is made invisible by these decisions (Datnow \& Park, 2014; Johnson, 2018)?

\section{Conclusion}

In the wide-reaching field of educational research, this study is a small piece of the puzzle of what it means to be an effective educator. At its core, this program and 
dissertation process have taught me that there is no single answer to the big questions in education. Every possible solution has a drawback, and any one program, policy, or author is bound to be incomplete. The answers are found in multiple places; when one approach works in one context, there is another approach that is better suited for a different context. There will always be those who claim to have all the answers, so an attitude of healthy skepticism and critical thought comprise the necessary antidote to falling for bullshit. 


\section{REFERENCES}

AAQEP. (2019a). Association for advancing quality in educator preparation. Retrieved from https://aaqep.org/

AAQEP. (2019b). Guide to AAQEP accreditation. Retrieved from https://aaqep.org/wpcontent/uploads/2019/02/Guide-to-AAQEP-Accreditation-2019.pdf

Affelt, A. (2020, July 1). The coronavirus infodemic. Information Today, 32-34.

Arnold, N. (2013). The role of methods textbooks in providing early training for teaching with technology in the language classroom. Foreign Language Annals, 46(2), $230-245$.

Auberry, K. (2018). Increasing students' ability to identify fake news through information literacy education and content management systems. The Reference Librarian, 59(4), 179-187.

Aybek, B. (2016). The relationship between prospective teachers' media and television literacy and their critical thinking dispositions. Eurasian Journal of Educational Research, 63, 261-278.

Badke, W. E. (2017). The authority crisis, trust, and information literacy. Online Searcher, 41(6), 57-59.

Bales, B. L. (2007). Making it personal: The policy micropolitics of stakeholders in the standards-based teacher education reform effort. Journal of Ethnographic and Qualitative Research, 2, 6-14.

Bauer, H. H. (2014). Anomalistics, pseudo-science, junk science, denialism: Corollaries of the role of science in society. Journal of Scientific Exploration, 28(1), 95-111. 
Bello, M., \& Shaver, A. N. (2011). The representation of Christopher Columbus in high school history textbooks. In E. F. Provenzo Jr., A. N. Shaver, \& M. Bello (Eds.), The textbook as discourse: Sociocultural dimensions of American schoolbooks (pp. 140-161). New York, NY: Routledge.

Berg, C., Phillip, R., \& Taff, S. D. (2019). Critical thinking and transformational learning: Using case studies as narrative frameworks for threshold concepts. Journal of Occupational Therapy Education, 3(3). Retrieved from https://encompass.eku.edu/jote/vol3/iss3/13

Bilos, A. (2019). Emerging focus on fake news issues in scientific research: A preliminary meta- analysis approach. Interdisciplinary Management Research, 15, 1139-1150.

Bocu, A. B., \& Razi, S. (2016). Evaluation of textbook series 'Life' in terms of cultural components. Journal of Language and Linguistic Studies, 12(2), 221-237.

Bogachenko, T., \& Perry, L. (2015). Vospitanie and regime change: Teacher-education textbooks in Soviet and post-Soviet Ukraine. Prospects, 45, 549-562.

Bolman, L. G., \& Deal, T. E. (2013). Reframing organizations: Artistry, choice and leadership (5th ed.). San Francisco, CA: Jossey-Bass.

Bomer, R., Dworin, J. E., May, L., \& Semingson, P. (2008). Miseducating teachers about the poor: A critical analysis of Ruby Payne's claims about poverty. Teachers College Record, 110(12), 2497-2531. 
Brass, A. (2016). Opening up the profession: Inclusive messages for pre-service teachers from a pedagogy textbook. In B. White, M. Chinnappan, \& S. Trenholm (Eds.), Opening Up Mathematics Education Research (Proceedings of the 39th Annual Conference of the Mathematics Education Research Group of Australasia) (pp. 142-149). Adelaide, Australia.

Brass, A., \& Harkness, S. S. (2016). Pre-service and first-year teachers' views on the influence of mathematics methods textbooks. In M. B. Wood, E. E. Turner, M. Civil, \& J. A. Eli (Eds.), North American Chapter of the International Group for the Psychology of Mathematics Education (pp. 720-726). Tucson, AZ: University of Arizona.

Brimble, L. J. F. (1948, May). The exposition of the truth. Bulletin of the Atomic Scientists, 4(5), 141-144.

Brusic, S. A., \& Shearer, K. L. (2014). The ABCs of 21st century skills. Children's Technology \& Engineering, 18(4), 6-10.

Bury, C. (2020, May 1). Artificial intelligence: Adding value or just another buzzword? TVB Europe, 26-27.

CAEP. (2019a). Council for the Accreditation of Educator Preparation. Retrieved from http://caepnet.org/

CAEP. (2019b). 2013 CAEP standards. Retrieved from http://www.ncate.org/ /media/Files/caep/standards/caep-standards-one-pager0219.pdf?la=en

Caled, D., Beyssac, P., Xexeo, G., \& Zimbrao, G. (2016). Buzzword detection in the scientific scenario. Pattern Recognition Letters, 69, 42-48. 
Cairns, R., \& Krzywoszynska, A. (2016). Anatomy of a buzzword: The emergence of 'the water-energy-food nexus' in UK natural resource debates. Environmental Science \& Policy, 64, 164-170.

Calik, M., \& Karatas, F. O. (2019). Does a "science, technology and social change" course improve scientific habits of mind and attitudes toward socio-scientific issues? Australian Journal of Teacher Education, 44(6), 35-52.

Carrino, C. B. (2016). Gatekeepers to success: Missouri's exclusionary approach to school discipline. Washington University Journal of Law and Policy, 52, 171-194.

Casner-Lotto, J. (2006). Are they really ready to work: Employers' perspectives on the basic knowledge and applied skills of new entrants to the 21st century U.S. workforce. New York, NY: The Conference Board.

Chang-Kredl, S. (2015). Constructing childcare in three American comedic films. Child Care in Practice, 21(4), 324-339.

CHEA. (2019). Council for Higher Education Accreditation: CHEA international quality group. Retrieved from https://www.chea.org/

Childers, S. (2003). Computer literacy: Necessity or buzzword? Information Technology \& Libraries, 22(3), 100-104.

Chu, Y. (2017). Twenty years of social studies textbook content analysis: Still "decidedly disappointing"?. The Social Studies, 108(6), 229-241.

Claxton, P. P. (1917). Bureau of Education: Practice teaching for teachers in secondary schools (Bulletin No. 29). Retrieved from https://files.eric.ed.gov/fulltext/ED540891.pdf 
Clow, K. E., Stevens, R. E., \& McConkey, C. W. (2006). Textbook adoption process by marketing professors. Journal for Advancement of Marketing Education, 8, 44-55.

Cochran-Smith, M., Burton, S., Cummings-Carney, M., Sanchez, J. G., \& Miller, A. F. (2017). Review of 'A new agenda: Research to build a better teacher preparation program’. Boulder, CO: National Education Policy Center. Retrieved from https://files.eric.ed.gov/fulltext/ED579507.pdf

CollegeStats. (2019). Biggest colleges in Missouri. CollegeStats.org. Retrieved from https://collegestats.org/colleges/missouri/largest/.

Colston, N. M., \& Thomas, J. (2019). Climate change skeptics teach climate literacy? A critical discourse analysis of children's books. Journal of Science and Communication, 18(4), A02, 1-22.

Cooke, N. A. (2017). Posttruth, truthiness, and alternative facts: Information behavior and critical information consumption for a new age. Library Quarterly: Information, Community, Policy, 87(3), 211-221.

Cope, J. T. (2017). The reconquista student: Critical information literacy, civics, and confronting student intolerance. Communications in Information Literacy, 11(2), 264-282.

Correll, M., Bertini, E., \& Franconeri, S. (2019). Truncating the y-axis: Threat or menace? arXiv of Cornell University. Retrieved from https://arxiv.org/abs/1907.02035v1

Cowhey, M. (2006). Black ants and Buddhists: Thinking critically and teaching differently in the primary grades. Portland, ME: Stenhouse. 
Crawford, K. (2003). The role and purpose of textbooks. International Journal of Historical Learning, Teaching and Research, 3(2), 5-10.

Creswell, J. W. (2014). Research design: Qualitative, quantitative, and mixed methods approaches (4th ed.). Thousand Oaks, CA: Sage.

Crist, C. A., Duncan, S. E., \& Bianchi, L. M. (2017). Incorporation of cross-disciplinary teaching and a wiki research project to engage undergraduate students to develop information literacy, critical thinking, and communication skills. Journal of Food Science Education, 16, 81-91.

Critten, J. (2015). Ideology and critical self-reflection in information literacy instruction. Communications in Information Literacy, 9(1), 145-156.

Datnow, A., \& Park, V. (2014). Data-driven leadership. San Francisco, CA: Jossey-Bass. Davis, M., Lohm, D., Flowers, P., Waller, E., \& Stephenson, N. (2014). “We became sceptics:" Fear and media hype in general public narrative on the advent of pandemic influenza. Sociological Inquiry, 84(4), 499-518.

Dehdar, M., Sayenagi, L., Arbab, E., Arzhandeh, M., Rashanray, M., Raeisi, A., \& Kuhi, L. (2019). Role of schools in educating the active citizen. UTC Journal of Social Sciences and Humanities Research, 7(2), 31-36.

Dewey, J. (1916/2015). Democracy and education. Project Gutenberg Ebooks (\#852). Retrieved from https://www.gutenberg.org/files/852/852-h/852-h.htm Digital Commons. (2019). Communications in information literacy. Retrieved from https://pdxscholar.library.pdx.edu/comminfolit/

Doughty, C. (2018). From here to eternity: Traveling the world to find the good death. New York, NY: W. W. Norton \& Company. 
Ducharme, E. R., \& Ducharme, M. K. (2019). Teacher education: Historical overview, international perspective. The Education Encyclopedia of State University. Retrieved from https://education.stateuniversity.com/pages/2479/TeacherEducation.html

Dunaway, M. K. (2011). Connectivism: Learning theory and pedagogical practice for networked information landscapes. Reference Services Review, 39(4), 675-685.

Dyer, J. (2017). Can news literacy be taught? Nieman Reports, Spring 2017, 8-12.

Educational Testing Services. (2020). The Praxis tests. Retrieved from https://www.ets.org/praxis/states_agencies/?WT.ac=praxishome_praxisstateageng cies_180911

El Rayess, M., Chebl, C., Mhanna, J., \& Hage, R. M. (2018). Fake news judgement: The case of undergraduate students at Notre Dame University-Louaize, Lebanon. Reference Services Review, 46(1), 146-159.

Erceg, N., Galic, Z., \& Bubic, A. (2019). "Dysrationalia" among university students: The role of cognitive abilities, different aspects of rational thought and self-control in explaining epistemically suspect beliefs. Europe's Journal of Psychology, 15(1), $159-175$.

Eriandsson, A., Nilsson, A., Tinghog, G., \& Vastfjall, D. (2018). Bullshit-sensitivity predicts prosocial behavior. PLOS ONE, 13(7), 1-12. 
Ferraro, M. F., \& Chipman, J. C. (2019, February 8). Fake news threatens our businesses, not just our politics. The Washington Post. Retrieved from https://www.washingtonpost.com/outlook/fake-news-threatens-our-businessesnot-just-our-politics/2019/02/08/f669b62c-2b1f-11e9-984d-

9b8fba003e81_story.html?noredirect=on\&utm_term=.90041f6371f1

Field, A. (2018). Discovering statistics using IBM SPSS statistics. Thousand Oaks, CA: Sage.

Flores-Koulish, S. A., \& Deal, D. (2008). Reacting to change: Critical media literacy for United States reading teachers? Simile, 8(3), 1-14.

Folk, A. L. (2019). Reframing information literacy as academic cultural capital: A critical and equity-based foundation for practice, assessment, and scholarship. College and Research Libraries, 80(5), 658-673.

Foster-Kaufman, A. (2019). Wikipedia-based assignments and critical information literacy: A case study. In A. Pashia \& J. Critten (Eds.), Critical Approaches to Credit-Bearing Information Literacy Courses (pp. 271-294). Chicago, IL: Association of College and Research Libraries.

Frankfurt, H. G. (2005). On bullshit. Princeton, NJ: Princeton University Press.

Frau-Meigs, D. (2019). Information disorders: Risks and opportunities for digital media and information literacy? Media Studies, 10(19), 10-28.

Freire, P. (1993). Pedagogy of the oppressed. London, UK: Penguin Classics. (Original work published 1970) 
Fulkerson, D. M., Ariew, S. A., \& Jacobson, T. E. (2017). Revisiting metacognition and metaliteracy in the ACRL framework. Communications in Information Literacy, 11(1), 21-41.

Garcia-Marin, D. (2020). Global infodemic: Information disorders, false narratives, and fact checking during the Covid-19 crisis. El Profesional de la información, 29(4), 1-20.

Garrido, M., Fellows, M., \& Norlander, B. (2019). Progressing toward meaningful A2I, and emerging threats. In International Federation of Library Associations and Institutions, Development and Access to Information 2019 (pp. 3-16). Retrieved from https://da2i.ifla.org/da2i-report-2019/

Giroux, H. A., \& Pollock, G. (2010). The mouse that roared: Disney and the end of innocence. Lanham, MD: Rowman \& Littlefield.

Goyette, K. A. (2017). Education in America. Oakland, CA: University of California Press.

Grambo, K. (2019). Fake news and racial, ethnic, and religious minorities: A precarious quest for truth. Journal of Constitutional Law, 21(5), 1299-1348.

Greenberg, J., Putman, H., \& Walsh, K. (2014). Training our future teachers: Classroom management. National Council on Teacher Quality. Retrieved from https://files.eric.ed.gov/fulltext/ED556312.pdf

Gretter, S., Yadav, A., \& Gleason, B. (2016). Computational thinking and media \& information literacy: An integrated approach to teaching twenty-first century skills. TechTrends, 60, 510-516. 
Gretter, S., Yadav, A., \& Gleason, B. (2017). Walking the line between reality and fiction in online spaces: Understanding the effects of narrative transportation. Journal of Media Literacy Education, 9(1), 1-21.

Grigoryan, A., \& King, J. M. (2008). Adbusting: Critical media literacy in a multi-skills academic writing lesson. English Teaching Forum, 4, 2-9.

Gross-Klussmann, A., Koenig, S., \& Ebner, M. (2019). Buzzwords build momentum: Global financial Twitter sentiment and the aggregate stock market. Expert Systems with Applications, 136, 171-186.

Grotluschen, A., Buddeberg, K., Redmer, A., Ansen, H., \& Dannath, J. (2019). Vulnerable subgroups and numeracy practices: How poverty, debt, and unemployment relate to everyday numeracy practices. Adult Education Quarterly, 69(4), 251-270.

Grzanka, P. R. (2020). From buzzword to critical psychology: An invitation to take intersectionality seriously. Women \& Therapy, 43(3/4), 244-261.

Gutstein, E. R. (2013). Rethink mathematics and its intersection with race. In E. R. Gutstein \& B. Peterson (Eds.), Rethinking Mathematics: Teaching Social Justice by the Numbers (2nd Ed.) (pp. 26-29). Milwaukee, WI: Rethinking Schools.

Hall, G. E., Quinn, L. F., \& Gollnick, D. M. (2020). Introduction to teaching: Making a difference in student learning. Thousand Oaks, CA: Sage.

Hardos, P. (2019). Lee McIntyre: Post-truth [Book review]. Organon F, 26(2), 311-316.

Harkness, S. S., \& Brass, A. (2017). Selecting and using mathematics methods texts: Nontrivial tasks. The Mathematics Educator, 26(2), 82-105. 
Harris, S. (Producer), \& Levin, C. (Director). (2001). Only a teacher [Motion picture]. United States of America: PBS.

Harshman, J. (2017). Developing globally minded, critical media literacy skills. Journal of Social Studies Education Research, 8(1), 69-92.

Higgins, J. W., \& Begoray, D. (2012). Exploring the borderlands between media and health: Conceptualizing 'critical media health literacy'. Journal of Media Literacy Education, 4(2), 136-148.

Holbrook, M. B. (2005). Marketing miseducation and the MBA mind: Bullshit happens. Marketing Education Review, 15(3), 1-5.

Hollis, H. (2019, June). Information literacy and critical thinking: Different concepts, shared conceptions. Paper presented at Conceptions of Library and Information Science 10th International Conference, Ljubljana, Slovenia. Retrieved from http://discovery.ucl.ac.uk/10074076/

Hootnick, A. (2014). Teach for America's growing pains. The Nation, 298(18), 22-25.

Ingersoll, R. M., \& Smith, T. M. (2003). The wrong solution to the teacher shortage. Educational Leadership, 60(8), 30-33.

Is “What's printed true?". (1917, February). America, 16(19), 450.

Iwuanyanwu, P. N. (2019). What we teach in science, and what learners learn: A gap that needs bridging. Pedagogical Research, 4(2), 1-12.

Jacobson, T. E., \& Mackey, T. P. (2013). Proposing a metaliteracy model to redefine information literacy. Communications in Information Literacy, 7(2), 84-91.

Joanou, J. P. (2017). Examining the world around us: Critical media literacy in teacher education. Multicultural Perspectives, 19(1), 40-46. 
Johansson, V., \& Limberg, L. (2017). Seeking critical literacies in information practices: Reconceptualising critical literacy as situated and tool-mediated enactments of meaning. Information Research, 22(1), 1-16.

Johnson, A. G. (2018). Privilege, power, and difference (3rd ed.). New York, NY: McGraw-Hill.

Johnson, M. (2018). Fighting "fake news": How we overhauled our website evaluation lessons. Knowledge Quest, 47(1), 32-36.

Jones, S. P., Pearman, C. J., \& Sheffield, E. C. (Eds.). (2007). Why kids hate school. Dubuque, IA: Kendall Hunt.

Joseph, P. B., \& Burnaford, G. E. (Eds.). (2009). Images of schoolteachers in America (2nd ed.). Mahwah, NJ: Taylor \& Francis.

Kalsnes, B. (2018). Fake news. Oxford Research Encyclopedia of Communication. DOI: 10.1093/acrefore/9780190228613.013.809

Kedar, H. E. (2019). Fake news in media art: Fake news as media art practice vs fake news in politics. Postdigital Science and Education, 2, 132-146.

Kellner, D., \& Share, J. (2005). Toward critical media literacy: Core concepts, debates, organizations, and policy. Discourse: Studies in the Cultural Politics of Education, 26(3), 369-386.

Khan, N. (2017). Adaptive or transactional leadership in current higher education: A brief comparison. International Review of Research in Open and Distributed Learning, 18(3), 178-183. 
Klitmoller, J. (2016). Educational practice, student experience, and the purpose of education: A critique of 'pedagogy in practice'. Oxford Review of Education, 42(6), 646-660.

Kovalik, C. L., Jensen, M. E., Schloman, B., \& Tipton, M. (2010). Information literacy, collaboration, and teacher education. Communications in Information Literacy, 4(2), 145-168.

Kraft, J., Schmiesing, D., \& Phillips, S. (2016). Critical thinking: From buzzword to action. Children's Technology and Engineering, 20(4), 16-19.

Kurup, P. M., Li, X., Powell, G., \& Brown, M. (2019). Building future primary teachers' capacity in STEM based on a platform of beliefs, understandings and intentions. International Journal of STEM Education, 6(10), 1-14.

Labaree, D. (2008). An uneasy relationship: The history of teacher education in the university. In M. Cochran-Smith, S. Feiman-Nemser, J. McIntyre, \& K. Demers (Eds.), Handbook of research on teacher education (3rd ed., pp. 290-306). New York: Routledge.

Lawal, V. (2019). Critical information literacy and participatory democracy: An analysis of the role of libraries in Jos Metropolis, Plateau State. Library Philosophy and Practice (e-journal), 2637, https://digitalcommons.unl.edu/libphilprac/2637

Le, T., \& Le, Q. (2009a). Critical discourse analysis: An overview. In T. Le, Q. Le, \& M. Short (Eds.), Critical discourse analysis: An interdisciplinary perspective (pp. 315). New York, NY: Nova Science Publishers. 
Le, Q., \& Le, T. (2009b). Being self-critical in research as a meaning-making process. In T. Le, Q. Le, \& M. Short (Eds.), Critical discourse analysis: An interdisciplinary perspective (pp. 91-98). New York, NY: Nova.

Lee, A., \& Otsuji, E. (2009). Critical discourse analysis and the problem of methodology. In T. Le, Q. Le, \& M. Short (Eds.), Critical discourse analysis: An interdisciplinary perspective (pp. 65-77). New York, NY: Nova.

Lee, N. M. (2018). Fake news, phishing, and fraud: A call for research on digital media literacy education beyond the classroom. Communication Education, 67(4), 460466.

Leitner, G. (2019). Introduction. In International Federation of Library Associations and Institutions, Development and Access to Information 2019 (pp. ii-v). Retrieved from https://da2i.ifla.org/da2i-report-2019/

Levin, S., Sidanius, J., Rabinowitz, J. L., \& Federico, J. (1998). Ethnic identity, legitimizing ideologies, and social status: A matter of ideological asymmetry. Political Psychology, 19(2), 373-404.

Levitt, S. D., \& Dubner, S. J. (2014). Think like a freak: Secrets of the rogue economist. London, UK: Penguin.

Locke, T. (2004). Critical discourse analysis. New York, NY: Continuum.

Lopez-Medina, B. (2016). Developing a CLIL textbook evaluation checklist. LACLIL, 9(1), 159-173.

Lubell, S., Drake, G., \& Putman, H. (2017). Landscapes in teacher prep: Undergraduate secondary. National Council on Teacher Quality. Retrieved from https://files.eric.ed.gov/fulltext/ED590847.pdf 
Ma, J., Li, C., \& Liang, H. N. (2019). Enhancing students' blended learning experience through embedding metaliteracy. Education Research International, 2019, 1-8.

Magnus, E., Faber, M., \& Belanger, J. (2019). A consideration of power structures (and the tensions they create) in library assessment activities. Library Assessment Conference: Building Effective, Sustainable, Practical Assessment. Retrieved from https://www.researchgate.net/publication/336574179_A_Consideration_of_Power _Structures_and_the_Tensions_They_Create_in_Library_Assessment_Activities

Martel, C., Pennycook, G., and Rand, D. G. (2019). Reliance on emotion promotes belief in fake news. Unpublished manuscript, Department of Psychology, Yale University, New Haven, CT.

McBain, B., Yardy, A., Martin, F., Tose, H., Phelan, L., Van Altenaa, I., McKeowen, J., Pemberton, C., Fratus, L., \& Bowyer, M. (2019). Avoiding the science stupidity trap. Proceedings of the Australian Conference on Science and Mathematics Education (pp. 155-161), Sydney, Australia: The University of Sydney.

McGrew, S., Ortega, T., Breakstone, J., \& Wineburg, S. (2017). That challenge that's bigger than fake news: Civic reasoning in a social media environment. American Educator, Fall 2017, 4-10.

McLaughlin, J. A., \& Jordan, G. B. (2015). Using logic models. In K. E. Newcomer, H. P. Hatry, \& J. S. Wholey (Eds.), Handbook of Practical Program Evaluation (4th ed.). Hoboken, NJ: Wiley.

McMillan, C. (2018). 'I've learned to question everything': Critical thinking, or, the pedagogical logic of late capitalism. Journal for Critical Education Policy Studies, 16(1), 1-29. 
McPhetres, J., \& Pennycook, G. (2019). Science beliefs, political ideology, and cognitive sophistication. OSFPreprints. Retrieved from https://osf.io/ad9v7/

Merriam, S. B., \& Tisdell, E. J. (2016). Qualitative research: A guide to design and implementation (4th ed.). San Francisco, CA: Jossey-Bass.

Meyer, S. J. (2016). Understanding field experiences in traditional teacher preparation programs in Missouri. REL 2016-145. U.S. Department of Education: The National Center for Education Evaluation and Regional Assistance. Retrieved from https://files.eric.ed.gov/fulltext/ED566957.pdf

Misak, C. (2008). Pragmatism on solidarity, bullshit, and other deformities of truth. Midwest Studies in Philosophy, 32, 111-121.

Mitchel, A. L., \& King, M. S. (2016). A new agenda: Research to build a better teacher preparation program. Bellwether Education Partners. Retrieved from https://files.eric.ed.gov/fulltext/ED577709.pdf

Mogashoa, T. (2014). Understanding critical discourse analysis in qualitative research. International Journal of Humanities Social Sciences and Education, 1(7), 104113.

Molina, M. D., Sundar, S. S., Le, T., \& Lee, D. (2019). "Fake news" is not simply false information: A concept explication and taxonomy of online content. American Behavioral Scientist, 63(11), 1-33.

Montague, M. (2002). Improving the preparation of personnel to serve children with high-incidence disabilities: Learning, emotional, and behavioral disabilities teacher preparation program (LEBD) final report. Retrieved from https://files.eric.ed.gov/fulltext/ED477880.pdf 
Moral Instruction in Public Schools. (1882). Education, 2(3), 253.

Morrell, E. (2012). 21st-century literacies, critical media pedagogies, and language arts. The Reading Teacher, 66(4), 300-302.

Mott-Stenerson, B. (2005). "The humbuggery of bullshit" vs. "the scholarship of teaching": Perspective from a newly minted Ph.D. Marketing Education Review, 15(3), 7-10.

Muniz-Velasquez, J. A., \& Delmar, J. L. (2019). The fake first round about the Earth: The case of the supposed Chinese circumnavigation of 1421 from the post-truth paradigm. Revista Latina de Comunicacion Social, 74, 950-968.

Neuman, Y., Nave, O., \& Dolev, E. (2011). Buzzwords on their way to a tipping-point: A view from the blogosphere. Complexity, 16(4), 58-68.

Nguyen, H. (2018). Teacher preparation programs in the United States. International Journal of Progressive Education, 14(3), 76-92.

Nicholls, J. (2003). Methods in school textbook research. International Journal of Historical Learning, Teaching and Research, 3(2), 11-26.

Northouse, P. G. (2016). Leadership: Theory and practice (7th ed.). Thousand Oaks, CA: Sage.

O’Keeffe, L., \& O’Donoghue, J. (2015). A role for language analysis in mathematics textbook analysis. International Journal of Science and Mathematics Education, $13,605-630$.

O'Leary, Z. (2005). Researching real-world problems: A guide to methods of inquiry. Thousand Oaks, CA: Sage. 
Oleskeviciene, G. V., Puksas, A., Gulbinskiene, D., \& Mockiene, L. (2019). Student experience on the development of transversal skills in university studies. Pedagogika/Pedagogy, 133(1), 63-77.

Oliphant, T. (2019). The self and others: Revisiting information needs and libraries as public, social institutions in a post-truth world. Open Information Science, 3, 261273.

Orlowski, P. (2006). Educating in an era of Orwellian spin: Critical media literacy in the classroom. Canadian Journal of Education, 29(1), 176-198.

Ornstein, A. C., \& Levine, D. U. (2002). Foundations of education (8th Ed.). Boston, MA: Houghton Mifflin.

O’Sullivan, M., \& Scott, T. (2000). Teaching internet information literacy: A critical evaluation. Multimedia Schools, 7(2), 40-43.

Palmer, G. H., \& Palmer, A. F. (1908). The teacher: Essays and addresses on education. New York, NY: Houghton Mifflin.

Patton, M. Q. (2008). Utilization-focused evaluation (4th ed.). Thousand Oaks, CA: Sage. Pennycook, G., Cheyne, J. A., Barr, N., Koehler, D. J., \& Fugelsang, J. A. (2015). On the reception and detection of pseudo-profound bullshit. Judgment and Decision Making, 10(6), 549-563.

Pennycook, G., \& Rand, D. G. (2018a). Who falls for fake news? The roles of bullshit receptivity, overclaiming, familiarity, and analytic thinking. Journal of Personality. Retrieved from https://papers.ssrn.com/sol3/papers.cfm?abstract_id=3023545 
Pennycook, G., \& Rand, D. G. (2018b). Lazy, not biased: Susceptibility to partisan fake news is better explained by lack of reasoning than by motivated reasoning. Cognition, 188(30), 39-50.

Pfattheicher, S., \& Schindler, S. (2016). Misperceiving bullshit as profound is associated with favorable views of Cruz, Rubio, Trump and Conservatism. PLoS ONE, 11(4), 1-7.

Pinto, M., Cordon, J. A., \& Diaz, R. G. (2010). Thirty years of information literacy (1977-2007): A terminological, conceptual, and statistical analysis. Journal of Librarianship and Information Science, 42(1), 3-19.

Pomerance, L., Greenberg, J., \& Walsh, K. (2016). Learning about learning: What every new teacher needs to know. Washington, DC: National Council on Teacher Quality.

Porterfield, J. M. (2018). Overcoming challenges to critical information literacy: Primary source analysis as consciousness-raising. Pennsylvania Libraries: Research \& Practice, 6(2), 106-112.

Prichett, A. (2019). Missouri higher education core transfer curriculum (Core 42). Retrieved from https://dhewd.mo.gov/core42.php

Rahman, M. M. (2019). 21st century skill "problem solving”: Defining the concept. Asian Journal of Interdisciplinary Research, 2(1), 71-81.

Rainie, L., \& Anderson, J. (2017, May 3). The future of jobs and jobs training. Report from the Pew Research Center. Retrieved from https://www.pewinternet.org/2017/05/03/the-future-of-jobs-and-jobs-training/ 
Ravitch, D. (2007). EdSpeak: A glossary of education term, phrases, buzzwords, and jargon. Alexandria, VA: Association for Supervision and Curriculum Development.

Rezaee, P., \& Hashemi, A. (2017). English textbook evaluation in EFL classrooms: A critical approach. Proceedings of the 15th International TELLSI Conference, Iran. Retrieved from http://tellsi15.conference.riau.ac.ir/Files/News/Rezaee\%20\&\%20Hashemi.pdf

Rheingold, H. (2012). Stewards of digital literacies. Knowledge Quest, 41(1), 52-55.

Rodesiler, L. (2010). Empowering students through critical media literacy: This means war. The Clearing House, 83, 164-167.

Rogers, R. \& Schaenen, I. (2013). Critical discourse analysis in literacy education: A review of the literature. Reading Research Quarterly, 49(1), 121-143.

Ross, R. M., Rand, D. G., \& Pennycook, G. (2019). Beyond "fake news:" The role of analytic thinking in the detection of inaccuracy and partisan bias in news headlines. Unpublished manuscript, Department of Philosophy, Macquarie University, Sydney, Australia.

Rothman, R. (2012). A common core of readiness. Educational Leadership, 69(7), 10-15. RSA Animate (Producer). (2010, October 14). Changing education paradigms [Video file]. Retrieved from https://www.youtube.com/watch?v=zDZFcDGpL4U

Ruswick, B. (2015). What does it mean to be an American? Training history students and prospective teachers to see the assumptions in their textbooks. The History Teacher, 48(4), 667-692. 
Rymarz, R. M., and Engebretson, K. (2005). Putting textbooks to work: Empowering religious education teachers. British Journal of Religious Education, 27(1), 53-63.

Saglam, A. C., Cankaya, I., Ucer, H., \& Cetin, M. (2017). The effect of information literacy on teachers' critical thinking disposition. Journal of Education and Learning, 6(3), 31-40.

Schildkamp, K., Poortman, C. L., Ebbeler, J., \& Pieters, J. M. (2019). How school leaders can build effective data teams: Five building blocks for a new wave of datainformed decision making. Journal of Educational Change, 20(3), 283-325.

Serenko, A., Bontis, N., \& Moshonsky, M. (2012). Books as a knowledge translation mechanism: citation analysis and author survey. Journal of Knowledge Management, 16(3), 495-511.

Shaffer, K. (2019). Data versus democracy: How big data algorithms shape opinions and alter the course of history. New York, NY: Apress.

Shang, S., \& Petrocelli, J. V. (2019, May). Bullshitting, fast and slow: How lay beliefs of speed affect self-perceptions of bullshit behavior. Poster session presented at the 2019 WFU First Year Colloquium, Wake Forest University. Retrieved from http://samanthaxshang.com/wp-content/uploads/2019/05/FYP-2019_Bullshittingfast-and-slow.pdf

Short, M. (2009). Performance anxieties: Grammar and teacher identity. In T. Le, Q. Le, \& M. Short (Eds.), Critical discourse analysis: An interdisciplinary perspective (pp. 151-161). New York, NY: Nova. 
Sileo, T. W., \& Prater, M. A. (1998). Preparing professionals for partnerships with parents of students with disabilities: textbook considerations regarding cultural diversity. Exceptional Children, 64(4), 513-528.

Simmons, M. H. (2005). Librarians as disciplinary discourse mediators: Using genre theory to move toward critical information literacy. Librarians and the Academy, 5(3), 297-311.

Simons, M., Meeus, W., \& T’Sas, J. (2017). Measuring media literacy for media education: Development of a questionnaire for teachers' competencies. Journal of Media Literacy Education, 9(1), 99-115.

Sinclair, C. (2019). Parody: Fake news, regeneration and education. Postdigital Science and Education, 2, 61-77.

Soltys, S., \& McClintlock, S. (2014). Freakatistics: Discussion assignments for the statistics classroom. PRIMUS, 24(1), 81-94.

Sommariva, S., Vamos, C., Mantzarlis, A., Doa, L. U. L., \& Tyson, D. M. (2018). Spreading the (fake) news: Exploring health messages on social media and the implications for health professionals using a case study. American Journal of Health Education, 49(4), 246-255.

Song, A. Y. (2017). Critical media literacies in the twenty-first century: writing autoethnographies, making connections, and creating virtual identities. Journal of Media Literacy Education, 9(1), 64-78.

Sparke, M. (2018). Textbooks as opportunities for interdisciplinarity and planetarity. Area, 50, 59-62. 
Sperry, C. (2012). Teaching critical thinking through media literacy. Science Scope, 35(9), 56-60.

Stahl, B. C. (2006). On the difference or equality of information, misinformation, and disinformation: A critical research perspective. Informing Science Journal, 9, 8396.

Steinmetz, K. (2018, August). The real fake news crisis. Time, 192(7), 26-31.

Sterling, J., Jost, J. T., \& Pennycook, G. (2016). Are neoliberals more susceptible to bullshit? Judgment and Decision Making, 11(4), 352-360.

Stix, G. (2011). How to build a better learner. Scientific American, 305(2), 50-57.

Stoll, J. D. (2020, May 1). Sustainability was corporate America's buzzword. This crisis changes that. The Wall Street Journal [online edition]. Retrieved from https://www.wsj.com/articles/sustainability-was-corporate-americas-buzzwordthis-crisis-changes-that-11588352181

Sterling, J., Jost, J. T., \& Pennycook, G. (2016). Are neoliberals more susceptible to bullshit? Judgment and Decision Making, 11(4), 352-360.

Stoll, J. D. (2020, May 1). Sustainability was corporate America's buzzword. This crisis changes that. The Wall Street Journal [online edition]. Retrieved from https://www.wsj.com/articles/sustainability-was-corporate-americas-buzzwordthis-crisis-changes-that-11588352181

Storksdieck, M. (2016). Critical information literacy as core skill for lifelong STEM learning in the 21st century: reflections on the desirability and feasibility for widespread science media education. Cultural Studies of Science Education, 11(1), 167-182. 
Subreenduth, S. (2013). Insidious colonialism in post-apartheid education: Interplay of black teacher narratives, educational policy and textbook analysis. Qualitative Research in Education, 2(3), 213-241.

Suckow, M. A. (2018). Annual report card on California teacher preparation programs for the academic year 2016-2017 as required by title II of the Higher Education Act. California Commission on Teacher Credentialing. Retrieved from https://files.eric.ed.gov/fulltext/ED592981.pdf

Suranna, K. J., \& Moss, D. M. (2002). Exploring teacher leadership in the context of teacher preparation. Paper presented at the 83rd annual American Educational Research Association Meeting, New Orleans, LA.

Sweet, C. A., Shermak, T., \& Swanson, J. (2019). "You shall listen to all sides and filter them from yourself': Information literacy and post-truth skepticism. In A. P. Baer, R. Schroeder, \& E. S. Cahoy (Eds.), Libraries Promoting Reflective Dialogue in a Time of Political Polarization (pp. 91-111). Chicago, IL: Association of College and Research Libraries.

Taylor \& Francis Group. (2019). Aims and scope. Discourse: Studies in the Cultural Politics of Education. Retrieved from https://www.tandfonline.com/action/journalInformation?show=aimsScope\&journ alCode $=\operatorname{cdis} 20$

Taylor \& Francis Online. (2019). Action in teacher education: Aims and scope. Retrieved from https://www.tandfonline.com/action/journalInformation?show=aimsScope \&journalCode $=$ uate 20 
Tornberg, P. (2018). Echo chambers and viral misinformation: Modeling fake news as complex contagion. PLoS ONE, 13(9), 1-21.

Trujillo, T., \& Scott, J. (2014). Superheroes and transformers: rethinking Teach for America's leadership models. Phi Delta Kappan, 95(8), 57-61.

University Registrar. (2019). 2019-20 catalogs: Learning, teaching and curriculum. University of Missouri. Retrieved from http://catalog.missouri.edu/undergraduategraduate/collegeofeducation/learningtea chingandcurriculum/\#courseinventory.

U.S. Department of Education. (2019). U.S. Department of Education. Retrieved from https://www.ed.gov/

Vitucci, R., \& Brown, M. (2019). Cultivating teacher leaders: A union-led effort connects classroom practice to education policy. American Educator, 43(1), 4-11.

Wakefield, J. F. (1998, June). A brief history of textbooks: Where have we been all these years? Paper presented at the Meeting of Text and Academic Authors, St.

Petersburg, FL. Retrieved from https://files.eric.ed.gov/fulltext/ED419246.pdf

Walker, A. C., Stange, M., Dixon, M. J., Koehler, D. J., \& Fugelsang, J. A. (2019). Graphical depiction of statistical information improves gambling-related judgements. Journal of Gambling Studies, https://doi.org/10.1007/s10899-01909860-1

Warburton, T. (2016). Turning the lens: Reflexivity in research and teaching with critical discourse analysis. Critical Questions in Education, 7(3), 249-267. 
Weiland, T. (2016). Towards a framework for a critical statistical literacy in high school mathematics. In M. B. Wood, E. E. Turner, M. Civil, \& J. A. Eli (Eds.), Proceedings of the 38th Annual Meeting of the North American Chapter of the International Group for the Psychology of Mathematics Education (pp.984-991), Tucson, AZ: University of Arizona.

Weiland, T. (2017). Problematizing statistical literacy: An intersection of critical and statistical literacies. Educational Studies in Mathematics, 96, 33-47.

Wells, C. M. (2010). Preparing superintendents for building teacher leadership: Implications for university programs. The International Journal of Educational Leadership Preparation, 5(2), 1-9.

Wiggan, G., Scott, S., Watson, M., \& Reynolds, R. (2014). Unshackled: Education for freedom, student achievement, and personal emancipation. Boston, MA: Sense.

Winter, S. (2001). Ontology: buzzword or paradigm shift in GL science? International Journal of Geographical Information Science, 15(7), 587-590.

Woodward, S., Lloyd, A., \& Kimmons, R. (2017). Student voice in textbook evaluation: Comparing open and restricted textbooks. International Review of Research in Open and Distributed Learning, 18(6), 150-163. 
World Health Organization. (2020, September 23). Managing the COVID-19 infodemic: Promoting healthy behaviours and mitigating the harm from misinformation and disinformation [Joint statement by WHO, UN, UNICEF, UNDP, UNESCO, UNAIDS, ITU, UN Global Pulse, and IFRC]. Retrieved from https://www.who.int/news-room/detail/23-09-2020-managing-the-covid-19infodemic-promoting-healthy-behaviours-and-mitigating-the-harm-frommisinformation-and-disinformation

Yamashita, L., \& Robinson, D. (2015). Making visible the people who feed us: Educating for critical food literacy through multicultural texts. Journal of Agriculture, Food Systems, and Community Development, 6(2), 269-281.

Yang, K. W. (2009). Mathematics, critical literacy, and youth participatory action research. New Directions for Youth Development, 123, 99-118.

Yanzi, H., Hidayat, O. T., Mentari, A., \& Budimansyah, D. (2019). Global citizens’ awareness through digital literacy in the fourth industrial revolution: A review of the literature. Advances in Social Science, Education and Humanities Research, 317, 65-69.

Yoo, K. (2019). Behavioral and structural remedies for cognitive bias on legal information: The evolving role of law libraries and enhanced integrated library systems design. AALL/LexisNexis Call for Papers, summer 2019 winner. Retrieved from https://works.bepress.com/aallcallforpapers/103/

Zittleman, K., \& Sadker, D. (2002). Teacher education textbooks: The unfinished gender revolution. Educational Leadership, 60(4), 59-63. 


\section{APPENDICES}

\section{Appendix A}

\section{Preliminary Data Collection: Largest Public Universities by State and their}

Foundations of Education Courses

\begin{tabular}{|c|c|c|}
\hline State & $\begin{array}{l}\text { Largest Public University (by } \\
\text { Enrollment), } 2019\end{array}$ & $\begin{array}{l}\text { Education/Foundations } \\
\text { Course (Code: Title) }\end{array}$ \\
\hline Alabama & University of Alabama at Tuscaloosa & $\begin{array}{l}\text { EDU 200: Education as a } \\
\text { Profession }\end{array}$ \\
\hline Alaska & University of Alaska Anchorage & $\begin{array}{l}\text { (UAA lost CAEP } \\
\text { accreditation - program } \\
\text { transferred to UA } \\
\text { Fairbanks) } \\
\text { ED F201: } \\
\text { Introduction to Education }\end{array}$ \\
\hline Arizona & Arizona State University Tempe & $\begin{array}{l}\text { SPF 301: Culture and } \\
\text { Schooling }\end{array}$ \\
\hline Arkansas & University of Arkansas Fayetteville & $\begin{array}{l}\text { CIED 1013: Introduction to } \\
\text { Education }\end{array}$ \\
\hline California & University of California Los Angeles & $\begin{array}{l}\text { Education 10: } \\
\text { Introduction to Educational } \\
\text { Issues and Scholarship }\end{array}$ \\
\hline Colorado & University of Colorado Boulder & $\begin{array}{l}\text { EDUC 3013: School and } \\
\text { Society }\end{array}$ \\
\hline Connecticut & University of Connecticut Storrs & $\begin{array}{l}\text { EDCI 2100: } \\
\text { Power, Privilege, and } \\
\text { Public Education }\end{array}$ \\
\hline Delaware & University of Delaware Newark & $\begin{array}{l}\text { EDUC 247: } \\
\text { History of Education in } \\
\text { America }\end{array}$ \\
\hline
\end{tabular}




\begin{tabular}{|c|c|c|}
\hline $\begin{array}{l}\text { District of } \\
\text { Columbia }\end{array}$ & University of the District of Columbia & $\begin{array}{l}\text { ELED 220: Foundations of } \\
\text { Education }\end{array}$ \\
\hline Florida & Miami Dade College & $\begin{array}{l}\text { EDF 1005: Introduction to } \\
\text { the Teaching Profession }\end{array}$ \\
\hline Georgia & University of Georgia Athens & $\begin{array}{l}\text { EDUC 2110: Investigating } \\
\text { Critical and Contemporary } \\
\text { Issues in Education }\end{array}$ \\
\hline Hawaii & University of Hawai'i at Manoa & $\begin{array}{l}\text { EDEF 310: Education in } \\
\text { American Society }\end{array}$ \\
\hline Idaho & Boise State University & $\begin{array}{l}\text { ED-CIFS 201: Foundations } \\
\text { of Education }\end{array}$ \\
\hline Illinois & $\begin{array}{l}\text { University of Illinois at Urbana- } \\
\text { Champaign }\end{array}$ & $\begin{array}{l}\text { EDUC 201: Identity and } \\
\text { Difference in Education }\end{array}$ \\
\hline Indiana & Indiana University Bloomington & $\begin{array}{l}\text { EDUC-M 300: Teaching in } \\
\text { a Pluralistic Society }\end{array}$ \\
\hline Iowa & Iowa State University Ames & $\begin{array}{l}\text { EDUC 204: Social } \\
\text { Foundations of Education } \\
\text { in the United States }\end{array}$ \\
\hline Kansas & University of Kansas Lawrence & $\begin{array}{l}\text { C\&T 100: } \\
\text { Introduction to the } \\
\text { Education Profession }\end{array}$ \\
\hline Kentucky & University of Kentucky Lexington & $\begin{array}{l}\text { EPE 301: Education in } \\
\text { American Culture }\end{array}$ \\
\hline Louisiana & Louisiana State University & $\begin{array}{l}\text { EDCI 2001: Education, } \\
\text { Schooling, and Society }\end{array}$ \\
\hline Maine & University of Maine Orono & $\begin{array}{l}\text { EHD 202: Education in a } \\
\text { Multicultural Society }\end{array}$ \\
\hline Maryland & $\begin{array}{l}\text { University of Maryland University } \\
\text { College }\end{array}$ & $\begin{array}{l}\text { No undergrad teacher prep } \\
\text { program }\end{array}$ \\
\hline Massachusetts & University of Massachusetts Amherst & $\begin{array}{l}\text { 351: Foundations of } \\
\text { Education }\end{array}$ \\
\hline
\end{tabular}




\begin{tabular}{|c|c|c|}
\hline Michigan & Michigan State University & $\begin{array}{l}\text { TE 201: Current Issues in } \\
\text { Education }\end{array}$ \\
\hline Minnesota & University of Minnesota, Twin Cities & $\begin{array}{l}\text { CI 1121: Educational } \\
\text { Movements Past and } \\
\text { Present: Multicultural } \\
\text { Perspectives }\end{array}$ \\
\hline Mississippi & University of Mississippi (Ole Miss) & $\begin{array}{l}\text { EDCI 352: Education, } \\
\text { Society, \& the K-12 } \\
\text { Learner }\end{array}$ \\
\hline Missouri & University of Missouri, Columbia & $\begin{array}{l}\text { LTC 2040: Inquiry into } \\
\text { Schools, Community, and } \\
\text { Society I }\end{array}$ \\
\hline Montana & Montana State University & $\begin{array}{l}\text { EDU 101US: Teaching and } \\
\text { Learning }\end{array}$ \\
\hline Nebraska & University of Nebraska, Lincoln & $\begin{array}{l}\text { EDPS 121: U.S. Education } \\
\text { in the Age of Globalization }\end{array}$ \\
\hline Nevada & University of Nevada, Las Vegas & $\begin{array}{l}\text { EDU 202: Introduction to } \\
\text { Secondary Education }\end{array}$ \\
\hline $\begin{array}{l}\text { New } \\
\text { Hampshire }\end{array}$ & $\begin{array}{l}\text { University of New Hampshire, } \\
\text { Durham }\end{array}$ & $\begin{array}{l}\text { EDUC 402: Introduction to } \\
\text { Educational Studies }\end{array}$ \\
\hline New Jersey & Rutgers University & $\begin{array}{l}\text { GSE } \\
\text { 5:300:200: Introduction to } \\
\text { Education }\end{array}$ \\
\hline New Mexico & $\begin{array}{l}\text { University of New Mexico, } \\
\text { Albuquerque }\end{array}$ & $\begin{array}{l}\text { EDUC 1120: Introduction } \\
\text { to Education }\end{array}$ \\
\hline New York & New York University & $\begin{array}{l}\text { HSED.UE.1005: } \\
\text { Introduction to Education }\end{array}$ \\
\hline $\begin{array}{l}\text { North } \\
\text { Carolina }\end{array}$ & $\begin{array}{l}\text { North Carolina State University at } \\
\text { Raleigh }\end{array}$ & $\begin{array}{l}\text { ELP 344: School and } \\
\text { Society }\end{array}$ \\
\hline North Dakota & $\begin{array}{l}\text { University of North Dakota, Grand } \\
\text { Forks }\end{array}$ & $\begin{array}{l}\text { T\&L 250: Introduction to } \\
\text { Education }\end{array}$ \\
\hline
\end{tabular}




\begin{tabular}{|c|c|c|}
\hline Ohio & Ohio State University, Columbus & $\begin{array}{l}\text { ESPHE 3206: School and } \\
\text { Society }\end{array}$ \\
\hline Oklahoma & University of Oklahoma, Norman & $\begin{array}{l}\text { EDS 5003: School and } \\
\text { Society }\end{array}$ \\
\hline Oregon & Portland State University & $\begin{array}{l}\text { ED 420: Introduction to } \\
\text { Education and Society }\end{array}$ \\
\hline Pennsylvania & Pennsylvania State University & $\begin{array}{l}\text { EDTHP 115: Education in } \\
\text { American Society }\end{array}$ \\
\hline Rhode Island & University of Rhode Island & $\begin{array}{l}\text { EDC 102: Introduction to } \\
\text { American Education }\end{array}$ \\
\hline $\begin{array}{l}\text { South } \\
\text { Carolina }\end{array}$ & $\begin{array}{l}\text { University of South Carolina, } \\
\text { Columbia }\end{array}$ & $\begin{array}{l}\text { EDFI 300: Schools in } \\
\text { Communities }\end{array}$ \\
\hline South Dakota & $\begin{array}{l}\text { South Dakota State University, } \\
\text { Brookings }\end{array}$ & $\begin{array}{l}\text { EDFN 351: Teaching and } \\
\text { Learning I }\end{array}$ \\
\hline Tennessee & University of Tennessee, Knoxville & $\begin{array}{l}\text { No general, non-subject- } \\
\text { specific education course } \\
\text { required/offered here }\end{array}$ \\
\hline Texas & University of Texas Arlington & $\begin{array}{l}\text { EDUC 2302: The } \\
\text { Professional Educator }\end{array}$ \\
\hline Utah & Utah Valley University & $\begin{array}{l}\text { EDSC 3050: Foundations } \\
\text { of American Education }\end{array}$ \\
\hline Vermont & University of Vermont & $\begin{array}{l}\text { EDSS 001: Schooling, } \\
\text { Learning, and Society }\end{array}$ \\
\hline Virginia & George Mason University & $\begin{array}{l}\text { EDUC 200: Introduction to } \\
\text { Education: Teaching, } \\
\text { Learning, and Schools }\end{array}$ \\
\hline Washington & University of Washington, Seattle & $\begin{array}{l}\text { EDTEP 511: School and } \\
\text { Society }\end{array}$ \\
\hline West Virginia & West Virginia University & $\begin{array}{l}\text { No general, non-subject- } \\
\text { specific education course } \\
\text { required/offered }\end{array}$ \\
\hline
\end{tabular}




\begin{tabular}{|l|l|l|}
\hline Wisconsin & University of Wisconsin, Madison & $\begin{array}{l}\text { ED POL 140: Introduction } \\
\text { to Education }\end{array}$ \\
\hline Wyoming & University of Wyoming & $\begin{array}{l}\text { EDST 1230: The Citizen } \\
\text { Factor: Schooling and } \\
\text { Democracy in the U.S. }\end{array}$ \\
\hline
\end{tabular}




\section{Appendix B}

\section{Rubric for Textbook Data Collection}

Textbook citation:

Source information: University:

Course code/Title:

Chapter selected for analysis:

Purpose for this chapter's selection:

Data Collection for Chapter

*Note that reflexive commentary should be coded in blue*

\section{Part I. Direct Content Analysis}

(a) Epistemological and philosophical paradigms

a. Description

b. Interpretation

i. Prosody

ii. Cohesion

iii. Discourse organization

iv. Contextualization signals

v. Thematic organization

c. Explanation/Critical commentary

(b) Evaluating sources of information

a. Description

b. Interpretation

i. Prosody

ii. Cohesion

iii. Discourse organization

iv. Contextualization signals

v. Thematic organization

c. Explanation/Critical commentary

(c) Epistemically suspect statements and buzzwords

a. Description

b. Interpretation
i. Prosody
ii. Cohesion
iii. Discourse organization
iv. Contextualization signals
v. Thematic organization 


\section{c. Explanation/Critical commentary}

(d) Power dynamics, biases, ideologies, and underlying assumptions in media and scholarly work

a. Description

b. Interpretation
i. Prosody
ii. Cohesion
iii. Discourse organization
iv. Contextualization signals
v. Thematic organization

c. Explanation/Critical commentary

\section{Part II. Indirect Content Analysis}

(a) Epistemological and philosophical paradigms in education

a. Description

b. Interpretation
i. Prosody
ii. Cohesion
iii. Discourse organization
iv. Contextualization signals
v. Thematic organization

c. Explanation/Critical commentary

(b) Modelling of evaluating sources of information

a. Description

b. Interpretation
i. Prosody
ii. Cohesion
iii. Discourse organization
iv. Contextualization signals
v. Thematic organization
c. Explanation/Critical commentary

(c) Awareness and/or use of epistemically suspect statements and buzzwords

a. Description

b. Interpretation
i. Prosody
ii. Cohesion
iii. Discourse organization
iv. Contextualization signals
v. Thematic organization

c. Explanation/Critical commentary 
(d) Indirect or unacknowledged demonstration of power dynamics, biases, ideologies, and underlying assumptions
a. Description
b. Interpretation
i. Prosody
ii. Cohesion
iii. Discourse organization
iv. Contextualization signals
v. Thematic organization
c. Explanation/Critical commentary

\section{Part III. Table of Contents Analysis}

(a) Epistemological and philosophical paradigms

(b) Evaluating sources of information

(c) Epistemically suspect statements and buzzwords

(d) Power dynamics, biases, ideologies, and underlying assumptions in media and scholarly work 


\section{Appendix C}

\section{Data Collection Book List}

Adams, M., Blumenfeld, W. J., Chase, D., Catalano, J., DeJong, K. S., Hackman, H. W., Hopkins, L. E., Love, B. J., Peters, M. L., Shlasko, D., Zuniga, X. (Eds.). (2018). Readings for Diversity and Social Justice (4th ed.). New York, NY: Routledge.

Berner, A. R. (2017). No one way to school: Pluralism and American public education. Baltimore, MA: Johns Hopkins University Press.

Blair, E., \& Medina, Y. (Eds.). (2016). The social foundations reader: Critical essays on teaching, learning, and leading in the 21 st century. New York, NY: Peter Lang Publishing.

Calarco, J. M. (2018). Negotiating opportunities: How the middle class secures advantages in schools. New York, NY: Oxford University Press.

Cowhey, M. (2006). Black ants and Buddhists: Thinking critically and teaching differently in the primary grades. Portland, ME: Stenhouse.

Dayton, J. (2018). School law for everyone: The essential guide. Bangor, ME: Wisdom Builders Press.

Delpit, L. (1995). Other people's children: Cultural conflict in the classroom. New York, NY: The New Press.

Eaton, S. (2006). The children in room E4: American education on trial. Chapel Hill, NC: Algonquin Books.

Feinberg, W., \& Soltis, J. F. (2009). School and society (5th ed.). New York, NY: Teachers College Press. 
Fenstermacher, G. D., \& Soltis, J. F. (2009). Approaches to teaching (5th ed.). New York, NY: Teachers College Press.

Fraser, J. W. (Ed.). (2016). Teach: A question of teaching (2nd Ed.). New York, NY: Routledge.

Fraser, J. W. (Ed.). (2019). The school in the United States: A documentary history. New York, NY: Taylor \& Francis.

Giroux, H. A., \& Pollock, G. (2010). The mouse that roared: Disney and the end of innocence. Lanham, MD: Rowman \& Littlefield.

Goldstein, D. (2015). The teacher wars: A history of America's most embattled profession. New York, NY: Anchor Books.

Gorski, P. G., \& Pothini, S. G. (2018). Case studies on diversity and social justice education ( $2^{\text {nd }}$ ed.). New York, NY: Routledge.

Goyette, K. A. (2017). Education in America. Oakland, CA: University of California Press.

Graham, P. A. (2005). Schooling America: How the public schools meet the nation's changing needs. New York, NY: Oxford University Press.

Hagopian, J. (Ed.). (2014). More than a score: The new uprising against high stakes testing. Chicago, IL: Haymarket.

Hall, G. E., Quinn, L. F., \& Gollnick, D. M. (2020). Introduction to teaching: Making a difference in student learning. Thousand Oaks, CA: Sage.

Hayes, W. (2009). All new real-life case studies for teachers. Lanham, MD: Rowman \& Littlefield. 
Johnston, P. H. (2012). Opening minds: Using language to change lives. Portland, ME: Stenhouse.

Kauchak, D., \& Eggen, P. (2016). Introduction to teaching: Becoming a professional (6th ed.). Hoboken, NJ: Pearson.

Koch, J. (2020). Teach: Introduction to education (4th Ed.). Thousand Oaks, CA: Sage.

Kozol, J. (1991). Savage inequalities: Children in America's schools. New York, NY: Random House.

Ladson-Billings, G. (1994). The dreamkeepers: Successful teachers of African American children. San Francisco, CA: Jossey-Bass.

Lareau, A. (2011). Unequal childhoods: Class, race, and family life (2nd ed.). Los Angeles, CA: University of California Press.

Lawrence-Lightfoot, S. (2003). The essential conversation: What parents and teachers can learn from each other. New York, NY: Random House.

Levinson, M., \& Fay, J. (Eds.). (2016). Dilemmas of educational ethics: cases and commentaries. Cambridge, MA: Harvard Education Press.

Love, B. L. (2019). We want to do more than survive: Abolitionist teaching and the pursuit of educational freedom. Boston, MA: Beacon.

Lumen Learning. (n. d.) Education, society, and the K-12 learner [e-book]. Retrieved from https://courses.lumenlearning.com/teachereducation $\times 92 \times 1 /$

Mondale, S., \& Patton, S. B. (2001). School: the story of American public education. Boston, MA: Beacon.

Nieto, S. (Ed.). (2014). Why we teach now. New York, NY: Teachers College Press. 
Ornstein, A. C., \& Levine, D. U. (2002). Foundations of education (8th Ed.). Boston, MA: Houghton Mifflin.

Parkay, F. W. (2020). Becoming a teacher (11th ed.). Hoboken, NJ: Pearson.

Pugach, M. C. (2009). Because teaching matters: An introduction to the profession. Hoboken, NJ: John Wiley \& Sons.

Ravitch. D. (2014). Reign of error: The hoax of the privatization movement and the danger to America's public schools. New York, NY: Vintage.

Ravitch, D. (2020). Slaying Goliath: The passionate resistance to privatization and the fight to save America's public schools. New York, NY: Alfred A. Knopf.

Rose, M. (2009). Why school? Reclaiming education for all of us. New York, NY: The New Press.

Ryan, K., Cooper, J. M., \& Bolick, C. M. (2016). Those who can, teach (14th ed.). Boston, MA: Cengage.

Sadker, D. M., \& Zittleman, K. (2018). Teachers, school, and society: A brief introduction to education (5th ed.). New York, NY: McGraw-Hill.

Spring, J. (2018a). American education (18th ed.). New York, NY: Routledge. Spring, J. (2018b). The American school: From the Puritans to the Trump era. New York, NY: Routledge.

Strike, K., \& Solti, J. F. (2009). The ethics of teaching (5th ed.). New York, NY: Teachers College Press.

Tomlinson, C. A., \& McTighe, J. (2006). Integrating differentiated instruction \& understanding by design: Connecting content and kids. Alexandria, VA: Association for Supervision and Curriculum Development. 
Urban, W. J., \& Wagoner, Jr, J. L. (2009). American education: A history (4th Ed.). New York, NY: Routledge.

Webb, D.L., Metha, A., \& Jordan, K.F. (2013). Foundations of American education (7th.ed.). Upper Saddle River, NJ: Pearson.

Westheimer, J. (2015). What kind of citizen? Educating our children for the common good. New York, NY: Teachers College Press.

Wilbur, K. (2007). The integral vision: A very short introduction to the revolutionary integral approach to life, god, the universe, and everything. Boston, MA: Shambhala.

Wise, T. (2011). White like me: Reflections on race from a privileged son, revised edition. New York: Soft Skull Press.

\section{BOOKS REMOVED FROM DATA COLLECTION POOL}

Alexie, S. (2007). The absolutely true diary of a part-time Indian. New York, NY: Little, Brown \& Company.

Reason for removal: Work of fiction - not a textbook

Berger, R. (2003). An ethic of excellence: Building a culture of craftsmanship with students. Portsmouth, NH: Heinemann.

Reason for removal: Memoir/personal narrative - not part of the textbook genre

Codell, E. R. (2009). Educating Esme: Diary of a teacher's first year. Chapel Hill, NC: Algonquin Books.

Reason for removal: Fictional narrative 
Chartock, R. K. (2004). Educational foundations: An anthology (2nd Ed.). Hoboken, NJ: Pearson.

Reason for removal: This is an anthology that anthology uses a number of excerpts from literature, plays, poetry, and paintings. Since this is an anthology of art and fiction, it does not fall within the genre of nonfiction textbook.

Edwardson, D. D. (2011). My name is not easy. Las Vegas, NV: Amazon.

Reason for removal: Work of fiction - not a textbook

McCourt, F. (2005). Teacher man. New York, NY: Scribner. Reason for removal: Memoir - not a textbook

Paley, V. G. (2000). White teacher (2nd ed.). Cambridge, MA: Harvard University Press. Reason for removal: Memoir; first-person narrative; not in the textbook genre Sleeter, C. (2015). White bread: Weaving cultural past into the present. Boston, MA: Sense Publishers. Reason for removal: Fable/fictional narrative meant for educational purposes not a textbook

Thomas, A. (2018). The hate u give. New York, NY: Harper Collins. Reason for removal: Work of fiction - not a textbook 
University of Colorado Boulder School of Education. (2017). School and society: A reader in the social foundations of education and educational diversity. Dubuque, IA: Kendall Hunt.

Reason for removal: While this work is genre-wise aligned with the purpose of this study, this book is a locally published, loose-leaf text made specifically for the University of Colorado. Since it is a local, course-specific text, it is not currently available to rent, purchase, or borrow.

Westover, T. (2018). Educated: A memoir. New York, NY: Random House. Reason for removal: Memoir - not a textbook 


\section{Appendix D}

\section{A Textbook Evaluation Checklist for Educators}

The following questions are intended to be used as a guide for evaluating education textbooks through the lens of critical information literacy/consumption.

- What kinds of questions are asked in the work?

Whether in the body of the text or located at the end of chapters for processing one's learning, questions should be thought-provoking, open-ended, and require critical reflection or metacognition on the part of the reader. Questions that can be answered by regurgitating passages from the work are typically insufficient for providing opportunities to practice CIL/CIC skills.

- How does the work approach the purpose(s) of schooling?

The purposes outlined in the work should align with those of the instructor and/or institution and include a multidimensional examination (that is, schooling tends to have social, economic, civic, and ethical objectives).

- How does the work engage readers in exploration of complexity, nuance, and ambiguity in the knowledge creation process?

Works that encourage the use of false dichotomies or oversimplify matters in the name of brevity do a disservice to its readers. In other words, "simplicity at the expense of accuracy is no virtue; complexity in the service of accuracy is no vice" (Patton, 2008, p. 482).

- How does the author directly or indirectly demonstrate their values?

A direct demonstration of values may look like the key terms that are bolded or an explicit statement of what the author is attempting to accomplish in the 
textbook; indirect demonstrations of values occur when an author uses examples to illustrate a concept in a positive or negative light or in how much space and references are devoted to a given topic.

- What assumptions has the author made about their readers?

Pay close attention to the use of the word 'we.' If the author uses this word to address the readers, how are the readers being grouped with the author? What traits or perspectives is the author imposing on the reader (or alienating the reader from) by assuming group membership with 'we'?

- How does the work use and comment on primary sources?

Some textbooks present passages from primary sources with little to no commentary on what the intended purpose of the passage's use is; a CIL/CICminded textbook will provide context, commentary, and critiques of a primary source to help the reader situate their understanding of the passage.

- Does the work 'practice what it preaches;' that is, does it model the values, behaviors, and habits of mind that are discussed in the text?

For example, if a work states the need for deeper thinking and complexity in education but does not adequately meet the questioning criterion listed above, then the reader is receiving conflicting messages from the text.

- How does the work treat educational jargon?

Linguistic granularity marks the difference between meaningful discourse and empty buzzwords. Consider how the author approaches the definitions of key terms, either in paragraph form or in special vocabulary sections. Is there space dedicated to common misconceptions of an educational term, or delineation of 
similar but distinct subsets of a key term or phrase (for example, explaining the difference between the educational opportunity gap versus the educational achievement gap).

- How does the work demonstrate the necessity of interdisciplinarity and considering multiple perspectives in learning?

Related to the direct versus indirect demonstration of values, lip service to multiple perspectives in learning is insufficient to assess a textbook author's commitment to it; for example, who does the author hail as expert? Who is considered an 'alternative' source? If a text praises truth as derived from multiple perspectives, but only showcases the perspectives of Western, white men, then perhaps it is not appropriately modeling this concept. Similarly, if a textbook hails interdisciplinarity as a necessity for critical education but does not, for example, encourage pre-service teachers to master more than one subject area, then there may be a dissonance between the author's espoused beliefs and actions.

- How does the work address whose voices are heard and whose are not in the messages it constructs? Further, how transparent is the work in acknowledging that all information messages are constructed, giving voice to the information producer?

In a similar capacity to some of the questions listed above, a CIL/CIC-minded textbook author will situate its information and its "isms" in the context of who constructed it, for what purposes, and to whom is the concept meant to be taught. Textbooks that minimize or disregard the need for discussion of the context and 
construction of information messages will likely overlook essential components of what it means to learn and teach in diverse educational settings.

- How does the work examine power asymmetry in the classroom and/or the teacher's role as gatekeeper?

Teachers have a complex relationship with empowerment, and therefore must be aware of their power over their students and over the information they are to teach. This is a nuanced, subtle topic that is not always intuitive, so a direct and frank discussion of it is a hallmark of a CIL/CIC-minded textbook.

- What connections are made in the work between education and social justice?

Education in the context of CIL/CIC is emancipatory and at its core opposed to accepting the status quo. Therefore, textbooks with this in mind will approach education as a necessity for marginalized groups to be empowered. 


\section{VITA}

Courtney Smith-Nelson is a high school math educator and a teacher-trainer in methods of teaching secondary mathematics. She has degrees in mathematics, education, and Spanish, and holds teaching certificates in mathematics, social studies, and health. 